\title{
An analysis of amenity-led rural economic *development in northeast region: A spatial simultaneous equations approach
}

\author{
Mulugeta Saare Kahsai \\ West Virginia University
}

Follow this and additional works at: https://researchrepository.wvu.edu/etd

\section{Recommended Citation}

Kahsai, Mulugeta Saare, "An analysis of amenity-led rural economic *development in northeast region: A spatial simultaneous equations approach" (2009). Graduate Theses, Dissertations, and Problem Reports. 2925.

https://researchrepository.wvu.edu/etd/2925

This Dissertation is protected by copyright and/or related rights. It has been brought to you by the The Research Repository @ WVU with permission from the rights-holder(s). You are free to use this Dissertation in any way that is permitted by the copyright and related rights legislation that applies to your use. For other uses you must obtain permission from the rights-holder(s) directly, unless additional rights are indicated by a Creative Commons license in the record and/ or on the work itself. This Dissertation has been accepted for inclusion in WVU Graduate Theses, Dissertations, and Problem Reports collection by an authorized administrator of The Research Repository @ WVU.

For more information, please contact researchrepository@mail.wvu.edu. 


\title{
An Analysis of Amenity-Led Rural Economic Development in Northeast Region: A Spatial Simultaneous Equations Approach
}

\author{
Mulugeta Saare Kahsai
}

Dissertation submitted to the Davis College of Agriculture, Forestry, and Consumer Sciences

at West Virginia University

in partial fulfillment of the requirements

for the degree of

Doctor of Philosophy

in

Natural Resource Economics

Dr. Tesfa Gebremedhin, Committee Chairperson

Dr. Peter V. Schaeffer, Co-chair

Dr. Tim T. Phipps

Dr. Dale Colyer

Dr. Stratford Douglas

Agricultural and Resource Economics Program

Division of Resource Management

Morgantown, West Virginia

2009

Keywords: Natural and built amenities, regional economic growth, spatial Durbin model

Copyright 2009 Mulugeta Saare Kahsai 
ABSTRACT

\title{
An Analysis of Amenity-Led Rural Economic Development in Northeast Region:
}

\section{A Spatial Simultaneous Equations approach}

\author{
Mulugeta Saare Kahsai
}

In a matter of just a few decades, the economic landscape of rural America has changed in fundamental ways. Industries once considered the backbone of rural economies have been transformed by globalization and marketing. Others, such as tourism and amenity-based economies or the service sector, have emerged to replace the traditional natural resource and manufacturing-based economies. These changes have invigorated some areas, and forever altered others. Consequently, Interest in an amenity focused development strategy has exploded as policymakers and community leaders realize that most of the jobs lost in recent decades will not return. Instead, these leaders are looking inside their communities for new sources of economic growth.

In an effort to analyze the role of natural and recreational amenities in rural economic growth, this study develops a simultaneous-equation system under the assumptions of profit maximization of firms and utility maximization of households as well as the neoclassical assumption of equilibrium growth in a partial lag-adjustment growth-equilibrium framework. Past studies assume that amenities have a direct and independent effect on economic growth, but in reality the availability of high amenity levels alone can only create the opportunity for economic growth. But to be an effective development tool it should be coupled with factors that can exploit its existence, encourage its use, and give it a comparative advantage.

This research extends existing studies in this area by incorporating interaction terms that account for the combined impact of amenities with proximity to metropolitan areas and accessibility (Interstate highway density). Furthermore, the study contributes to the amenity and regional growth literature by estimating a simultaneous spatial Durbin model using the two stages least square method. Historical and cultural amenities and water based recreational amenities are found to play a positive role in shaping the growth of population in the northeast region of the US. The role of natural amenities, land and winter based amenities is found to be negative or insignificant. One of the important findings of the study is the positive role of surrounding counties historical and cultural amenities in the growth of population and employment densities. Overall there is no evidence of a consistent and strong relationship and the results can be termed as mixed and inconclusive. 


\section{Dedication}

I would like to dedicate this work to the life and memory of my late father Saare Kahsai, my mother Ghenet Fessehazion, my late brother Alem

Saare, and my wife Yodit Asser. I am who I am because of you. You are my true inspiration. 


\section{Acknowledgments}

This dissertation would have been an impossible task without the support and guidance of my committee members. I would like to express my sincere thanks to all my committee members. I was very fortunate to have a Dr. Tesfa G. Gebremedhin as a chair and Dr. Peter V. Schaeffer as co-chair of my committee. I would first like to thank them for giving me enough freedom to develop my research while not allowing me to stray too far from the path. They supported and guided me to conduct a meaningful research and without their assistance I would not have been able to conduct my research in timely manner. Both professionally and personally, I have enjoyed my association with them. I am grateful to my committee member Dr. Dale Colyer for his comments, suggestions, insights, and for contributing his time generously to edit my manuscript. I wish to thank the other members of my committee, Dr. Tim Phipps, Dr. Stratford Douglas, and the associate dean of Davis College of Agriculture, Forestry, and Consumer Science Dr. Denny Smith for their critical comments, review of the manuscript, and helpful insights.

I am indebted to the Division of Resource Management, Davis College of Agriculture, Forestry, and Consumer Sciences, for providing me research assistantship for my first two and half years of my PhD studies. I am thankful to the faculty, staff, and graduate students of the Division of Resource Management. My deepest appreciations also to the Regional Research Institute (RRI) at West Virginia University, its Director Dr. Randall Jackson for the research assistantship for my last year of my study.

This dissertation benefited greatly from previous studies done in the Division of Resource Management. In this regard, I am grateful to Dr. Gebremeskel $\mathrm{H}$. Gebremariam and Dr. Yohannes G. Hailu for freely sharing their expertise and knowledge.

So many other people have helped me that it is impossible to thank them individually. However I must express my appreciation of the special assistance given to me by Lisa A. Lewis, Melanie Jimmie, Ellen Hartley-Smith, Mary Lou Myer, Ahadu Tecle, and Adiam Tsegai.

I wish to express my deepest thanks to my wife, Yodit Asser. Her patience, support, and encouragement was the source of my strength to finish this dissertation. Finally, the list of acknowledgments would be incomplete if I did not acknowledge the role of my family and friends all over the world. I am very blessed to be surrounded by a very special and caring family and friends who were always there for me. My special thanks to the family of Saare Kahsai, family of Fessehazion Haile, family of Asser Andemariam, family of Dr. Tesfa G. Gebremedhin, and family of Amanuel Tesfahunie. Their constant and unfailing love, financial, and moral support in my pursuit of graduate education, gave me the energy and motive to stay strong and successful complete this dissertation. I couldn't have done it without their support. 


\section{Table of Contents}

ABSTRACT

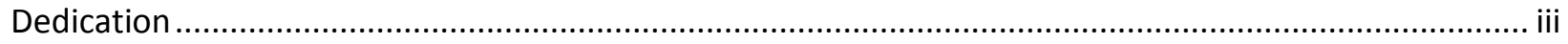

Acknowledgments................................................................................................................. iv

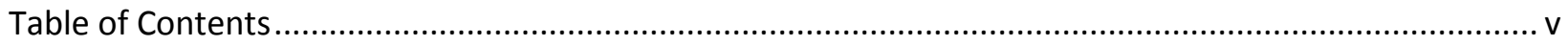

List of Tables ................................................................................................................................ vii

List of Figures ......................................................................................................................... viii

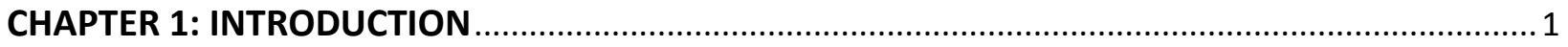

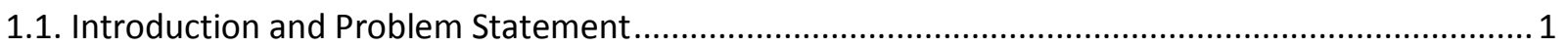

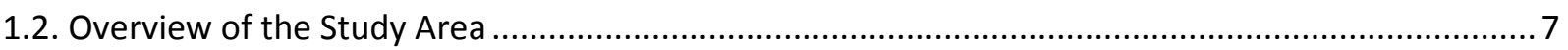

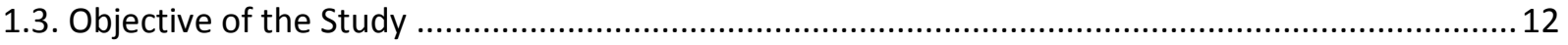

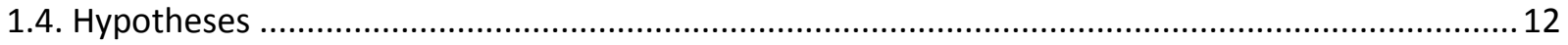

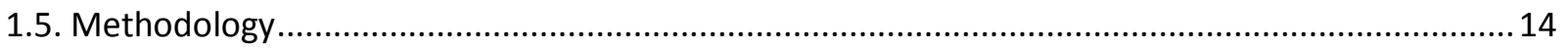

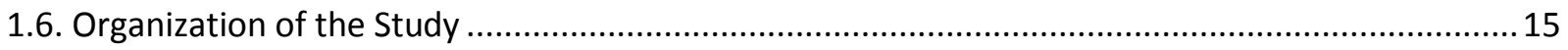

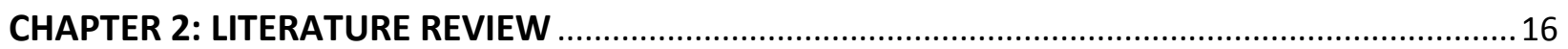

2.1. Amenities and Economic Development ................................................................................... 16

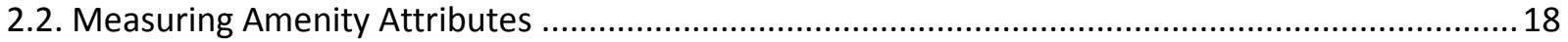

2.3. Review of Factors Associated With Amenity and Rural Development .........................................2 21

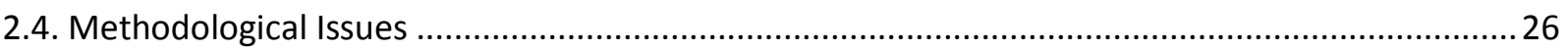

2.5. Summary and Shortcomings of Past Studies .............................................................................. 30

CHAPTER 3: THEORETICAL MODELS OF AMENITIES AND REGIONAL DEVELOPMENT ................. 32

3.1. Household and Firm Location ……......................................................................................... 32

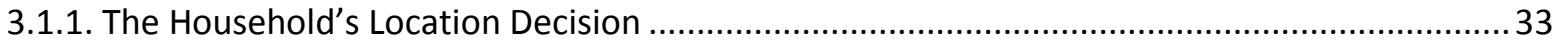

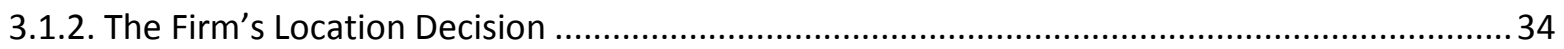

3.1.3. Interactions between Location Decisions of Households and Firms ..................................... 35

3.2. Traditional Export Theory and Amenity-Led Development ........................................................ 36

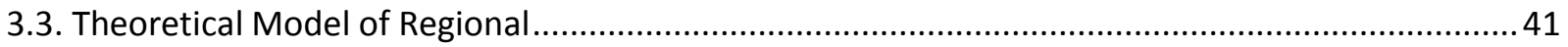




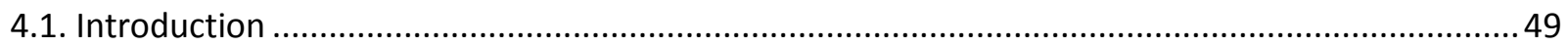

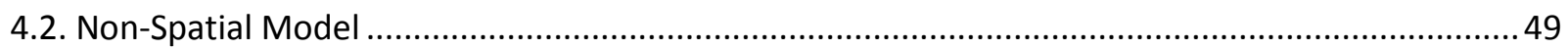

4.2.1. Growth in Per capita Income Equation (LPCl) .................................................................. 51

4.2.2. Growth in Population Density Equation (LPOPD) …........................................................ 54

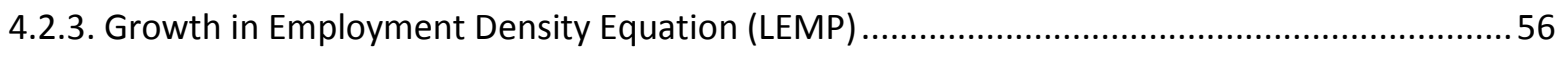

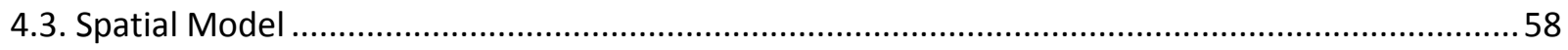

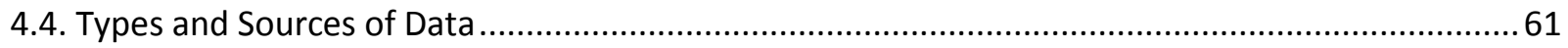

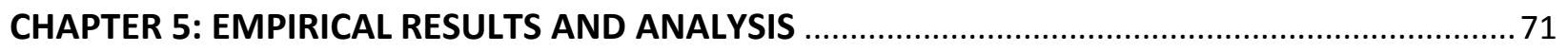

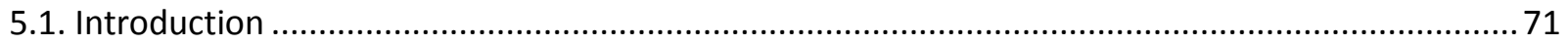

5.2. Findings and Analysis of Non-Spatial Regional Growth Model.................................................. 71

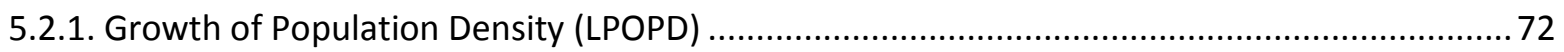

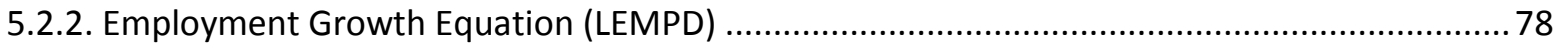

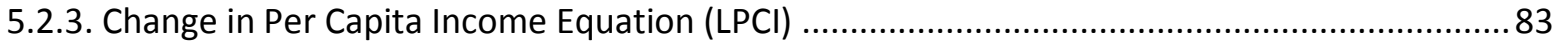

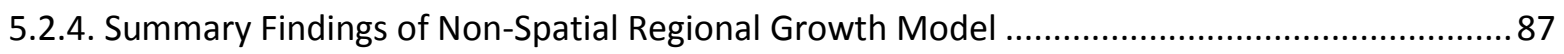

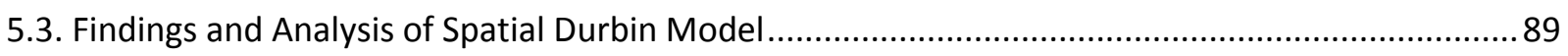

5.3.1. Spatial Result of Growth in Population Density ..................................................................... 91

5.3.2. Spatial Result of Employment Density Growth................................................................... 94

5.3.3. Spatial Result of Per Capita Income Growth..................................................................... 96

5.3.4. Summary Findings of Spatial Durbin Model .......................................................................... 99

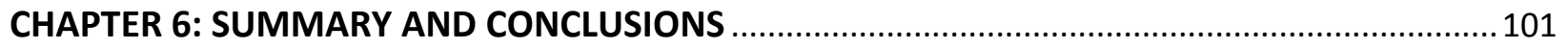

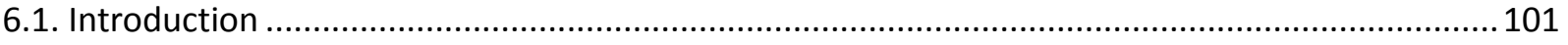

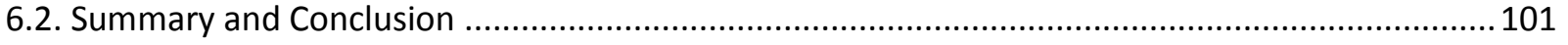

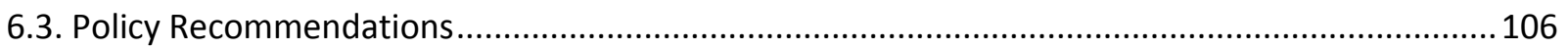

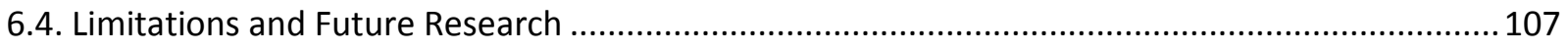

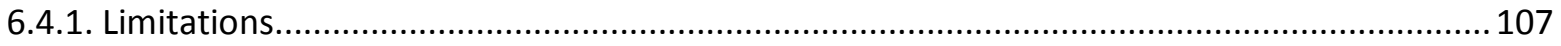

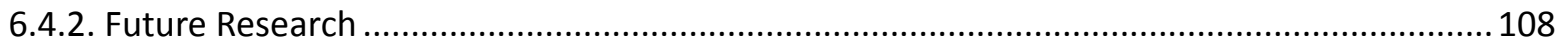

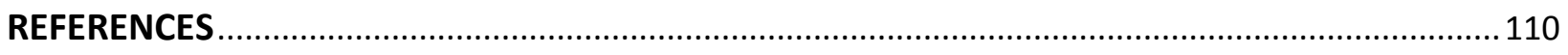

APPENDICES 


\section{List of Tables}

Table 1.1. Comparison of Jefferson and McDowell County, WV , 1980-2005........................................ 3

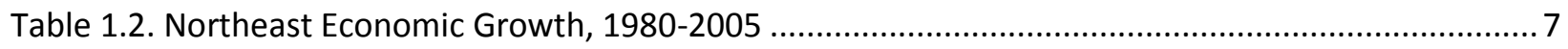

Table 1.2. Northeast Public and Private Natural Resources and Recreational Facilities .......................... 10

Table 4.4.1. Definition and Data Sources for the Endogenous and Initial Condition Variables ................62

Table 4.4.2. Definition and Data Sources for Natural Amenities and Outdoor Recreational Facilities ......63

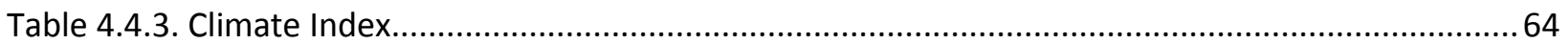

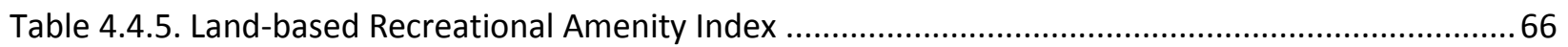

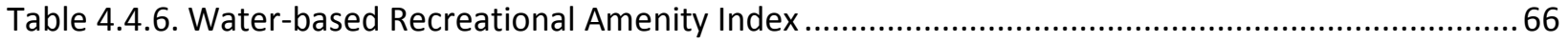

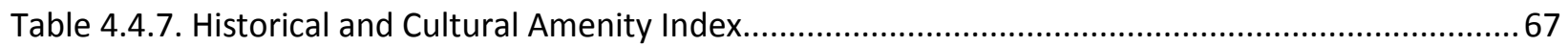

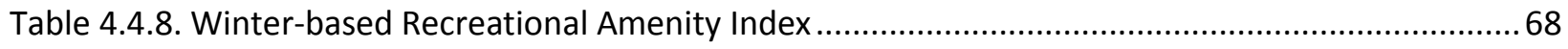

Table 4.4.9. Definition and Data Sources for Fiscal, Human Capital, Market Structure, and Economic

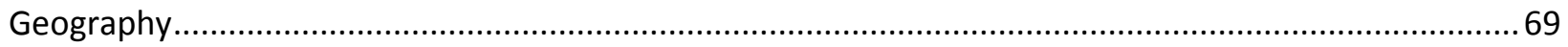

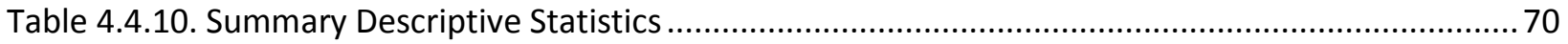

Table 5.2.1. Three Stage Least Square Estimation Results of Population Growth (LPOPD) and Amenities74 Table 5.2.2. Three Stage Least Square Estimation Results of Employment Growth and Amenities

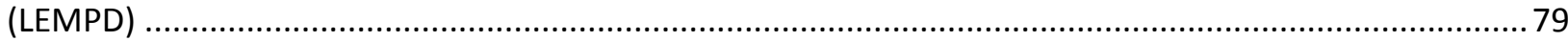

Table 5.2.3. Estimation Results of Income Growth and Amenities, 1980-2005 ..................................... 84

Table 5.3.1. Estimated Value of the Spatial Dependence Statistic, Rho .................................................91

Table 5.3.2. Spatial Durbin Estimation Results of Population Growth and Amenities .............................93

Table 5.3.3. Spatial Durbin Estimation Results of Employment Growth and Amenities ..........................95

Table 5.3.4. Spatial Durbin Estimation Results of Income Growth and Amenities..................................97

Table 5.3.5. Spatial Durbin Estimation Results of Population Growth and Amenities ............................ 120

Table 5.3.6.Spatial Durbin Estimation Results of Employment Growth and Amenities .......................... 121

Table 5.3.7. Spatial Durbin Estimation Results of Income Growth and Amenities................................122 


\section{List of Figures}

Figure 1.1. Overview of the Study Area and Regional Economic Indicators.

Figure 1.2. Comparisons of US and Northeast County Typology

Figure 3.2.1. Comparison of Traditional Export Theory and Amenity-Led Development

Figure 3.2.2. Amenities, Public Policy, and Regional Development

Figure 4.1. Climate Index . 117

Figure 4.2. Natural Resource Amenities 117

Figure 4.3. Land Based Recreational Amenities. 118

Figure 4.4. Water Based Recreational Amenities 118

Figure 4.5. Historical and Cultural Amenities 119

Figure 4.6. Winter Based Recreational Amenities .119 


\section{CHAPTER 1: INTRODUCTION}

\subsection{Introduction and Problem Statement}

There is no single way local policy makers can follow in developing the economy of their region. They may follow single or multiple paths based on their endowments and comparative advantages. They may build on natural resources, cultural resources, human resources, local amenities, institutional facilities or location advantages. The resulting direction of economic growth may involve manufacturing or supply chain development, resource extraction, tourism development, educational development or trade center development. The specific growth strategy followed by a specific region depends on the social, economic, political, and environmental dynamics of the region in question. In order to select and pursue a development path, policy makers must first understand the possible growth paths that may be relevant for their region.

Interest in an amenity focused development strategy has exploded as policymakers and community leaders realize that most natural resource based and manufacturing jobs lost in recent decades will not return. Instead, these leaders are looking inside their communities for new sources of economic growth. According to recent white papers of the 2007 Farm Bills, the largest growth in rural population and employment has generally occurred in areas which rely on nontraditional income sources. These regions include areas that have either capitalized on natural resources such as amenities and climatic conditions for recreation and retirement or areas that have proximity to urban areas. In a 2006 report, the Outdoor Industry Foundation, for example, found that active outdoor recreation contributes $\$ 730$ billion to the U.S. 
economy each year. For West Virginia, the study estimates that 61,000 jobs, $\$ 272$ million in state tax revenue and $\$ 4.3$ billion in sales are attributable to active recreation in its wonderful, wild land. The type, quality and quantity of recreational activities supported by the natural and recreational activities vary from region to region depending on local climate, land, and water resources. In most cases they include, several of the following: fishing, boating, paddling, and skiing, snowboarding, swimming, boating, biking, hiking, hunting, golfing, wildlife viewing, camping and trailing. All levels of government - federal, state, and local- and the private sector, are involved in providing amenity-based services to thousands of people every day. For many rural counties, these nature-based amenities are a major asset that gives the counties a comparative advantage over other regions.

The increasing demand for the consumption of amenities is influenced by decades of investment in transportation infrastructure which greatly enhanced the accessibility of these amenities. Many rural communities are now connected by good roads and the cost of isolation has been greatly reduced. The advance in information technology has provided knowledge workers the flexibility to reside where they want. The increase in income and changing preferences are two other factors that are stimulating demand for amenities. Natural and built amenities, by boosting the quality of life of regions, have become major forces behind the rural turnaround of the last decade, including migration from urban to rural areas. Now we see different faces of rural America: On one hand there are those areas which still depend on declining extractive resources such as agriculture, mining, and lumber based manufacturing. On the other hand, we find those which are within commuting distance to larger growing 
cities which are benefiting from agglomeration spillovers. Others have transformed their economies and are developing amenity based service industries (Lasley and Hanson 2003; Power, 1996; Deller, 2004).

Table 1.1. Comparison of Jefferson and McDowell County, WV, 1980-2005

\begin{tabular}{|l|c|c|c|c|c|c|}
\hline \multirow{2}{*}{ Indicators } & \multicolumn{3}{|c|}{ Jefferson County } & \multicolumn{3}{c|}{ McDowell County } \\
\cline { 2 - 7 } & 1980 & 2005 & $\begin{array}{c}\text { Growth } \\
(\%)\end{array}$ & 1980 & 2005 & $\begin{array}{c}\text { Growth } \\
(\%)\end{array}$ \\
\hline Population & 30,434 & 48,542 & 59.5 & 49,724 & 23,794 & -52.1 \\
\hline Jobs & 8,385 & 15,486 & 84.7 & 14,561 & 5,318 & -63.5 \\
\hline Per Capita & & & & & & \\
Income & 7,394 & 32,240 & 336.0 & 7,230 & 18,136 & 150.8 \\
\hline
\end{tabular}

Source: computed from Bureau of Economic Analysis data

A quarter of a century comparison of two counties- Jefferson and McDowell- of West Virginia gives a good comparison of the different faces of rural America (Table 1.1). McDowell County is a good example of a declining extractive resource dependent rural area. At its peak time in the 1950s, it was one of the important production centers of the coal mining industry and a major player in the state's economy. With the decline of the coal industry everything started to fall apart. Its population decreased from 100,000 in the 1950 s to an estimated 25,000 in 2005 . In a quarter of a century (19802005) alone, it lost more than $50 \%$ of its population and $63.5 \%$ of its employment. Even though it's per capita income increased by $150 \%$, it is the lowest in the state and the $69^{\text {th }}$ lowest among the US counties. About $33.8 \%$ of families and $37.7 \%$ of the population were below the poverty line, including $52.5 \%$ of those under age 18 and 
$21.6 \%$ of those aged 65 or over. McDowell County was not able to transform its economy and is lagging behind in almost every measure of economic activity.

Jefferson County, on the other hand, is an example of growing amenity based service industry. The county is home to Harpers Ferry National Historical Park, which is located at the confluence of the Potomac and Shenandoah Rivers. Due its ample recreational opportunities and its proximity to the Washington, D.C., it has attracted tourists and amenity migrants. In a quarter of a century (1980-2005) its population increased by $59.5 \%$. The ability of Jefferson County to transform its economy to an amenity based service industry helped to almost double its employment and increases its per capita income by $336 \%$. Only about $7.2 \%$ of families and $10.3 \%$ of the population were below the poverty line, including $11.4 \%$ of those under age 18 and $9.4 \%$ of those ages 65 or over. Even though, these two West Virginia counties are found in Appalachia, the difference in the development strategy they followed, the difference in proximity to large urban centers, the demand for and supply of their amenities resulted in two different growth paths. The story of Jefferson and McDowell Counties reflects the different faces of rural America and the challenges and opportunities they face in their development endeavors.

There is now a general understanding that natural and built amenities as quality of life indicators are playing and will play important roles in rural development (Beale and Johnson 1998; McGranahan 1999; Dissart 2005). Conceptually, amenities impact regional growth by affecting growth in population, employment, income, and housing values (due to land use changes for housing and recreational development). Several past empirical studies have documented the relationship between the presence of 
natural and built amenities within a region and economic growth by focusing on population (or net migration), employment, and income growth (Deller et al. 2001, 2005, 2007 and 2008; Goe and Green, 2005; McGranahan, 1999; Nzaku and Bukenya, 2005).

In all the studies there is a clear and consistent positive connection between high amenity areas and population growth while the relationship with employment is relatively weak and less consistent. Very few studies address the income and amenity relationship and it is difficult to generalize its impact based on them. Furthermore, there has been a continuous debate whether amenities contribute to job growth directly or indirectly through in-migration. At the same time awareness is growing that the economic supply, not the physical availability of amenities, is important (Deller et al. 2008). The economic supply of amenities (accessible) and its impact on regional growth vary significantly over space and are poorly understood. The different results seem to emanate from ambiguity in the definition of amenity, the stated objectives, and the method of analysis applied in the previous studies. These findings have created doubts about the overall impact of amenities on regional growth (Dissart, 2007; Waltert and Schläpfer, 2007).

State policy makers and local leaders need to have a full grasp of the relationship between amenities and regional growth. Unless they have a better understanding of what types of economic sectors and development programs are most appropriate in attracting businesses, in alleviating poverty, and in influencing economic development, they cannot design and follow a successful rural strategy. Thus, the determination and documentation of population growth, employment growth, income growth, and the distribution of amenity attributes that can provide the opportunity for economic growth in 
rural areas can be used to design appropriate rural development programs. The programs can create and retain rural employment opportunities, increase rural income levels, and help keep population in rural communities. They can also enhance the productivity and vitality of human and material resources, diversify the economic base of rural areas, and allow greater adaptability of rural areas to changing external economic and social forces.

This study will try to assess whether the 299 counties (148 are non-metropolitan) in the Northeast ${ }^{1}(\mathrm{NE})$ region of the US can build and pursue a growth strategy that depend on their local amenities (natural and built). Unlike past studies that implicitly assume that the physical availability of natural amenities have a direct and independent effect on economic growth, this study proposes that the availability of a high physical amenity alone can only create the opportunity for economic growth. But to be an effective development tool it should be coupled with factors that can exploit its existence, encourage its use, and provide a comparative advantage. This requires preserving local natural amenities, building recreational facilities, providing transportation infrastructure, and promoting it in potential demand markets. To test the relationship between amenities and such other factors, the study extends the models of Deller et al. (2001, 2005, and 2007 ) and Nzaku and Bukenya (2005) by incorporating interaction terms that account for the combined impact of amenities with proximity to metropolitan areas and accessibility (interstate highway density). Furthermore, the study also estimates a simultaneous spatial Durbin model using the two stage least square method to capture the direct and indirect effects that are ignored in in most past studies.

\footnotetext{
${ }^{1}$ The Northeast region of the US is defined here following the Northeast Center of Rural Development. It consists, the 9 New England states and Delaware, Maryland, and West Virginia.
} 
Table 1.2. Northeast Economic Growth, 1980-2005

\begin{tabular}{|c|c|c|c|c|c|c|}
\hline \multirow{3}{*}{$\begin{array}{l}\text { Growth } \\
\text { Indicator }\end{array}$} & \multicolumn{3}{|c|}{ Northeast Region } & \multicolumn{3}{|c|}{ Non-metro Northeast Region } \\
\hline & \multirow[b]{2}{*}{ Declining } & \multicolumn{2}{|c|}{ Growing } & & \multicolumn{2}{|c|}{ Growing } \\
\hline & & $\begin{array}{l}\text { Below US } \\
\text { Average }\end{array}$ & $\begin{array}{c}\text { Above US } \\
\text { Average }\end{array}$ & & $\begin{array}{l}\text { Below US } \\
\text { Average }\end{array}$ & $\begin{array}{l}\text { Above US } \\
\text { Average }\end{array}$ \\
\hline Population & $35.1 \%$ & 45.5 & 19.4 & 44.5 & 40 & 15.5 \\
\hline Employment & 6.7 & 61.2 & 32.1 & 7.4 & 64.2 & 28.4 \\
\hline $\begin{array}{l}\text { Per capita } \\
\text { income }\end{array}$ & 0 & 46.8 & 53.2 & 0 & 52.0 & 48.0 \\
\hline
\end{tabular}

\subsection{Overview of the Study Area}

The study area is the Northeast region of the U.S. as defined here. It is composed of 12 states (Figure 1.1.A) and consists of all the counties in the states of Connecticut, Delaware, Massachusetts, Maine, Maryland, New York, New Jersey, New Hampshire, Pennsylvania, Rohde Island, Vermont, and West Virginia. It covers $6 \%$ of US land area, $25 \%$ of total population and $11 \%$ of the non-metro population. The region is appropriate for assessing the role of amenities and regional growth due to its diverse spatial variation in economic growth and economic geography. According to the USDAERS County Typology 1993, the region is highly urbanized with $50.5 \%$ of its 299 counties considered metro areas. The non-metropolitan areas are divided between 84 (28.1\%) counties considered as adjacent to metro areas and $64(21.4 \%)$ counties considered as nonadjacent and completely rural. These 148 nonmetro counties can also grouped into $13.4 \%$ of the counties considered as micropolitan areas with a central city with at least 10,000 residents and $36.1 \%$ counties considered as noncore without a central city of at least 2500 residents. Three of the five states in the U.S., with more 
people residing in rural areas than in urban areas are found in this region (Maine, Vermont, and West Virginia).

Figure 1.1. Overview of the Study Area and Regional Economic Indicators
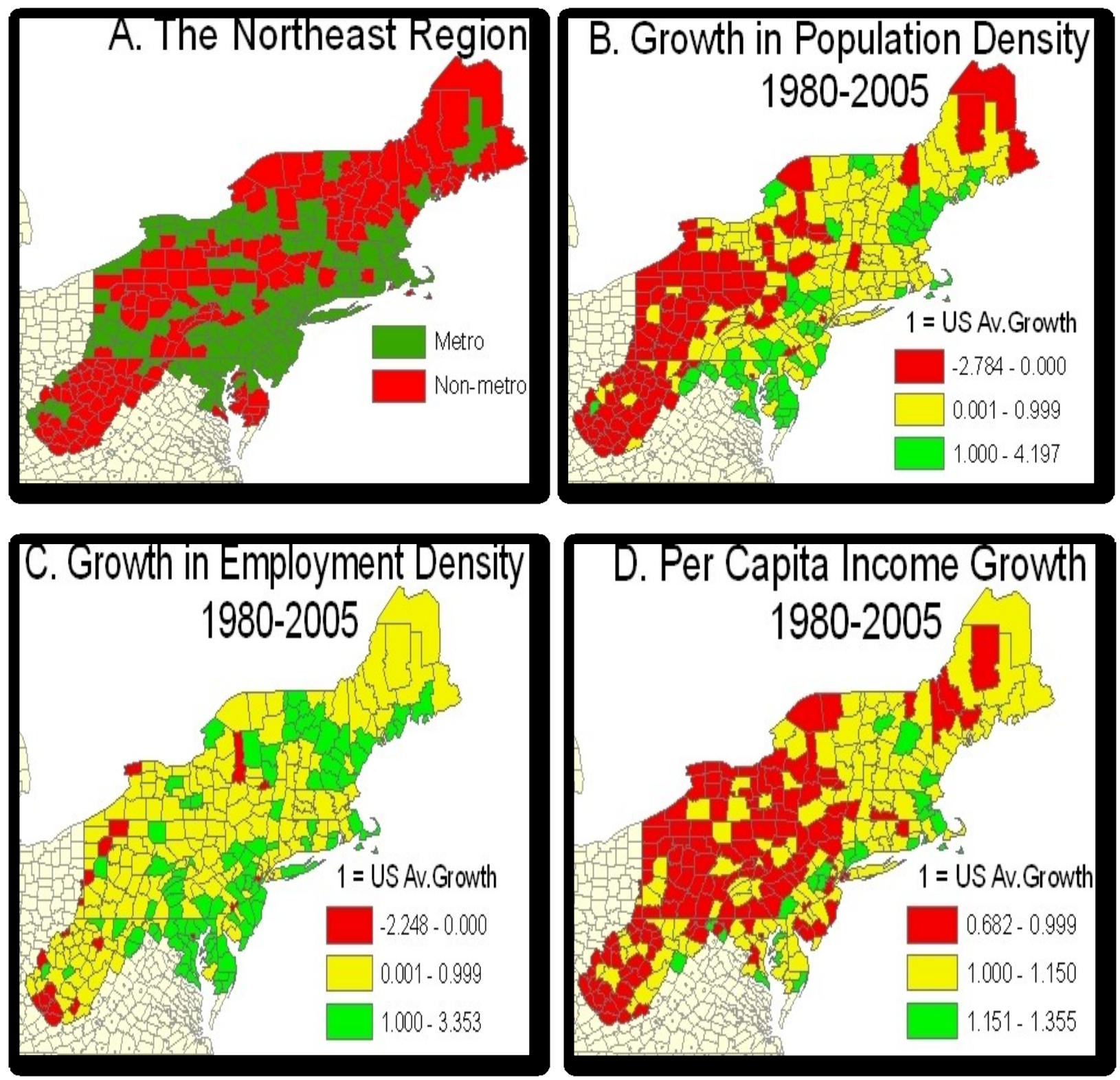

Table 1.2 and Figure 1.1.B -1.1.D provide a general description of regional economic growth during the 1980-2005 period. The spatial distribution of population growth is not uniform (Figure 1.1.B). $35.1 \%$ of the counties lost population, $45.5 \%$ 
recorded growth but below the national US average, and only $19.4 \%$ grew about US average (Table 1.2). Most of the population loss counties are found clustered in the Appalachian part of the region or in the northern part of Maine. Employment growth in the region is not as low as population growth. Only $6.7 \%$ of the counties show negative growth. More than $60 \%$ of the counties grew below national average while $32.1 \%$ grew above national average (Table 1.2). The most encouraging regional growth indicator is the growth in per capita income. $46.8 \%$ of the counties grew below the US average and 53.2 grew above it (Table 1.2). The spatial distribution of the of the regional growth indicators in the non-metro counties in the region is not that much different from the region as a whole (Table 1.2).

Figure 1.2. Comparisons of US and Northeast County Typology

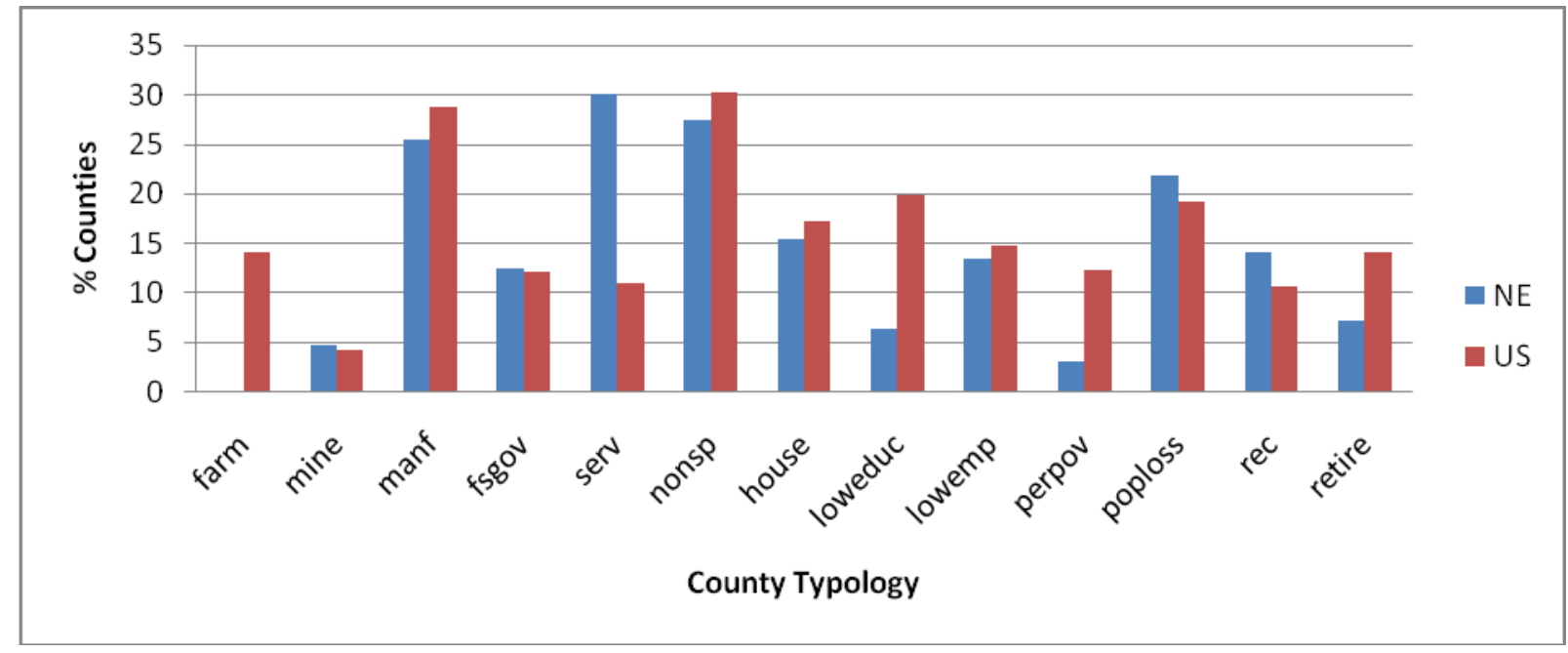

As shown in Figure 1.2 below, the economic geography is diverse. $30.1 \%$ of the NE counties are service dependent compared to $10.8 \%$ for all US counties. The NE region is endowed with high human capital as reflected by few counties with low levels of education ( $6.4 \%$ of the counties with low education compared to $18 \%$ for US). 
Although, the region as a whole has very few poverty persistent counties compared to the US, it has the highest population loss counties (21.7\%) due to out-migration.

Most of the population loss counties are found in the Appalachian part of the NE, counties found in West Virginia and Pennsylvania, upstate New York, and Maine (Figure 1.1.B). In the northeast region, with the exception of very few counties, all metro and non- metro counties in the region lost population aged 25-44 during the period of 2000-2005 (Yang and Snyder, 2007), which indicates the region is losing the most productive part of its population. In general, declining farm employment and lack of natural amenities are cited as the main reasons for population loss (MaGranahan and Beale, 2003). As shown in Figure 1.2, the Northeast region doesn't have any farm

Table 1.2. Northeast Public and Private Natural Resources and Recreational Facilities

\begin{tabular}{|l|l|l|l|l|l|l|l|l|l|l|}
\hline State & $\begin{array}{l}\text { Wild } \\
\text { Acres }\end{array}$ & $\begin{array}{l}\text { FS-NF } \\
\text { Acres }\end{array}$ & $\begin{array}{l}\text { NPS } \\
\text { Acres }\end{array}$ & $\begin{array}{l}\text { COE } \\
\text { Acres }\end{array}$ & $\begin{array}{l}\text { FWS } \\
\text { Acres }\end{array}$ & $\begin{array}{l}\text { NWSR } \\
\text { Miles }\end{array}$ & $\begin{array}{l}\text { NRI } \\
\text { River } \\
\text { Miles }\end{array}$ & $\begin{array}{l}\text { State } \\
\text { Park } \\
\text { Acres }\end{array}$ & $\begin{array}{l}\text { Private } \\
\text { Recreation } \\
\text { Business }\end{array}$ & $\begin{array}{l}\text { Public } \\
\text { Recreation } \\
\text { Facility }\end{array}$ \\
\hline CT & 0 & 0 & 7734.59 & 3232 & 712.88 & 0 & 115 & 175860 & 1419 & 942 \\
\hline DE & 0 & 0 & 0 & 0 & 26700.15 & 0 & 298 & 18189 & 313 & 175 \\
\hline ME & 19386 & 49166 & 90590.39 & 0 & 45404.54 & 95 & 1318 & 285264 & 1328 & 1030 \\
\hline MD & 0 & 0 & 69927.12 & 15 & 40731.32 & 0 & 784 & 292279 & 1778 & 1406 \\
\hline MA & 2420 & 0 & 55818.57 & 5206 & 12472.26 & 0 & 226 & 587558 & 2666 & 1942 \\
\hline NH & 102126 & 720016 & 10461.23 & 3436 & 5859.41 & 15 & 1656 & 341301 & 1115 & 1081 \\
\hline NJ & 10341 & 0 & 53175.23 & 0 & 60678.58 & 16 & 479 & 90693 & 3029 & 959 \\
\hline NY & 1363 & 13232 & 95655.92 & 0 & 26704.06 & 39 & 2812 & 20046 & 5854 & 2424 \\
\hline PA & 9705 & 513001 & 109172.7 & 12418 & 9773.59 & 55 & 580 & 283001 & 4756 & 5823 \\
\hline RI & 0 & 0 & 4.56 & 0 & 1523.39 & 0 & 34 & 8748 & 485 & 1031 \\
\hline VT & 59536 & 340130 & 14878.84 & 4961 & 6409.48 & 0 & 855 & 72610 & 694 & 981 \\
\hline WV & 80682 & 1024876 & 80829.89 & 2542 & 1642.96 & 17 & 1472 & 127811 & 570 & 2844 \\
\hline Total & 285559 & 2660421 & 588249 & 31810 & 238612.6 & 237 & 10629 & 2303360 & 24007 & 20638 \\
\hline
\end{tabular}

Compiled from the NORSIS data base

dependent county. All the counties in the region also score from moderately low to moderately high (-1 to 1 standard deviation from the mean) in the USDA-ERS natural 
amenity scale. In fact, the region is endowed with moderate natural amenities that are not part of the natural amenity scale. According to the National Outdoor Recreation Statistical Information System (NORSIS, 1997) of US- Department of Agriculture, Forest Service, the region is home to five national forests (FS-NF) that cover more than $2,660,421$ acres, 285,559 acres of wilderness, $20 \%$ of the 391 attractions managed by the national park system (NPS) in 588,249 acres, and 238,612 acres of wild life attractions managed by Fish and Wild life Services (FWS). The region also has 31,810 recreational acres of Corps of Engineers (COE), 237 miles of National River System (NWRS), and 10,629 river miles in the Natural Reserve Inventory (NRI). All these federally owned and managed natural endowments provide a wide range of recreational activities like fishing, wildlife watching, hunting, snowboarding, boating, swimming, golfing, camping and hiking in more than 20,000 built recreational facilities. An estimated 700 state parks with more than $2,303,360$ acres and 24,007 recreational private businesses also give the region additional attractions and competitiveness. Even though, the current NORSIS data base is not yet disseminated, the above data is expected to change.

State and local governments all over the US are using quality of life amenities as one of their competitive edges. Consequently, local investment in parks and recreation increased by $121 \%$ during the period of $1992-2006$. The rate of local development based on amenity-led development depends on local policy, the demand for and supply of amenities, spatial distribution of the counties, and the interdependence of regional growth factors (population density, employment density, and per capita income). 


\subsection{Objective of the Study}

The overall objective of this study is to provide policy makers with information on the role of natural and recreational amenities in rural economic development in the Northeast region. The specific objectives are to:

1. Develop a database of natural and built amenities, economic, social, fiscal and demographic variables of the Northeast region.

2. Estimate the impacts of regional economic growth and identify and measure the impacts of an amenity-led development strategy as reflected by growth in employment density, population density, and per capita income as the result of natural and built amenities in the Non-Metro areas of the Northeast region.

3. Identify the spatial distribution of amenities in the growth process.

4. Evaluate the role of proximity to demand market and accessibility in following amenity-led development.

5. Draw policy implications about amenity-led development strategies for rural economic development.

\subsection{Hypotheses}

The central focus of the study is to examine how amenities, controlling for a range of socio-demographic and growth variables, affect changing levels of economic development as expressed by growth in population and employment densities, and per capita income. Hence, the study attempts to empirically test economic relationships between growth factors and natural and built amenities in a regional growth setting. In establishing these relationships, this study, following previous literature makes the 
following basic assumptions. Utility-maximizing households migrate in search of utility derived from the consumption of market and non-market goods, and profit maximizing firms on the other hand become mobile when looking for regions that have lower production costs and higher market demand. Based on these free migration assumptions and rational expectations, the following relationships are hypothesized.

Hypothesis \#1: Regional growth, as measured by growth in population density, employment density, and per capita income, is conditional on local natural and built amenities.

Hypothesis \#2: Pursuing amenity-led development requires proximity to demand market (location matters) and accessibility factors, such as road density.

Hypothesis \#3: Growth is conditional on initial conditions.

Hypothesis \#5: Growth is conditional and affected by economic activities in surrounding counties.

These five hypotheses will be empirically tested using Northeastern regional data. To test these hypotheses, a spatial and non-spatial simultaneous equations model of growth in population and employment density, and growth in per capita income is used. The empirical methodology to test these hypotheses is discussed in detail in Chapter IV. 


\subsection{Methodology}

In this study a regional lag adjustment model will be used which is basically rooted in a compensating differentials framework that characterizes migration as a spatial response to economic opportunity, in the form of employment, higher wages, and/or other means of advancement, and personal preference for natural and built amenities, lifestyles, and other quality of life improvements. It is also an application of the partial adjustment model which uses a simultaneous-equation system that expresses the interdependencies among growth in population and employment density and growth in per capita income. In this study, a three equation regional adjustment model will be used wherein changes in population density, employment density, and per capita income are endogenously determined in the presence of natural and built amenities.

The model builds on the spirit of Carlino and Mills (1987), and extends the models of Deller et al. (2001, 2005, and 2007) and Nzaku and Bukenya (2005) by incorporating interaction terms to test for the combined impact of amenities with proximity to metropolitan areas and accessibility (interstate highway density). Spatial and non-spatial models will be constructed and estimated. A national dataset of all nonmetro counties will be used in the non-spatial empirical estimation of the model with amenity slope shifters for the Northeast region. The same model will also be separately estimated for the 148 nonmetro counties of the Northeast region. The nonspatial models will be estimated by three stage least squares. Furthermore, to capture the direct and indirect effects, a simultaneous spatial Durbin model will be estimated using a two stage 
least squares method for the 1980-2005 period. Even though the focus of the study is the Northeast Region, the study will use both datasets.

\subsection{Organization of the Study}

This study is comprised of five additional chapters. Chapter 2 provides an extensive review of literature in defining and measuring amenities, the relationship between amenity and regional growth, and relevant modeling approaches. Chapter 3 provides the theoretical foundation for modeling amenities and economic development decisions. Chapter 4 discusses specification of the empirical model and of the types and sources of data. Chapter 5 provides analysis of results from model estimation and a summary of the major findings of the study and its policy implications. Finally, Chapter 6 provides a summary, conclusions, and recommendations for policy measures to better preserve and utilize natural assets 


\section{CHAPTER 2: LITERATURE REVIEW}

The purpose of this chapter is to review the most relevant literature on amenities (natural and built) and rural development. The chapter is divided into four sections. The first section defines amenities and describes the potential relationship of amenities and rural development. The second section is devoted to describing how amenities are measured and used in different empirical studies. In the third section, the impact of amenities on economic growth and income distribution (two aspects of economic development) will be discussed. Finally, in the fourth section, methodologies used in amenity related empirical studies will be reviewed.

\subsection{Amenities and Economic Development}

According to Shaffer, et al. (2006) most of the time economic growth and economic development are used interchangeably. Though the concepts are related they are different. Economic growth is about the growth in employment, income, and resources of production. Economic development goes beyond economic growth to incorporate the institutional and structural change in the capacity to act, innovate, and move forward in all aspects of life. Therefore "economic growth can occur without development, and development can occur without growth" (p.61).

In the literature there are several related but somehow different definitions of amenities. Amenities can be broadly defined as non-marketed qualities of a region that make it an attractive place to live and work (Power 1988). The term amenities is also defined as any attribute of a geographic location for which a resident or potential 
migrant would be willing to pay, either through higher housing costs, lower wages, or other location-specific costs, but for which there is no market through which the individual can directly purchase a given amount of that good (Judson et al.1999). It has also been used to refer to the available stock of natural resources such as forests, mountains, hills, lakes and rivers (English, Marcouiller, and Cordell 2000) and/or to the availability of opportunities for recreational activity (Beale and Johnson 1998).

Amenities provide benefits to people directly through direct consumption and to firms by entering directly or indirectly into the production function of certain aspects of land, natural resource and human activities. In this study, Power's (1988) definition is adapted and modified to define natural and built amenities as "natural and built qualities of a region that make it an attractive place to live and work".

The above definition gives the flexibility to include some of the marketed amenitybased recreational attributes of a region along with the nonmarketed natural attributes. Examples of amenities are wildlife and flora, climate, recreational areas (golfing, skiing, fishing, hunting, hiking, and swimming) cultivated landscapes, unique settlement patterns, historic sites, and social and cultural traditions.

According to Green (2001) and OECD (1994), there are four potential relationships between amenities and development. The first possible relationship is that development can lead to the destruction of amenities. This is the case where economic growth leads to more pollution and congestion due to rapid population or employment growth in a region that contains a natural resource area. On the other hand, it is also true that in some cases the lack of economic development can lead to the destruction of 
amenities. One example of this type of relationship is the effects of depopulation on the maintenance of historical buildings and scenic landscapes. A third possibility is that preservation of amenities may lead to non-development. One controversial example of this might be the "potential curtailing of economic development" through designating a land area as a critical habitat for endangered species. Duffy-Denno (1997a), Lewis et al. (2002), and Keith and Fawson (1995) assessed the economic implications of wilderness and conservation of lands in different regions of the US. The results of these studies show no evidence of curtailing of economic growth due to the preservation of amenities.

The final possible relationship between amenities and development is that preservation or promotion of amenities leads to development. An example of this type of relationship might be eco-tourism projects that preserve the natural environment that help attract retirees and firms to move to the area. In this case amenities are used as any other goods for consumption or production to enhance the well being of the local population and create economic development. The main focus of most of the studies in the literature is to empirically test this possible positive relationship between amenities and economic development, specifically economic growth or/and income distribution. This study will follow the literature and try to assess the role of natural and built amenities on rural development.

\subsection{Measuring Amenity Attributes}

Measuring amenities has been a challenge to researchers. The main problem is that there is no market to derive a value. Furthermore, as discussed above, the definition of amenities is becoming broad and encompasses almost any attribute found in a location. In fact, the main sources of data for most studies, the National Outdoor 
Recreation Statistical Information System (NORSIS), which is compiled by the USDA Forest Service, has more than 300 amenity related variables.

Three approaches can be identified in the literature in measuring amenity attributes: single factor, a summary index (single index) approach and an aggregate factor score approach. The single factor approach tries to include all relevant amenity attributes in the model estimation. Duncombe, et al. (2000) applied this approach by including five amenity variables in their analysis of elderly migration. McGranahan (1999) used six amenity measures to study the population and employment changes in rural America during the 1970-1996 period. Others, like Roback $(1982,1988)$, and Carlino and Mills (1987), used number of sunny days as an amenity attribute in their studies. The advantage of the method is that it is straightforward for doing marginal analysis and interpreting the results as any other variable in the model. Its drawback is that you can't include all the relevant variables which may lead to omitted variable bias and, on the other hand, if you try to include all variables, it may lead to multicollinearity problems.

The summary index approach is an effort to define natural amenities as a single index of different amenity attributes. Nord and Cromartie (1997) produced the summary index to represent natural amenities in rural counties. Their summary index consisted of mild sunny winters, moderate summers with low humidity, varied topography, mountains, and the abundance of water. McGranahan (1999) generated a single index called a natural amenity index by summing six amenity measures: average January temperature, average January days with sun, low winter-summer temperature gap, low average July humidity, topographic variation, and water areas. Even though it is a 
broader measure than the single factor, the single index is criticized for being unidimensional in representing the very diverse nature of amenity distributions (ignores built recreational amenities and historical amenities among others) and for the subjectivity incorporated in the decisions about which amenity attributes should be included to develop the index. But despite this weakness, McGranahan's (1999) natural amenity index is the most widely used amenity measure in empirical studies.

The aggregate factor score approach is the latest trend in measuring amenities. It is an effort to reduce a wide array of natural amenity attributes into multiple but similar groups. The Principal Component Analysis (PCA) is a method of combining a set of related variables into a single scalar measure. Many recent studies have evaluated the economic impacts of natural amenity attributes using the Principal Component Analysis (PCA). Goe and Green (2002), using PCA, reduced thirty two amenity attributes into four groups: climate, land, water (two distinct sub groups of river and lake based), outdoor recreational amenities (two distinct categories warm and cold weather based), and historical/cultural amenities. Following the same approach (PCA), Deller et al. $(2005,2007)$ examined the economic effects of five amenity measures (created from more than 50 different attributes): climate, urban facilities, land, water, and winter amenity attributes. Finally, Monchuk (2003) reduced about fifty natural amenity and recreation site variables into five distinct categories unique to the states of Kansas, Minnesota, Missouri, Nebraska, North Dakota, and South Dakota. In all the above studies there is no uniformity in including or grouping the different attributes to create an index. For example, in developing the land index, Goe and Green used four while Deller et al. used sixteen different attributes. 
The aggregate factor score approach is also subjective as is the single index approach and the final measures (factor scores or principal component scores) may not be easy to interpret. The use of aggregate factor scores, however, can allow researchers to examine multidimensional aspects of natural amenity attributes (English, Marcouiller, and Cordell 2000; Deller et al. 2005; Marcouiller et al. 2004).

\subsection{Review of Factors Associated With Amenity and Rural Development}

Numerous studies (Deller et al. 2005, 2007; Monchuk, 2003; McGranahan 1999; Rudzitis, 1999; Gottieleb, 1995; Roback, 1982 and 1988) have documented that different types of amenities play an important role in economic development. Several of these studies link economic growth trends directly to some measure of natural or scenic amenities.

In seminal studies of the role of amenities, Roback (1982 and 1988), assessed the impact of amenities on wage rates and land rents in selected US cities. Her measure of natural amenity was climate. She found that climate and other quality of life factors are capitalized into wages and housing values and rents. People who prefer to live in higher amenity areas are willing to pay high housing values or rents. On the other hand it is expected that workers would be willing to receive lower wages in a location with high quality of life amenities. Hoehn et al. (1987) also found statistical differences in housing prices and wages due to location specific amenities. On the impact analysis of state parks on the economies of the counties of the inter mountain west, Duffy-Deno (1997b) found a relatively weak effect on county level population and employment growth.

All the above studies used a single measure of amenity attribute of a location. In reality 
a region could be endowed with multiple natural and built amenities that can influence the regional economy.

One way through which amenities affect firm location is through compensating wage differentials. If households require higher wages to live in low-amenity locations, the firms in those locations must have some productivity advantage to be able to pay the higher wages. Conversely, if households are willing to accept lower wages to live in amenity locations, firms would follow workers to those locations unless there are some offsetting disadvantages in those places. Gottieleb (1995) addressed the issue of amenities in firm location decisions. His model assumed that there is a direct link between residential amenities and firm location. Thus, the study omitted population (labor force) aggregates entirely, and focused on the long-run relationship between residential amenities, traditional business factors and employment location. He found that residential amenities are important factors in business location.

The widely cited work of McGranahan (1999) was a major contribution to the amenity literature in the 1990s. In the descriptive analysis, a positive relationship was found between natural amenity scale with rapid rates of population growth and employment change. High amenity counties had an average of three times as many jobs during this period than those that scored low on the amenity scale. However, employment change was much more variable during this period than population change, especially for high amenity counties. But in this simple descriptive analysis it was assumed implicitly that the physical availability of high amenities is related to regional growth without consideration of their economic supply. The analysis does not make any 
distinction between completely rural and isolated areas with those that are more accessible and close to high population centers.

In a similar study, the Center for the Study of Rural America used this same amenity measure to estimate the effect of amenities on employment growth while controlling for a much broader set of characteristics (Henderson and McDaniel, 1998). The results verify that while scenic amenities are associated with employment growth, the impact is quite small. White and Hanink (2003) using the same amenity scale but taking into consideration the impact of accessibility found that the accessibility of places with relatively high natural amenity endowments is a necessary factor in those amenities' ability to contribute to economic growth in the Northern Forest area of the Northeast region of the US. McGranahan (1999) also neglects the role of built amenities that take advantage of the physical availability of natural amenities (parks, play grounds, ski resort, golf courses, and others).

Deller et al. (2001, 2005, and 2007, 2008) expanded the single dimensional natural amenity scale to multiple dimensions that include built-in amenities. All these studies further confirmed the positive relationship between amenities and regional growth. Beyond population and employment growth these studies addressed the issue of income growth. Although climatic condition had a strong influence on population change, it had a relatively minor effect on employment and per capita income growth. Similarly, water amenities were significantly related to population change, but not to employment and per capita income growth. Even though these studies used more expanded measures of amenities they limited the study to population, employment, and income of regions. One of the greatest assets of rural communities, land, which is also 
affected by amenities and which in turn could have a feedback effect into these growth indicators is not included in the analyses. Furthermore, like McGranahan (1999) their analysis doesn't make any distinction between completely rural and isolated areas with those that are more accessible and close to high population centers (the issue of accessibility and proximity is not adequately addressed).

The role of spatial distribution of amenities and its impact on the local economy is addressed only in a very few studies. Regions with very low amenities can benefit from the presence of high amenities in their surroundings. Household and firms can find it cost effective to live in low amenity areas as long as there are easily accessible ample amenities in surrounding areas. Monchuk (2003) evaluated the role of surrounding counties' amenities for a county in six states of the Midwest. Using spatial lags of five amenity indices, he found that surrounding counties amenities are more important to employment growth than the local amenities in his study area. Deller et al. (2008) constructed five spatially weighted, narrowly defined specific recreational measures to estimate the role of own and adjacent county amenities on growth of per capita income. They used a neoclassical growth model and found that higher levels of developed resources, such as tourist attractions, amusement parks, zoos, and campgrounds have a positive impact on per capita income growth. But they also found that public acreage lands for recreation have a negative impact on growth. One common thing these two articles show is that the availability of amenities in surrounding counties matter in rural development. Empirical studies that ignore this spatial issue could suffer from omitted variable bias. 
Deller et al. $(2005,2007)$ using their expanded five dimension amenity attributes found that amenities are related to economic growth. Although climatic condition had a strong influence on population change, it had a relatively minor effect on employment and per capita income growth. Similarly, water amenities were significantly related to population change, but not to employment and per capita income growth.

The Economic Research Service (ERS, 1997) identified 514 in 1970 and 190 in early 1990s as retirement counties. Most of these non-metro retirement counties were near metro areas, whose more robust economies helped them outperform other nonmetro counties in attracting and retaining people of all ages, including the elderly. Rural retirement counties with substantial net in-migration of the elderly have enjoyed significantly more rapid population and employment growth than other types of metro and non-metro counties since the 1970s. The influx of retirees is also associated with increased family incomes, reduced unemployment rates, and greater economic diversification in rural areas.

However, others have also looked at this relationship from a different perspective and found different results. Duffy-Deno (1997a) examined whether local economies may be adversely affected by designation of federal-owned wilderness in the eight states of the intermountain western United States. He found no evidence that the existence of federal wilderness was directly or indirectly associated with population or employment growth between 1980 and 1990 . This conclusion is further reinforced by Lewis et al. (2003) findings of no evidence of lower wages due to alternative public land management policies in the Northern Forest region which stretches from northern 
Minnesota to Maine. Even though, they used different data sets and models, their results are a direct opposite of the negative effect found by Roback (1982 and 1988).

In an earlier study, Lewis et al. (2002) also assessed the impact of access to public conservation lands on the Northern Forest region to migration or employment growth of the region. They used a simultaneous regional growth model of net migration and employment. They found that the conservation land share had a positive direct but relatively small effect on net migration. On the other hand no significant direct effect on employment growth was detected. But, since net migration positively influenced employment at the end of period, we can conclude that it had an indirect effect on employment. State level studies in Alabama (Nzaku and Bukenya, 2005a) and Utah (Keith and Fawson, 1995) have also found no evidence that suggests a positive role of amenities on economic growth.

\subsection{Methodological Issues}

There are, broadly speaking, two empirical approaches, Regional economic models and hedonic pricing models, that look to the impact of amenities on economic growth. Both of these models use an equilibrium modeling framework. The hedonic models show that a wide variety of local amenity attributes are partly capitalized into local wages and land rents. Hedonic models indicate that money wages can be offset in places by environmental and other amenities. The uneven abundance of such amenities, therefore, can explain relatively uneven wages and rents in the contemporary economies (Roback 1988, 1982).

Regional economic models aim to identify the direct and indirect effects of amenities on change in population, employment and income, and to capture interactions 
between these variables. They are usually designed as simultaneous equations models and such models are used in this study. Models of this type have traditionally been used to explore empirically whether people follow jobs or jobs follow people. The model was first developed by Steinnes and Fisher (1974) and used it in their classic study to explain the intra-urban location of residents and employment in a two-equation microeconomic model. The models were further refined and operationalized by Carlino and Mills (1987), Deller (2001), and many others.

These models are also called lag adjustment models because in a way they are a compromise between the equilibrium and disequilibrium perspectives of regional development and migration. While they maintain the equilibrium assumption, they also recognize that the impact of the dis-equilibrating forces in the region. The models implicitly assume that the real equilibrium point is unknown and if there is one, a substantial lag is needed to move towards it. They operate on the assumption that there is an endogenous or bi-directional process at work in the various regions, where employment growth (labor demand) drives population growth and population growth (labor supply) drives employment growth. In general, researchers first assume that firms (employment) and households (population) are geographically mobile. Firms move to maximize profits and households to maximize their utility. Economic opportunity and personal preferences are assumed to be the motivating factors behind the movement of people and firms.

Consumer utility is derived from goods and services as well as from non-market, location-specific amenities. Firms maximize their profits by optimizing production costs and choice of a regional market. The result is an adjustment process in which "firms 
enter and leave regions until profits are equalized among regions at competitive levels, and households migrate until utility levels are equalized at alternative locations" (Carlino and Mills, 1987, p. 40). This is an improvement from the traditional regional models that depend only on economic opportunity and ignore the role of personal preferences. But earlier models account for the role of amenities either by dummy variables or climate. Graves and Muser (1993) were among the first to critique these models and point out the bias that can be created by "any unmeasured stable differences between locations.... such as land rent and natural amenities." In response, recent studies started to include explicit measures of natural amenities. One final major improvement was the work of Deller et al.(2001) which added a third equation to capture the income differences in locations and its impact on the growth process.

Many past studies have addressed the relationship between amenities and economic development using regional simultaneous equation models. Rudzitis (1999) examined growth in and around counties with federally designated wilderness and found that employment did not explain migration, while migration did explain employment. Vias (1999) also looked at 254 non-metropolitan counties in the Rocky Mountain West for three time periods, the 1970s, 1980s and 1980-1995 and found that population was the driving force for employment growth, but there was also an inverse relationship between employment and population. As employment declined, population increased.

Duffy-Deno (1997b) following a similar approach examined whether local economies may be adversely affected by designation of federal-owned wilderness in the eight states of the intermountain Western United States. He found no evidence that the 
existence of federal-owned wilderness was directly or indirectly associated with population or employment growth between 1980 and 1990. The two equation system is expanded to a three equation system. Recently, Deller et al. $(2001,2005,2007)$ applying the same approach have found that amenities have positive impacts on economic growth.

In all the above studies the role of space and spatially distributed amenities was ignored. Nzaku and Bukenya (2005b) introduced a spatial lag component to capture the spatial dependence and extended these models. Recent works of Deller et al. (2005 and 2007) also used a spatial error model to capture the unobserved spatial distribution of amenities on the region. But both the extended works of Deller et al. (2001, 2005, and 2007) and Nazaku and Bukenya (2005b) never tried to estimate the spatial impact of surrounding county amenities estimated on regional economic growth. In the presence of spatial dependence on the distribution of amenities, ignoring this spatial effect can lead to biased estimators. Thus, their studies reflect only the direct effect of amenities on the regional growth indicators ignoring the spillover effects coming from surrounding counties.

Furthermore, they estimated a reduced form which captures the total effect. They did not attempt to estimate the impact of amenities in the structural equations. If amenities impact population growth and population growth positively affects employment and income growth, amenities may have an indirect effect on employment and income growth even if they do not have direct effects. This study will use a spatial simultaneous equation model to capture both the direct and indirect effect of amenities. 


\subsection{Summary and Shortcomings of Past Studies}

The contribution of studies in terms of refining the definition of amenities, measuring amenities and evaluating their direct effects on a regional economy is enormous. The works of Power (1988 and 2005), Roback (1988 and 1982), McGranahan (1999), and Deller et al. $(2001,2005,2007,2008)$ are some of the major contributions to our understanding of the role of amenities in regional development. But additional work is required to more fully understand and evaluate the overall effects of amenities on regional development.

Past studies assume that amenities have a direct and independent effect on economic growth, but in reality the availability of high amenity levels alone can only create the opportunity for economic growth. But to be an effective development tool it should be coupled by factors that can exploit its existence, encourage its use, and give it a comparative advantage. For example, two counties with more or less similar amenities could have a difference in their development due to the difference in infrastructure, local policies and economic geography. Therefore, there is a need to account for these factors in empirical studies. An effective development tool for rural areas should be able to provide the optimal mix of policies to complement the particular set of amenities possessed by a region.

With the exception of Nzaku and Bukenya (2005b) and Deller et al. (2005) in almost all past studies the role of space is ignored. Spatial autocorrelation is not controlled. Ignoring spatial autocorrelation and estimating using OLS leads to inefficient standard errors which in turn affects the significance levels of the variables (Wooldridge 
p.6 and 134). Predictions made based on this will be misleading and may have undesired policy implications.

In terms of population growth, amenities have been found to contribute rather than detract from it. Furthermore, the extent to which an amenity exerts a positive effect on the locale, both in terms of attracting people to that county and, in turn, its development depends heavily on people's preference for a particular amenity.

The direct impact of amenities on employment and income growth is mixed. In most studies it is positive but small. In others it is found to have no effect. This may be explained in part by the desire of people to forego income and employment benefits in higher amenity areas. But as discussed above many of the studies have ignored the indirect effects of surrounding county amenities by only focusing on own county amenities. Thus, it is difficult to evaluate the overall effects of amenities on regional growth. This study attempts to extend past studies further not only by capturing the total effects of amenities but also by explicitly evaluating the role of proximity to the demand market and accessibility to amenities. Furthermore, using a spatial Durbin model, the study will estimate the impact of surrounding county amenities on regional economic growth. 


\section{CHAPTER 3: THEORETICAL MODELS OF AMENITIES AND REGIONAL DEVELOPMENT}

\subsection{Household and Firm Location}

Regional development to a great extent is determined by the location decisions (mobility behavior) of firms and households. Both these behaviors impact regional labor markets by demanding and supplying labor. Amenities, ${ }^{2}$ which are location specific, play a role as one of the important determinants of location decisions (Roback, 1982 and 1988). Thus, closer understanding of the relative importance of amenities as a determinant of mobility behavior serves as a starting point for understanding the variation in development in a region.

This section presents a model to analyze the interaction between the location decisions of firms and households and their effect on spatial variations in economic development. The model was originally developed by Roback (1982) and will be discussed below with minor changes. It is a simple general equilibrium model which allows for wages and land rents to interact in the location decision of households and firms.

The model is based on the following assumptions: (1) locations differ by natural and built amenities (a) ; (2) labor and capital move freely from location to location with zero movement costs; (3) Workers (households) are assumed to be identical in tastes and skills while firms are identical in technology and are subject to constant returns to scale; (4) households in each region produce and consume a composite commodity

\footnotetext{
${ }^{2}$ Amenities are defined as in chapter two as "location specific natural and built attributes that make a place an attractive place to live or work".
} 
(Hicksian consumption bundle), $X$, whose price is determined by world markets and will be taken as the numeraire; (5) each household supplies a single unit of labor independently of the wage rate $(w)$ and; (6) the supply curve for land is upward sloping ${ }^{3}$.

\subsubsection{The Household's Location Decision}

At each location, the problem of the representative household is, given the quantity of $a$ in its location, to choose quantities of $X$, and the residential land $\left(I_{C}\right)$ to satisfy the budget constraint. At each location, a household solves the following utility maximization problem:

$$
\begin{aligned}
& \operatorname{Max} U\left(x, I_{c} ; a\right) \\
& \text { s.t. } \quad w+I=x+r I_{c}
\end{aligned}
$$

The wage rate is denoted by $w$, the rental payment is denoted by $r$, and $l$ is non-labor income and is assumed to be independent of location.

The optimal solution of (3.1.1) yields the demand functions for residential land and the composite good:

$$
x^{d}=x(w, r ; \mathrm{a}, l) .
$$

Substituting equations (3.1.2) and (3.1.3) into (3.1.1), we get the indirect utility function $V(w, r ; \mathbf{a}, l)$ which gives the maximum utility attainable given the wage, the residential land price, the level of amenities, and the nonwage income. Thus, households choose residential locations to maximize utility $V(w, p ; a, l)$ by considering the trade-offs

\footnotetext{
${ }^{3}$ According to Roback (1982), a rising supply price of land assures a boundary on the size of the city (p.1259).
} 
between wage $(w)$, residential land price $(r)$, and amenities (a). Since households are assumed to be completely mobile and migration is assumed to be costless, equilibrium for households requires that wages and residential land prices adjust to equalize utility in all locations. The market equilibrium condition for utility maximizing workers is given by:

$$
V(w, r ; \mathbf{a}, I)=k
$$

Where $\mathbf{k}$ is the constant utility level, exogenous to individual locations. The equilibrium condition implies that utility at all locations is equalized in an interregional equilibrium, with the common level of utility equal to some constant $k$. If this doesn't happen, some workers would have an incentive to move to maximize their utility. One of the main properties of the indirect utility function is $\partial V / \partial a>0$ because higher amenity levels increase utility.

\subsubsection{The Firm's Location Decision}

Firms choose production locations to minimize total cost of producing the composite good $X=f\left(n, I_{p}, a\right)^{4}$ by considering the tradeoff between input prices, given the quantity of a (a can be productive or unproductive in the production process) in the location. The production function is assumed to exhibit constant returns to scale and diminishing marginal returns to each factor. So, at any given location, a firm chooses the best combination of labor $(n)$ and land used in production $\left(I_{p}\right)$ to minimize the total production cost ( $r$ and $w$ are price of land and wage rate respectively):

$$
\min w n+r l_{p}
$$

\footnotetext{
${ }^{4}$ According to Roback (1982, p.1260) " $\mathrm{X}$ is a function of capital..... but since capital is perfectly mobile and is uninfluenced by amenities, its rate of return will be equal in all places.......capital.....optimized out of the problem".
} 


$$
\text { s.t. } \quad X=f\left(n, I_{p}, a\right)
$$

Costless mobility and open entry assure that firms everywhere produce at a minimum cost and that marginal cost equals unit price. The optimal solution of (3.5) yields the demand functions for land in production and labor:

$$
n_{d}=n_{d}(w, r ; a)
$$

Equilibrium for firms requires that wages and rents adjust to equalize unit cost in all locations which has to equal product price of unity:

$$
C(w, r, a)=1
$$

This condition assures the spatial equilibrium of firms. If this does not happen, some firms would have an incentive to move to their capital to maximize their profits.

\subsubsection{Interactions between Location Decisions of Households and Firms}

If a region wants to attract new firms and households, the amenities in the region should insure that the cost per unit is below unity $(C(w, r ; a) \leq 1)$ and the indirect utility should be above the regional desired equilibrium $(V(w, r ; \mathbf{a}, I) \geq K)$. This will give the region cost and quality of life comparative advantage to attract new firms and households until it is eventually equalized. For a given set of amenities, an increase in land price must be offset by an increase in wages to maintain consumer indifference. Increases in wages must be offset by reductions in rent to maintain unit costs equal to unity. The equilibrium conditions for firms and households, (3.1.4) and (3.1.8), together determine the equilibrium level of wage and land price. That is, the interaction between 
the two sides of the markets determines the equilibrium level of wages and housing prices. In equilibrium, locations with higher amenities will have higher land prices and lower wages. Regions with lower amenities will have lower land prices and higher wages.

\subsection{Traditional Export Theory and Amenity-Led Development}

The central focus of this study is to examine how amenities, controlling for a range of socio-demographic and growth variables, affect changing levels of economic development as expressed by population, employment, and income growth. The figure below, which is adapted from Power (1996), captures how amenity led development works and compares it with the traditional economic base theory. Power suggests that the logic of amenity-led development turns traditional export base theory on its head. $\mathrm{He}$ compares what he refers to as the extraction and environmental views of the economy. The extraction view of the local economy assumes that to spur development it is necessary to extract resources from the natural environment for export to external markets. The income generated from this export activity is multiplied throughout the economy and puts additional people to work.

The environmental view of the local economy argues that environmental quality is at the root of economic development. Improvements in environmental quality attract workers and businesses to move to the area and increase the amount of retirement income. The new economic activity leads to diversification of the economy and additional jobs and income.

As discussed in Chapter 2.1, Green (2001) and OECD (1994) presented four possible relationships between amenities and development. One of the four possible 


\section{Figure 3.2.1. Comparison of Traditional Export Theory and Amenity-Led Development}

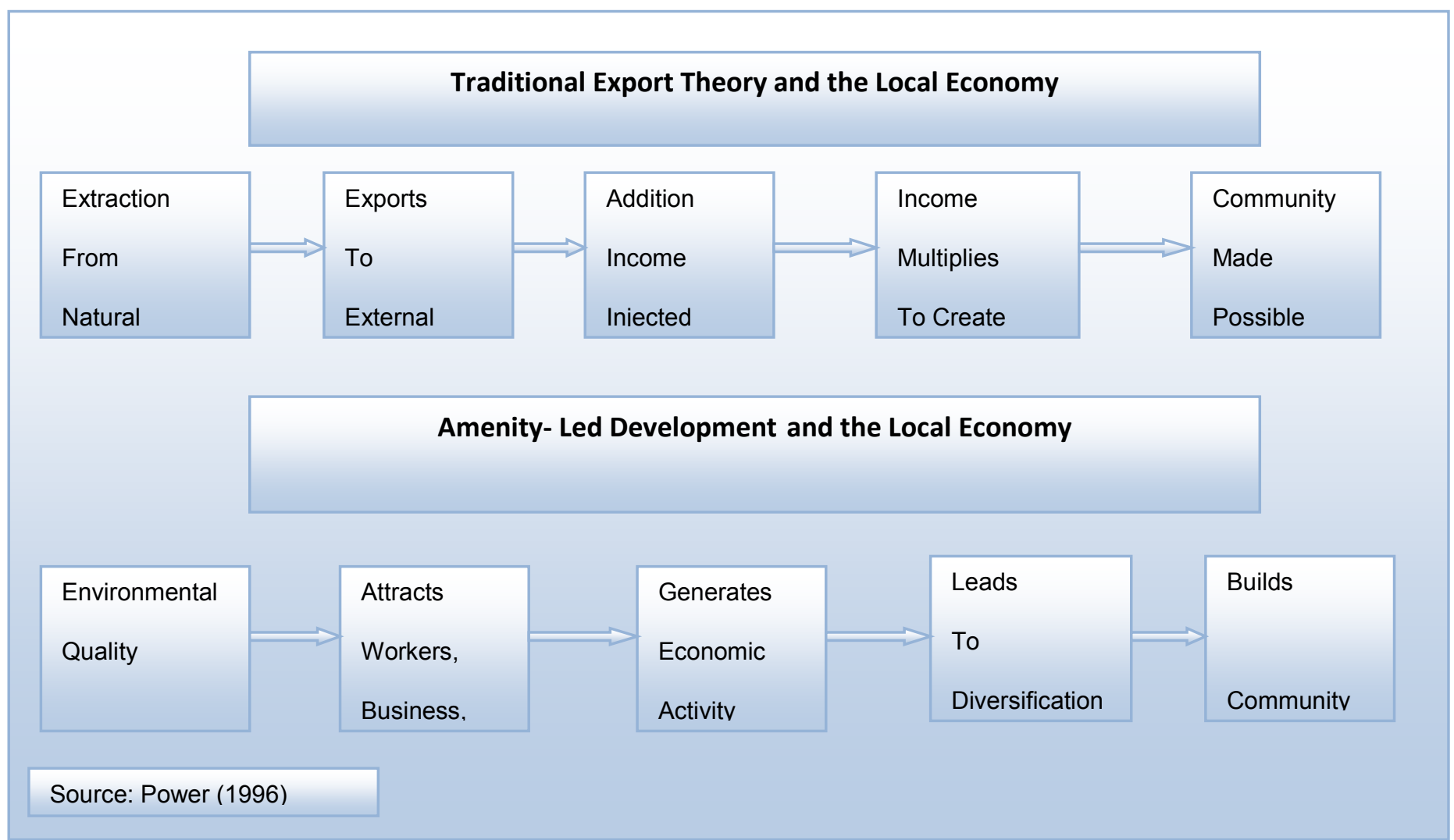

relationships was that preservation or promotion of amenities leads to development. Local policy makers have the choice to preserve and promote their natural amenities to attract households and businesses to move to their area. If they choose so, then they have to encourage public and private investment to make it accessible and build public and private recreational facilities. They also have to create a conducive environment for effective management and sustainable use of the natural resources. This influences the demand for and supply of amenities. The rise in income and change in preferences are factors that push the demand for amenities. Advances in communication technology and transportation infrastructure decrease the cost of accessing amenities in rural 
areas. Amenity focused public policy, the supply of, and demand for amenities create a conducive environment for households and firms to move to the area and influence the local labor market. The move of firms increases the demand for labor, while the move of households influences the supply of labor. Both the demand and supply of labor determine the local wage rate (Figure 3.2.2).

There are several ways in which local amenities impact local economic development. Power (2005) and Gottlieb (1994) discuss the process of how amenities impact a local economy. Generally, there are five types of groups that can influence amenity-led regional development: tourists, second-home owners, retirees, working - age inmigrants and relocating/expanding/new businesses. First, amenities draw tourists, i.e., temporary visitors who want to enjoy local amenities. Businesses focused on serving these visitors' needs may be created or expanded. Some visitors are more regular and persistent and build second-homes to use during their visits. The spending of these visitors supports local businesses. Third, retirees may also be attracted to high- amenity areas. They can choose to reside in the locations that appeal most to them, without regard to employment opportunities. Such choices by retirees contribute to boosting local population and spending (via lower - but more stable - transfer income).

Though, the base of the economy is the service sector instead of the traditional goods producing sector, these three means are consistent with the economic base view of the local economy (a labor demand model). In this perspective, local development is stimulated by external demand, that is, by the injection of additional income from the 
Figure 3.2.2. Amenities, Public Policy, and Regional Development

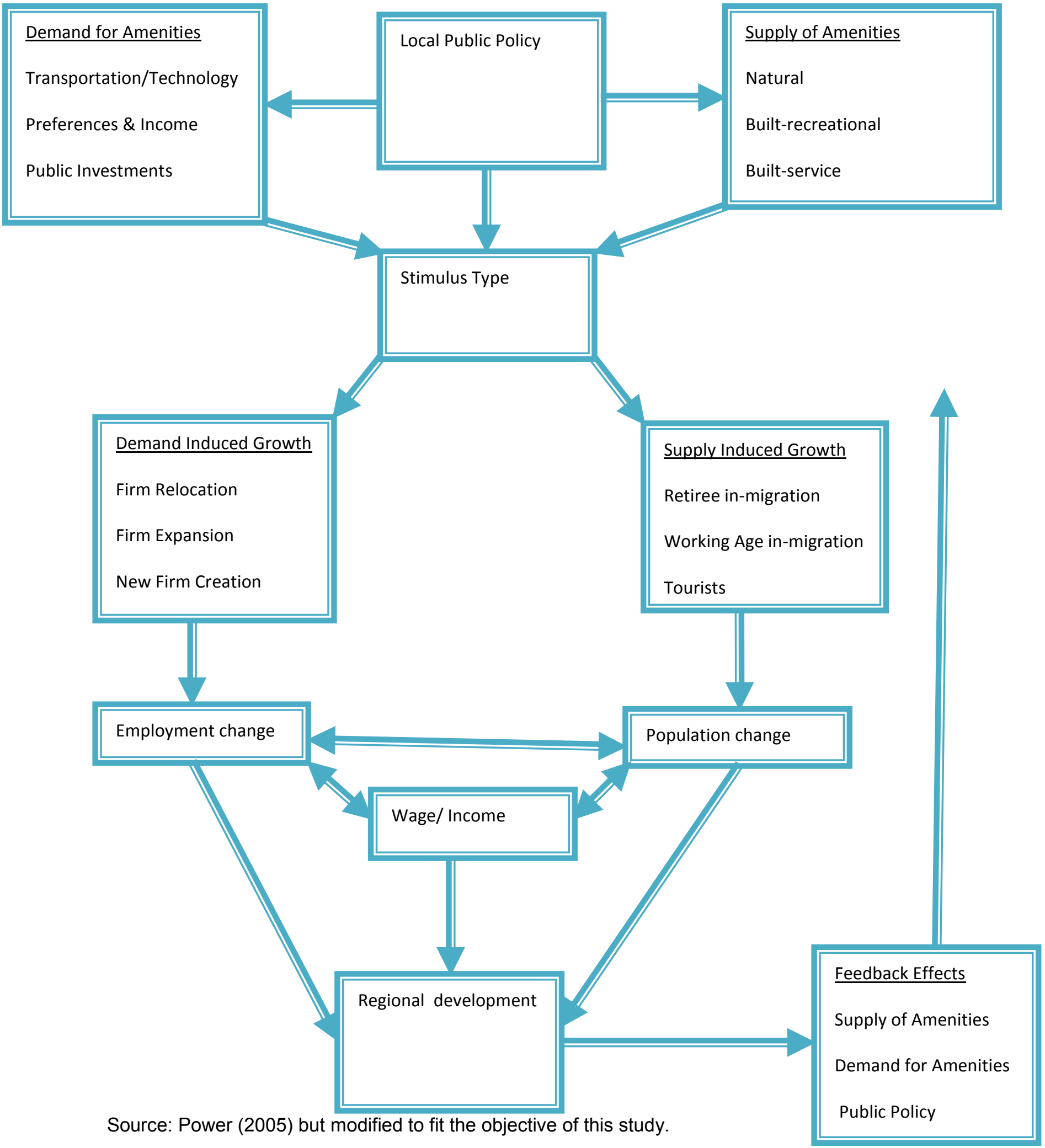


outside into the local economy. Additional income originates from an export activity and is circulated throughout the economy to generate additional employment via multiplier impacts on locally-oriented businesses.

Amenities can also spur the local economy by influencing the supply of labor. They attract in-migrants of working age who take up residence in the area and create their own jobs (Power, 2005). In general, these working age in-migrants are assumed to be knowledge workers who are flexible and innovative. The flow of these workers, attract businesses that are in need of those skills (Gottlieb, 1994). Therefore, amenities can impact the local economy by influencing both sides of the labor market.

The magnitude of the impact of amenities on the local economy depends not only on the interplay of public policy, demand for, and supply of amenities, but also on the spatial distribution of the counties and the rate of urbanization. The physical availability of high quality amenities doesn't guarantee economic growth. The cost of accessing these amenities depends on how far they are from the demand market. Proximity to the demand market plays a big role in reducing the cost. Building recreational infrastructure and roads needs a tax base to support it. Sparsely populated counties may have difficulty in financing projects that can enhance the competitiveness of their region. In most amenity related empirical studies, the role of proximity and level of urbanization are ignored or are not adequately addressed.

This study will account for these factors by creating an interaction variable between amenity and measures of proximity and accessibility. This will enable us to differentiate the magnitude of the impact and feasibility of following amenity led 
development. Figure 3.2.2 is a diagrammatic framework which summarizes the above discussion. It shows how local public policy, demand for, and supply of amenities interrelate to each other and induce regional development. The structural model developed in the next section builds on the theoretical discussions of sections 3.1 and 3.2.

\subsection{Theoretical Model of Regional}

In order to empirically estimate regional growth, Carlino and Mills (1987) developed a model that integrated economic base theory with regional adjustment models. In their study they addressed the simultaneity nature of population-employment interaction in regional growth. Deller et al. (2001) expanded the model by explicitly introducing income into the structural framework to draw attention to the question of job quality as measured by income levels of jobs (wage levels). The theory behind regional growth adjustment models is a compensating differentials framework (discussed in Chapter3) that characterizes migration as a spatial response to economic opportunity, in the form of employment, higher wages, and/or other means of advancement, and personal preference, for particular amenities, lifestyles, and/or other quality of life improvements. Within this context, population and employment dynamically adjust via a process that eventually produces a steady state where, in net, change no longer occurs.

Following Deller et al. (2001, 2005, and 2007) this study assumes the interaction between population desity (POPD), employment density (EMPD), and per capita income (PCl) growth to be interdependent among each other. Deller et al. (2005) assumed that utility-maximizing households migrate in search of utility derived from the consumption of market and non-market goods, and profit maximizing firms on the other 
hand become mobile when looking for regions that have lower production costs and higher market demand. The relationship between amenity and measures of economic development is expressed in a three equation system of " Jobs-People-Income" as:

(3.3.1) POPD $^{*}=\mathbf{f}\left(\right.$ EMPD $\left.^{*}, \mathbf{P C I}^{*} / \mathbf{A}, \Omega^{\mathbf{P}}\right)$

(3.3.2) $\mathbf{E M P D}^{*}=\mathbf{g}\left(\mathbf{P O P D}^{*}, \mathbf{P C I}^{*} / \mathbf{A}, \Omega^{\mathbf{E}}\right)$

(3.3.3) $\mathbf{P C I}^{*}=\mathbf{h}\left(\mathbf{P O P D}^{*}, \mathbf{E M P D}^{*} / \mathbf{A}, \Omega^{\mathbf{Y}}\right)$

where POPD *, EMPD *, and PCI *are equilibrium levels of population density, employment density, and per capita income, respectively; $A$, is a vector of measures of local amenity indices and their interaction; $\Omega^{P}, \Omega^{E}$,and $\Omega^{\mathrm{Y}}$ are vectors of variables describing initial conditions and other predetermined variables that affect the equilibrium level of population density, employment density, and per capita income at the county level. The relations in (3.3.1), (3.3.2), and (3.3.3) are based in the interdependence of Jobs-People-Income. A simple linear relationship between the three variables can be expressed as:

(3.3.4) POPD $^{*}=\boldsymbol{\alpha}_{0 \mathbf{P}}+\boldsymbol{\beta}_{1 \mathrm{P}} \mathbf{E M P D}^{*}+\boldsymbol{\beta}_{2 \mathrm{P}} \mathbf{P C I}^{*}+\prod_{I \mathrm{P}} \mathbf{A}+\sum \boldsymbol{\delta}_{\mathrm{IP}} \Omega^{\mathrm{P}}$

(3.3.5) $\mathbf{E M P D}^{*}=\boldsymbol{\alpha}_{0 \mathrm{E}}+\boldsymbol{\beta}_{1 \mathrm{E}} \mathbf{P O P D}^{*}+\boldsymbol{\beta}_{2 \mathrm{E}} \mathrm{PCI}^{*}+\Pi_{\mathrm{IE}} \mathbf{A}+\sum \boldsymbol{\delta}_{\mathrm{IE}} \Omega^{\mathrm{E}}$

(3.3.6) PCI $^{*}=\alpha_{0 \mathbf{Y}}+\beta_{1 Y}$ POPD $^{*}+\beta_{2 \mathbf{Y}}$ EMPD $^{*}+\prod_{I Y} \mathbf{A}+\sum \delta_{I Y} \Omega^{\mathbf{Y}}$

Where $\alpha, \beta, \pi, \delta$ are coefficients that will be estimated. Following Carlino and Mills (1987) and Deller et al. (2001, 2005 and 2007), assuming partial adjustment to 
equilibrium, actual population density, employment density, and per capita income are related to their lagged values plus an adjustment to the desired equilibrium level. $\lambda_{P}, \lambda_{E}$, and $\lambda_{Y}$ are speed adjustment coefficients to the desired level of population, employment, and income, respectively.

(3.3.7) POPD $_{t}=$ POPD $_{t-1}+\lambda_{\mathbf{P}}\left(\mathbf{P O P D}^{*}-\right.$ POPD $\left._{t-1}\right)$

(3.3.8) $\mathbf{E M P D}_{\mathbf{t}}=\mathbf{E M P D}_{t-1}+\lambda_{\mathbf{E}}\left(\mathbf{E M P D}^{*}-\mathbf{E M P D}_{\mathbf{t}-1}\right)$

(3.3.9) $\mathbf{P C I}_{\mathbf{t}}=\mathbf{P C I}_{\mathbf{t}-1}+\lambda_{\mathbf{Y}}\left(\mathbf{P C I}^{*}-\mathbf{P C I}_{\mathbf{t}-1}\right)$

According to McDonald (1992), the speed adjustment coefficients are expected to be between zero and one if employment, population, and income move toward the equilibrium level (to reflect dynamic stability), whereas negative values will exist if they overshoot the desired level and this reflects dynamic instability ${ }^{5}$. POPD $\mathrm{t}_{-1}, \mathrm{EMPD}_{\mathrm{t}-1}$, and $\mathrm{PCl}_{\mathrm{t}-1}$ are initial conditions of population density, employment density and per capita income, respectively. Rearranging terms and using $\Delta$ to represent the change in the respective variables, we derive the following equivalent equations:

$$
\begin{aligned}
& \Delta \mathbf{P O P D}=\mathbf{P O P D}_{\mathbf{t}}-\mathbf{P O P D}_{\mathrm{t}-1}=\lambda_{\mathrm{P}}\left(\mathrm{POPD}^{*}-\mathbf{P O P D}_{\mathrm{t}-1}\right), \\
& \triangle E M P D=\text { EMPD }_{t}-\text { EMPD }_{t-1}=\lambda_{\mathbf{E}}\left(\mathbf{E M P D}^{*}-\mathbf{E M P D}_{\mathbf{t}-1}\right) \\
& \Delta \mathbf{P C I}=\mathbf{P C I}_{\mathbf{t}}-\mathbf{P C I}_{\mathbf{t}-1}=\lambda_{\mathbf{Y}}\left(\mathbf{P C I}^{*}-\mathbf{P C I}_{\mathbf{t}-1}\right)
\end{aligned}
$$

The level of change is a direct function of the difference between the theoretical equilibrium level and the observed level at the beginning of the period times the

\footnotetext{
${ }^{5}$ Boarnet (1994) discusses the conditions and implications for speed adjustment coefficients below zero.
} 
adjustment coefficient. The greater the distance observed or initial levels are from equilibrium the greater the level of growth to the equilibrium level. In practice, the theoretical equilibrium levels are not observable but can be solved from equations (3.3.11)-(3.312).

$$
\text { POPD }^{*}=\text { POPD }_{t-1}+\frac{1}{\lambda_{P}}\left(\text { POPD }_{t}-\text { POPD }_{t-1}\right),
$$

$$
\text { EMPD }^{*}=\text { EMPD }_{\mathrm{t}-1}+\frac{1}{\lambda_{\mathrm{E}}}\left(\text { EMPD }_{\mathrm{t}}-\text { EMPD }_{\mathrm{t}-1}\right)
$$

$$
\mathbf{P C I}^{*}=\mathbf{P C I}_{\mathbf{t}-1}+\frac{1}{\lambda_{\mathbf{Y}}}\left(\mathbf{P C I}_{\mathbf{t}}-\mathbf{P C I}_{\mathbf{t}-1}\right)
$$

Substituting (3.3.13), (3.3.14), and (3.3.15) into equations (3.3.1), (3.3.2), and (3.3.3), and rearranging terms yields the following equations (assuming linear relationship of the endogenous variables)

$$
\Delta \mathrm{POPD}=\lambda_{\mathrm{P}}\left(\begin{array}{l}
\boldsymbol{\alpha}_{0 \mathrm{P}}+\boldsymbol{\beta}_{1 \mathrm{P}} \frac{1}{\lambda_{\mathrm{E}}} \Delta \mathbf{E M P D}+\boldsymbol{\beta}_{2 \mathrm{P}} \frac{1}{\lambda_{\mathbf{Y}}} \Delta \mathrm{PCI}+\gamma_{1 \mathrm{P}} \mathbf{E M P D}_{\mathrm{t}-1}+\gamma_{2 \mathrm{P}} \mathbf{P C I}_{\mathrm{t}-1} \\
-\gamma_{3 \mathrm{P}} \mathbf{P O P D}_{\mathrm{t}-1}+\Pi_{\mathrm{IP}} \mathbf{A}+\sum \boldsymbol{\delta}_{\mathrm{IP}} \Omega^{\mathrm{P}}
\end{array}\right),
$$

$$
\Delta \text { EMPD }=\lambda_{\mathrm{E}}\left(\begin{array}{l}
\boldsymbol{\alpha}_{0 \mathrm{E}}+\frac{1}{\lambda_{\mathrm{P}}} \boldsymbol{\beta}_{1 \mathrm{E}} \Delta \mathbf{P O P D}+\frac{1}{\lambda_{\mathbf{Y}}} \boldsymbol{\beta}_{2 \mathrm{E}} \Delta \mathrm{PCI}+\boldsymbol{\gamma}_{1 \mathrm{E}} \text { POPD }_{\mathrm{t}-1}+\gamma_{2 \mathrm{E}} \mathbf{P C I}_{\mathrm{t}-1} \\
-\boldsymbol{\gamma}_{3 \mathrm{E}} \mathbf{E M P D}_{\mathrm{t}-1}+\prod_{\mathrm{IE}} \mathbf{A}+\sum \boldsymbol{\delta}_{\mathrm{IE}} \Omega^{\mathrm{E}}
\end{array}\right)
$$




$$
\Delta \mathbf{P C I}=\lambda_{\mathbf{Y}}\left(\begin{array}{l}
\boldsymbol{\alpha}_{0 \mathbf{Y}}+\frac{1}{\lambda_{\mathbf{E}}} \boldsymbol{\beta}_{1 \mathrm{Y}} \Delta \mathbf{P O P D}+\frac{1}{\lambda_{\mathbf{P}}} \boldsymbol{\beta}_{2 \mathbf{Y}} \Delta \mathbf{E M P D}+\boldsymbol{\gamma}_{1 \mathbf{Y}} \mathbf{P O P D}_{\mathrm{t}-1}+\boldsymbol{\gamma}_{2 \mathbf{Y}} \mathbf{E M P D}_{\mathrm{t}-1} \\
-\gamma_{3 \mathbf{Y}} \mathbf{P C I}_{\mathrm{t}-1}+\Pi_{\mathrm{IIY}} \mathbf{A}+\sum \boldsymbol{\delta}_{\mathrm{IY}} \Omega^{\mathbf{Y}}
\end{array}\right)
$$

Equations (3.3.16), (3.3.17), and (3.3.18) form the theoretical foundations for the non-spatial structural model. Note that in the structural model, following Deller et al. (2001), the speed adjustment coefficients $\left(\lambda_{P,}, \lambda_{E,,}\right.$ and $\left.\lambda_{Y}\right)$ are embedded in the linear coefficient parameters $\beta, \gamma$, and $\delta$.

$$
\begin{aligned}
& \Delta \mathrm{POPD}=\boldsymbol{\beta}_{1 \mathrm{P}} \Delta \mathrm{EMPD}+\boldsymbol{\beta}_{2 \mathrm{P}} \Delta \mathrm{PCI}+\boldsymbol{\gamma}_{1 \mathrm{P}} \mathrm{EMPD}_{\mathrm{t}-1}+\gamma_{2 \mathrm{P}} \mathbf{P C I}_{\mathrm{t}-1}-\gamma_{3 \mathrm{P}} \mathbf{P O P D}_{\mathrm{t}-1}+\Pi_{\mathrm{IP}} \mathrm{A}+\sum \boldsymbol{\delta}_{\mathrm{IP}} \Omega^{\mathrm{P}} \\
& \Delta \mathrm{EMPD}=\boldsymbol{\beta}_{1 \mathrm{E}} \Delta \mathrm{POPD}+\boldsymbol{\beta}_{2 \mathrm{E}} \Delta \mathrm{PCI}+\boldsymbol{\gamma}_{1 \mathrm{E}} \mathrm{POPD}_{\mathrm{t}-1}+\gamma_{2 \mathrm{E}} \mathrm{PCI}_{\mathrm{t}-1}-\gamma_{3 \mathrm{E}} \mathrm{EMPD}_{\mathrm{t}-1}+\Pi_{\mathrm{IE}} \mathrm{A}+\sum \boldsymbol{\delta}_{\mathrm{IE}} \Omega^{\mathrm{E}} \\
& \Delta \mathrm{PCI}=\boldsymbol{\beta}_{1 \mathbf{Y}} \Delta \mathrm{POPD}+\boldsymbol{\beta}_{2 \mathbf{Y}} \Delta \mathrm{EMPD}+\boldsymbol{\gamma}_{1 \mathrm{Y}} \mathrm{POPD}_{\mathrm{t}-1}+\gamma_{2 \mathrm{Y}} \mathrm{EMPD}_{\mathrm{t}-1}-\gamma_{3 \mathbf{Y}} \mathbf{P C I}_{\mathrm{t}-1}+\Pi_{\mathrm{IY}} \mathbf{A}+\sum \boldsymbol{\delta}_{\mathrm{IY}} \Omega^{\mathbf{Y}}
\end{aligned}
$$

The non-spatial model described above ignores the role of space in the growth process. However, regions are made of multiple counties that influence one another's activities. Data generated from these interdependent activities are likely to show spatial dependence. Consequently, specifying and estimating models without accounting for the spatial dependence results in biased estimators. Furthermore, the spatial distribution of amenities is not dependent on political or administration jurisdiction, the unit for which data are reported. A possible mismatch between the geographical units and the spatial distribution of the natural amenities being studied may result in misspecification problems and misleading policy implications (Doreian 1980, 1981; LeSage 1997; Anselin 1988; Anselin and Bera 1998). Spatial dependency and spatial 
mismatch of natural amenities require methods that take into account the distinct spatial characteristics of natural amenities. Furthermore, most socioeconomic and demographic variables also tend to have spatial dependence (Doreian, 1980, 1981).

For this reason it is necessary to account for spatial dependence in the data representing growth in population density ( $\triangle P O P D)$, growth in employment density ( $\triangle \mathrm{EMPD})$, and growth in per capita income $(\triangle \mathrm{PCl})$. There are several approaches to account for spatial dependence. This can be accomplished by adding spatial lags of the dependent variable, modeling as spatial error, or as the spatial Durbin method.

The spatial error model (3.3.22) is a technique that incorporates the spatial autocorrelation of the variables through the error term. It arises when there are observations are interdependent through unmeasured variables that are correlated across space or measurement error that is correlated with space. The spatial autocorrelation is treated as a missing variable represented by the unobserved error terms. When errors are spatially correlated the problem of using ordinary least squares is that the estimator tends to underestimate the true standard errors. The spatial error model, by accounting for spatial autocorrelation produces more efficient estimators than does ordinary least squares method. It can be formulated as follows:

\subsubsection{2 $\mathbf{y}=\mathbf{X} \boldsymbol{\beta}+\mathbf{u}$, where $\mathbf{u}=\boldsymbol{\rho W u}+\varepsilon$}

$W$ is $(n \times n)$ spatial weight matrix, $Y$ is $(n \times 1)$ vector of dependent variable, $X$ is a matrix of independent variables, $u$ is a $(n \times 1)$ vector of error terms that are spatially correlated, $\varepsilon$ is the uncorrelated $(n \times 1)$ error vector, $\rho$ is the measure of spatial dependence, and $\beta$ is a vector of parameter estimates of the independent variables. 
In a spatial lag model (3.3.23) the dependent variable is affected by the values of the dependent variables in nearby places. Ordinary least squares ignore the interdependence of the dependent variables and the spatial lag becomes part of the error term that leads to inconsistent estimates. The spatial lag model can be formulated as:

\subsubsection{3 $\mathbf{y}=\boldsymbol{\rho W y}+\mathbf{X} \boldsymbol{\beta}+\mathbf{u}$}

The notations are the same as equation 3.3.22. The only difference is that now the spatial dependency is captured through the dependent variable.

Despite the attempt to include a large number of independent variables, there are always important variables that are excluded from a model. If the omitted variable exhibits spatial dependence and is correlated with the explanatory variables, this leads to omitted variable bias and the coefficient estimates are biased. In this case, the preferred spatial approach is the spatial Durbin model (Lesage and Pace, 2009).In this study, it is hard to account all for all the amenity attributes and other local factors that affect economic growth. Thus, the spatial dependence due to the unit of analysis, in this study county, or because of the spatial distribution of amenities, spatial Durbin model is specified. To account for spatial dependence among counties, each equation is expanded to contain a spatial lag of the dependent variable and independent variables resulting in the following spatial Durbin structural system of equations. 


$$
\begin{gathered}
\triangle P O P D=\beta_{1 P} W \triangle P O P D+\beta_{2 P}(I+W) \triangle P C I+\beta_{3 P}(I+W) \Delta E M P D+\gamma_{1 P}(I+W) E M P D_{t-1} \\
+\gamma_{2 P}(I+W) P C I_{t-1}-\gamma_{3 P}(I+W) P O P D_{t-1}+\Pi_{I P}(I+W) A+\sum \delta_{I P}(I+W) \Omega^{P}
\end{gathered}
$$

$$
\begin{gathered}
\triangle E M P D=\beta_{1 E} W \Delta E M P D+\beta_{2 E}(I+W) \Delta P C I+\beta_{3 E}(I+W) \Delta P O P D+\gamma_{1 E}(I+W) P O P D_{t-1} \\
+\gamma_{2 E}(I+W) P C I_{t-1}-\gamma_{3 E}(I+W) E M P D_{t-1}+\Pi_{I E}(I+W) A+\sum \delta_{I E}(I+W) \Omega
\end{gathered}
$$

$$
\begin{aligned}
\Delta P C I= & \beta_{1 Y} W \Delta P C I+\beta_{2 Y}(I+W) \Delta E M P D+\beta_{3 Y}(I+W) \Delta P O P D+\gamma_{1 Y}(I+W) P O P D_{t-1} \\
& +\gamma_{2 Y}(I+W) E M P D_{t-1}-\gamma_{3 Y}(I+W) P C I_{t-1}+\Pi_{I Y}(I+W) A+\sum \delta_{I Y}(I+W) \Omega^{Y}
\end{aligned}
$$

$\mathrm{W}$ is an $\mathrm{n}$ by $\mathrm{n}$ spatial weight matrix. $\mathrm{I}$ is an identity and the rest notations are the same as in the nonspatial model. 


\section{CHAPTER 4: EMPIRICAL MODELS AND DATA DESCRIPTION}

\subsection{Introduction}

In Chapter 3, a theoretical model was developed to serve as a base for the empirical model. The theoretical model reflects the interdependence of household residential choices and firm location decisions. This interdependence is influenced by the demand for and supply of amenities. The models outlined above and summarized in (3.3.19.-3.3.21.) and (3.3.24.-3.3.26) are estimated using nonmetro county-level data for the whole US and Northeast Region of the U.S. for the 1980-2005 period. Even though the focus of this study is the Northeast Region, the study will use both datasets. The national dataset will be used in the non-spatial empirical estimation of the model with amenity slope shifters for the Northeast region. In section 4.1 the non-spatial model is followed by the specification of three equations. In section 4.2 the spatial model is described and in section 4.3 the description of data is presented.

\subsection{Non-Spatial Model}

An empirical model with the set of equations 4.2.1.- 4.2.3. will be estimated using data from the 2,256 nonmetro counties of the 48 lower states of the United States for the time period $1980-2005$. This will be followed by separate estimations for the 148 non-metro counties to assess the impact of amenities in the rural northeast region. The econometric relationships of the regional growth indicators and amenity measures can be specified for the non-spatial model as: 


$$
\begin{aligned}
\Delta \mathbf{P C I}= & \boldsymbol{\alpha}_{\mathbf{Y}}+\boldsymbol{\beta}_{1 \mathbf{Y}} \Delta \mathbf{P O P D}+\boldsymbol{\beta}_{2 \mathbf{Y}} \Delta \mathbf{E M P D}+\gamma_{3 \mathbf{Y}} \text { POPD }_{\mathrm{t}-1}+\gamma_{4 \mathbf{Y}} \text { EMPD }_{\mathrm{t}-1}+\gamma_{3 \mathbf{Y}} \mathbf{P C I}_{\mathrm{t}-1} \\
& +\Pi_{\mathrm{iY}} \mathbf{A}+\sum \boldsymbol{\delta}_{\mathrm{iY}} \Omega^{\mathbf{Y}}+\boldsymbol{\varepsilon}_{\mathbf{Y}}
\end{aligned}
$$

(4.2.2) $\quad \Delta$ POPD $=\alpha_{\mathrm{P}}+\boldsymbol{\beta}_{1 \mathrm{P}} \Delta$ EMPD $+\boldsymbol{\beta}_{2 \mathrm{P}} \Delta \mathrm{PCI}+\boldsymbol{\gamma}_{1 \mathrm{P}} \mathrm{EMPD}_{\mathrm{t}-1}+\boldsymbol{\gamma}_{2 \mathrm{P}} \mathbf{P C I}_{\mathrm{t}-1}+\boldsymbol{\gamma}_{3 \mathrm{P}}$ POPD $_{\mathrm{t}-1}$ $+\prod_{\mathrm{iP}} \mathbf{A}+\sum \boldsymbol{\delta}_{\mathrm{iP}} \Omega^{\mathrm{P}}+\boldsymbol{\varepsilon}_{\mathrm{P}}$

(4.2.3) $\Delta$ EMPD $=\boldsymbol{\alpha}_{\mathrm{E}}+\boldsymbol{\beta}_{1 \mathrm{E}} \Delta \mathrm{POPD}+\boldsymbol{\beta}_{2 \mathrm{E}} \Delta \mathrm{PCI}+\boldsymbol{\gamma}_{1 \mathrm{E}} \mathbf{P O P D}_{\mathrm{t}-1}+\boldsymbol{\gamma}_{2 \mathrm{E}} \mathbf{P C I}_{\mathrm{t}-1}+\boldsymbol{\gamma}_{3 \mathrm{E}} \mathbf{E M P D}_{\mathrm{t}-1}$ $+\prod_{\mathrm{iE}} \mathbf{A}+\sum \boldsymbol{\delta}_{\mathrm{iE}} \Omega^{\mathrm{E}}+\boldsymbol{\varepsilon}_{\mathrm{E}}$

$\varepsilon_{P}, \varepsilon_{E}$, and $\varepsilon_{Y}$ are the residuals of the change in population, employment, and per capita income equations, respectively. The remaining notations are the same as described in Chapter 3. This model, which builds on Carlino and Mills (1987) and Deller (2001), captures growth dynamics of population, employment, and per capita income within a region. The model hypothesizes no spillover effects in population, employment, and per capita income among various regions. Within the framework just described above, growth in population, employment, and per capita income are characterized as pushing one another toward equilibrium values in the growth process, meaning that the system is expected to register upfront a particular pattern of feedback among the three growth variables.

The main objective of the study is to assess the role of amenities in the regional economic growth process. Natural amenities and outdoor recreational facilities are assumed to have a positive effect on changes in population density and employment density, and negative effect on per capita income. Furthermore, the role of proximity of natural amenities to the demand markets and accessibility to the supply of natural amenities is tested. In most amenity related studies, the role of proximity and accessibility is not recognized or totally ignored. This study contends that the availability 
of high amenity levels alone can only create the opportunity, but to effectively promote development, it must be complemented by other factors that can exploit the amenities and create a comparative advantage. For example, two counties with more or less similar amenities could follow a different development process due to differences in infrastructure, local policies, and level of urbanization. Therefore, amenities are only one factor, and to have effective development in rural areas requires a mix of different factors.

This study attempts to account for proximity and accessibility by extending the Deller (2001) model. The model is extended by introducing interaction terms to capture the combined effect of natural and built amenities with proximity to metropolitan areas (adjacency) and accessibility (Interstate highway density). In addition to these general descriptions of the uniqueness of the model of this study, the equations in the model are specified in detail in the following sections. In the empirical estimation, each equation in the model is first specified and estimated with amenity slope shifters for the northeast ${ }^{6}$ using ordinary least squares method. This is followed by the estimation of the whole model as a system of equations using three stage least squares with and without augmenting the interaction terms described above.

\subsubsection{Growth in Per capita Income Equation (LPCI)}

Growth in per capita income is measured as the percentage change of per capita income from 1980 to 2005 . The growth in per capita income (LPCl) equation is specified as a function of the endogenous variables of growth in population density (LPOPD) and

\footnotetext{
${ }^{6}$ Each amenity variable is multiplied by a dummy variable that identifies the Northeast region. The amenity variables will be multiplied by $(I+N E)$. $I$ is an identity and NE is a dummy that equals 1 for counties in the Northeast region and 0 otherwise. These slope shifters will test whether the natural and built amenities in the Northeast region have different impacts than in the rest of rural America.
} 
employment density (LEMPD), the initial condition of per capita income in $1980\left(\mathrm{PCl}_{80}\right)$, measures of amenities and a vector of control variables. Equation 4.2.4 forms the base equation in the model. This equation is expanded to include the interaction of natural amenity (NAMTY) with highway density and adjacency to metro areas to form a proxy for proximity of natural amenities to demand markets (NAMTYADJ) and accessibility of natural amenities (NAMTYHWD).

$$
\begin{aligned}
& L P C I=\delta_{0}+\delta_{1} L P O P D+\delta_{2} L E M P D+\delta_{3} P C I_{80}+\delta_{4} P O P D_{80}+\delta_{5} N A M T Y+\delta_{6} L A N D R E C \\
& +\delta_{7} H A M T Y+\delta_{8} W A T R E C+\delta_{9} W I N R E C+\delta_{10} M H V+\delta_{11} P C T A X+\delta_{12} E D U+\delta_{13} U N E M P R \\
& +\delta_{14} N R S D+\delta_{15} M F G+\delta_{16} S R V+\varepsilon_{y}
\end{aligned}
$$

Growth in per capita income (LPCl) is expected to be negatively influenced by growth in population density (LPOPD) and positively influenced by growth in employment density (LEMPD). The opposite effects of growth in population (-) and growth in employment $(+)$ in the per capita income equation are related to the difference between supply and demand-induced growth. Growth in population increases the labor supply and reduces the wage rate, while growth in employment increases the demand for labor and increases the wage rate. However, if the change in population is mainly due to retirees or other relatively wealthy migrants (relative to the existing population) then the prevailing wage rate may not be affected. If the retirees are wealthy enough, they might positively affect per capita income. ${ }^{7}$ The initial condition variable reflects the dynamics of income convergence or divergence in the region.

The measures of amenities used in the equation reflect the natural (physical and climatic) and recreational attributes of a county. They are Natural Resource Amenities

\footnotetext{
${ }^{7}$ Change in per capita income is a function of change in total income and population. If the change in total income is greater than the change in population, then we can have a positive effect, the opposite when it is less than it, and no effect when both are equal.
} 
(NAMTY), Historical and Cultural Amenities (HAMTY), and outdoor recreational facilities (land-based, water-based, and winter-based, i.e., LANDREC, WATREC, and WINREC, respectively). In the expanded equation, the role of proximity to demand markets and accessibility of the supply of amenities is captured by two interaction terms (NAMTYADJ and NAMTYHWD) as discussed in detail in section 4.3. According to Roback (1982 and 1988), amenities are expected to have a negative effect on per capita income because households are willing to accept lower wages in high amenity areas. However, this assumption is being challenged by Wu and Mishra (2008) and the findings of Deller et al.(2008). Wu and Mishra (2008) argue that, "because amenities attract human capital, which in turn attracts firms, locations with superior amenities tend to have a higher demand for labor and thus higher wage rates" (p.98). Deller (2008) also found a positive relationship between amenities and income. It seems that the direct effect is negative and the indirect effect is positive. If this is the case, then, the net effect of amenities on income depends on the elasticity of the direct and indirect effects.

The other control variables included in the model reflect fiscal, human capital, market structure and economic geography for the year 1980. Per capita tax (PCTAX) is included as a control variable to capture the negative effect of tax on change in per capita income. The percent of 25 years and older county population with bachelor's degree or higher $(E D U)$ is used as a proxy for human capital growth and is expected to positively affect income. The local market structure variables included in the model are the percentage earnings in natural resource dependent sector $^{8}$ (NRSD) earnings in manufacturing (MFG), and service sector (SRV). The unemployment rate (UNEMPR) is

\footnotetext{
${ }^{8}$ In this study, percentage earnings in natural resource dependent sector (NRSD) is defined as all earnings in farms, agricultural services, forestry, and fishing, and mining.
} 
included to account for the labor market condition of the area. The urban influence code $\left(\right.$ UIFC) ${ }^{9}$, developed by USDA Economic Research Service (1993) is used as a proxy for the economic geography of a county. The code classifies a county based on its population size and proximity to large urban centers. This index measures adjacency to metro areas, and takes the lowest value (one) for metro counties with at least one million people and the highest value (12) for counties that are the most isolated. This index is expected to negatively affect per capita income.

\subsubsection{Growth in Population Density Equation (LPOPD)}

Growth in per population density is measured as the percentage change of total population in county i from 1980 to 2005 . As shown in equation 4.2.5, the growth in population density equation is specified as a function of the initial population density $\left(P O P D_{80}\right)$, growth in per capita income $(L P C l)$, growth in employment density (LEMPD), initial per capita income $\left(\mathrm{PCl}_{80}\right)$, amenity measures, and their interaction terms. A number of exogenous variables that are hypothesized to affect household utility and also explain temporal changes in population growth are also included. Equation 4.2.5 forms the base equation in the model. This equation is expanded to include the interaction of natural amenity (NAMTY) with highway density and adjacency to metro areas to form a proxy for proximity of natural amenities to demand markets (NAMTYADJ) and accessibility of natural amenities (NAMTYHWD). All the variables

\footnotetext{
${ }^{9}$ The urban influence codes are: $1=$ Large-in a metro area with at least 1 million residents or more; $2=$ Small-in a metro area with fewer than 1 million residents; $3=$ adjacent to a large metro area which contains a city with at least 10,000 residents; $4=$ adjacent to a large metro area that does not have a city with at least 10,000 residents; $5=$ adjacent to a small metro area which contains a city with at least 10,000 residents; $6=$ adjacent to a small metro area that does not have a city with at least 10,000 residents; $7=$ not adjacent to a metro and contains a city with 10,000 residents; $8=$ not adjacent to a metro and contains a town with $2500-9,999$ residents; $9=$ not adjacent to a metro and does not contain a town with at least 2500 residents.
} 
take the 1980 values to avoid simultaneity and to help in isolating the direction of causation.

$$
\begin{aligned}
L P O P D= & \delta_{0}+\delta_{1} L P C I+\delta_{2} L E M P D+\delta_{3} P C I_{80}+\delta_{4} P O P D_{80}+\delta_{5} N A M T Y+\delta_{6} L A N D R E C+\delta_{7} H A M T Y \\
& +\delta_{8} W A T R E C+\delta_{9} W I N R E C+\delta_{10} M H V+\delta_{11} P C T A X+\delta_{12} D L G E X P+\delta_{13} U N E M P R+ \\
& \delta_{14} N R S D+\delta_{15} M F G+\delta_{16} U I F C+\varepsilon_{P}
\end{aligned}
$$

Growth in population density ( $L P O P D)$ is expected to be positively influenced by change in employment density (LEMPD) and change in per capita income (LPCI). The higher is the demand for labor as reflected by an increase in employment, the higher will be the number of migrants who move to take advantage of the higher job opportunity. An increase in income in an area indicates a movement towards a higher economic status. This attracts new immigrants. Following past studies (Treyz et al.. 1993 and Roback, 1983), a positive relationship is expected between growth in population density $(L P O P D)$ and growth in per capita income (LPCI). The inclusion of the initial population level $\left(P O P D_{80}\right)$ will capture the dynamics of population convergence or divergence in the region.

All the amenity variables discussed in sections 4.2.1. and 4.3. are expected to positively affect growth in population density (LPOPD) by attracting new migrants to the area and discouraging long-term residents from leaving the region. The fiscal factors included in the model are the direct general local government expenditures per capita (DGLEXP) and the per capita tax rate. A high public expenditure per capita could indicate the quantity and quality of public services provided by the local government. Higher government spending in terms of education, health services and other basic community services may encourage in-migration. But the higher public expenditure depends on the tax revenue the local government can collect. Households are assumed 
to be more attracted to counties with relatively lower levels of per capita local taxes (PCTAX). Therefore, a higher local tax rate is expected to discourage population growth.

The local market structure variables included in the model are the percentage earnings in the natural resource dependent sector (NRSD) and earnings in manufacturing (MFG). Another local characteristic that may affect population density is the median housing value (MHV). Though it is difficult a priori to conclude on the relationship between housing value and population growth, it may be argued that lower housing prices may encourage population growth (though higher population growth may increase the demand for housing and increase the price as well). The unemployment rate (UNEMPR) is included to account for the labor market condition of the area. A higher unemployment rate may reflect a lack of employment opportunities or a depressed local economy. The urban influence code is included to account for the role played by agglomeration and isolation on change in population. Areas that are close to large urban centers are more likely to have greater population increases than those that are more remote. Since this index takes the lowest value (one) for metro counties with at least one million people and the highest value (12) for counties that are the most isolated. It is expected to have a negative effect on growth in population density.

\subsubsection{Growth in Employment Density Equation (LEMP)}

Growth in employment density is measured as the percentage change of total employment in county i from 1980 to 2005 . Equation 4.2 .6 describes the specification of growth in employment density (LEMPD) equation. It is a function of the growth in per capita income (LPCI), growth in population density (LPOPD), the initial employment density $\left(E M P D_{80}\right)$, initial per capita income $\left(P C l_{80}\right)$, and amenity measures $\left(A_{i}\right)$ as 
shown in equation 4.2.6. Growth in employment (LEMP) is expected to be positively influenced by growth in population (LPOPD) and per capita income (LPCI). As population and income increases, there is more demand for goods and services which translates into more demand for labor by firms. The initial level of employment density will capture the divergence and convergence in employment density in the region. The initial level of per capita income $\left(\mathrm{PCl}_{80}\right)$ will serve as a proxy to the relative initial strength of the economy.

The same amenity variables discussed in Sections 4.2.1. and 4.2.2 are included in this equation (4.2.6). Power (1996) argues that some firms may view the attractiveness of the region as a place to work and do business. In addition, these areas may attract or have high quality labor forces which are willing to work in the region for lower wages. Thus, the amenity variables are expected to have a positive effect on change in employment density by attracting new firms to the area and increasing the demand for labor.

$$
\begin{aligned}
L E M P D & =\delta_{0}+\delta_{1} L P C I+\delta_{2} L P O P D+\delta_{3} P C I_{80}+\delta_{4} E M P D_{80}+\delta_{5} N A M T Y+\delta_{6} L A N D R E C+\delta_{7} H A M T Y \\
& +\delta_{8} W A T R E C+\delta_{9} W I N R E C+\delta_{10} E D U+\delta_{11} P C P T A X+\delta_{12} D L G E X P+\delta_{13} C R E A T I V E+\delta_{14} N R S D \\
& +\delta_{15} M F G+\delta_{16} S R V+\delta_{17} U I F C+\varepsilon_{P}
\end{aligned}
$$

In addition, a number of exogenous variables are also included to determine growth in employment density (LEMPD). Direct local government expenditures (DLGEXP) are included to capture the role of public local services in attracting business to the region. Per capita property tax (PCPTAX) is included to account for business costs imposed by local governments. Taxes reduce business profits and adversely affect the ability of firms to demand for more labor. Since firms may be attracted to a 
region with a relatively higher-quality labor force, the percent of the population with bachelor's degree or higher (EDU) is included to measure this effect. The percentage of workers considered as part of the creative class (CREATIVE) is included to account for the creativeness of an area in generating new ideas and jobs. The market structure variables included in the model are the percentage of earnings in the natural resource dependent sector (NRSD), the percentage of earnings in manufacturing (MFG), and percentage earnings in services (SRV). The urban influence code is also included to account for the role of agglomeration and isolation in growth in employment density (LEMPD). Areas that are close to large urban centers are more likely to have greater demands for goods and services, high quality of public infrastructure, and low cost of information (due to formal and informal networks) compared to those that are more remote. This condition creates a conducive environment for the growth of firms. Since this index takes the lowest value (one) for metro counties with at least one million people and the highest value (12) for counties that are the most isolated, it is expected to have a negative effect on change in employment density (LEMPD).

\subsection{Spatial Model}

In the amenity and regional growth literature, the role of spillover effects is recognized in very few studies. The spatial model developed below is different from Deller et al. (2005) and Nzaku and Bukenya (2005). Both studies extended the Deller et

al. (2001) model by incorporating a spatial component to capture the role of spatial interdependence among the variables. Nzaku and Bukenya (2005) included a spatial lag of the dependent variable in each equation. Deller et al. (2005) estimated a spatial error model to account for the spatial interdependence in the error terms. These 
extensions moved the empirical models of amenities and regional growth models one step forward but the estimation of these empirical models of both studies didn't account for the spatial distribution of amenities. The empirical model developed in this study will account for the spatial dependency and mismatch of amenities by adapting the spatial Durbin method.

Each of the three equations in the model are specified as a function of endogenous dependent variables (LPOPD,LEMPD, and LPCI), Amenities (A), other exogenous variables $(X)$, and spatially weighted dependent variables(WLPOPD, WLEMPD, and WLPCI), amenities (WA), and independent variables (WX). The amenity (A) and exogenous variables $(x)$ in each equation in the spatial Durbin model are the same as the variables in the equations $(4.2 .4-4.2 .6)$ of the nonspaitial model.

$$
\begin{aligned}
& L P O P D=\rho^{*} W L P O P D+\beta_{1 P}(I+W) L E M P+\beta_{2 P}(I+W) L P C I+\gamma_{1 P}(I+W) P O P D_{80} \\
& +\prod_{I P}(I+W) A+\sum \delta_{I P}(I+W) \Omega^{P}+u_{P} \\
& L E M P D=\rho^{*} W L E M P D+\beta_{1 E}(I+W) L P O P D+\beta_{2 E}(I+W) L P C I Y+\gamma_{2 E}(I+W) E M P D_{80} \\
& +\Pi_{I E}(I+W) A+\sum \delta_{I E}(I+W) \Omega^{E}+u_{E} \\
& \text { (4.3.3) } \quad L P C I=\rho^{*} W P C I+\beta_{1 Y}(I+W) L P O P D+\beta_{2 Y}(I+W) L E M P D+\gamma_{3 Y}(I+W) P C I Y_{80} \\
& +\Pi_{I Y}(I+W) A+\sum \delta_{I Y}(I+W) \Omega^{Y}+u_{Y}
\end{aligned}
$$

$\rho$ (rho) is a measure of strength of the spatial dependence and is the coefficient of the spatial lag of the dependent variable in each of the equations. W is $299 \times 299(n \times n)$ row-standardized weight matrix constructed from the nearest neighbors (the number of the nearest neighbors differs from study to study). I is an identity. The residuals of the growth in population, employment, and per capita income equations are $u_{P}, u_{E}$, and $u_{Y}$, respectively. The remaining notations are the same as defined in the non-spatial model. 
Each variable in the model is multiplied by $(I+W)$ to reflect the own county values and the average of the surrounding counties. For example, in the population equation, $(I+W)$ LEMPD represents county $\mathrm{i}$ employment growth (LEMPD) and the weighted average of the nearest neighbors (WLEMPD). Note that because each dependent variable depends on its value in neighboring counties, WLEMPD, WLPOPD, WLPCI, are endogenous to $\angle P O P D, \angle E M P D$, and $L P C I$, respectively. That is, the growth in population density, employment density, and per capita income in county $i$ depend on the contemporaneous levels of these variables in surrounding counties. This condition creates an additional endogeniety problem that needs to be solved before estimating the parameters in the model. For this reason, the study follows the traditional approach of instrumenting the dependent variables. First, a reduced form will be estimated to generate the fitted values of the dependent variables. This estimated dependent variables are then included as any other independent variable in estimating the spatial Durbin method.

The estimation and interpretation of the coefficient in spatial Durbin method is not straight forward. According to Kirby and LeSage (2009), in the spatial Durbin method, changes in the independent variable $x_{i}$ leads to a direct impact (effect) on a county's marginal regional economic growth as well as a spatial spillover (indirect) impact on neighboring counties marginal regional economic growth. Thus, the spatial derivative of this direct and indirect effect takes the form of $n$ by $n$ matrix. Assuming $Y_{i}$ as a measure of regional growth, the partial derivative takes the form of

$$
\frac{\partial Y_{i}}{\partial x_{i}}=\left(I_{n}-\hat{p} W\right)^{-1}\left(I_{n} \hat{\alpha}_{1 i}+W \hat{\alpha}_{2 i}\right)
$$

Where $\hat{\alpha}_{1 i}$ and $\hat{\alpha}_{2 i}$ are the coefficient estimates associated with the independent 
variable $x_{i}$ and $W x_{i}$ respectively. The coefficient $\hat{p}$ measures the strength of the spatial dependence. LeSage and Pace (2009) developed a scalar summary measure for the $n$ by $\mathrm{n}$ partial derivative of direct and indirect effects arising from the change in the independent variable. This study will follow their approach and present the direct, indirect, and total effects alongside the estimated coefficients of the model in chapter 5. Beyond this general description of the relationship of the variables, the expected sign of the relationship of the variables remains the same as in the nonspatial model.

\subsection{Types and Sources of Data}

In order to estimate the empirical model, relevant data, including the endogenous variables, initial conditions of the endogenous variables, amenities and their interaction, and local county characteristics (fiscal, human capital, market structure, and economic geography) are collected for the 2,256 counties of the U.S. However, the focus of the study is the Northeast region which has 299 counties of which 148 are non-metro counties.

The data used in the study reflects the 1980-2005 period. All the dependent variables are expressed as growth rates of the period 1980-2005. All the independent variables take the 1980 values to avoid simultaneity and to help in isolating the direction of causation. With the exception of the amenity variables, the rest of the variables are expressed as location quotients or the ratio of the local value to the national mean. This transformation ensures that each observation is pegged to the US economic system as a whole (Carruthers, Hollar, Mulligan, (2006). The result is unit free and enables direct comparison of growth in population density, employment density, and per capita income at equilibrium. The secondary data used in the study are drawn from several sources. 
This section presents the types and sources of data, definition of the variables, and summary statistics.

The study constructs and uses growth in population density (LPOPD), employment density (LEMPD), and per capita income (LPCI), from 1980 to 2005 as endogenous variables. The initial condition variables reflect the beginning for period value of population density, employment density, and per capita income. These variables are collected from Regional Information Services (REIS) and the Census Bureau (see table 4.4.1).

Table 4.4.1. Definition and Data Sources for the Endogenous and Initial Condition Variables

\begin{tabular}{|c|c|c|}
\hline Variable Name & Variable Definitions & Data Source \\
\hline \multicolumn{3}{|c|}{ Endogenous variables } \\
\hline LPOPD & Growth in population density from 1980 to 2005 & REIS and U.S. Census /Computed \\
\hline LEMDP & Growth in employment density from 1980 to 2005 & REIS and U.S. Census / Computed \\
\hline $\mathrm{LPCl}$ & Growth in per capita income from 1980 to 2005 & REIS and U.S. Census / Computed \\
\hline \multicolumn{3}{|c|}{ Initial Condition Variables } \\
\hline POPD80 & Population density 1980 & REIS and U.S. Census \\
\hline EMPD80 & Employment density 1980 & REIS and U.S. Census \\
\hline $\mathrm{PCl} 80$ & Per capita income 1980 & REIS \\
\hline
\end{tabular}

As shown in table 4.4.2. six amenity indices are constructed from the USDA Forest service database of National Outdoor Recreation Supply Information System $(\text { NORSIS, 1997 })^{10}$. This study uses principal component analysis (PCA) to condense a set of related amenity attributes into a smaller set of amenity scores. This approach

\footnotetext{
${ }^{10}$ The amenity measure data is drawn from the NORSIS (National Outdoor Recreation Statistical Information System) compiled by the USDA Forest Service, which contains a wide range of data on outdoor recreational facilities, natural resources and cultural/historical attractions, among other variables. As an outflow of the 1998 Resource Planning Act, the Forest Service maintains an extensive county-level data set documenting facilities and resources that support outdoor recreation activities. The NORSIS data set contains over three hundred separate variables ranging from population density, the proportion of county acres in each cropland, forest, pasture/range-land, mountains and water surface, employment and income levels in recreational industries, to the number of public libraries.
} 
allows measuring and evaluating multiple natural amenities into distinct groupings. Following the National Outdoor Recreation Supply Information System (NORSIS, 1997), Goe and Green (2002), and Deller (2001, 2005, 2007), the groupings included in this study are Natural Resource Amenities, Historical and cultural amenitiesHistorical and Cultural Amenities, and built-in outdoor recreational facilities (land-based, water-based, and winter-based). More than 35 county level attributes are used to construct these six amenity indices. Even though, the

Table 4.4.2. Definition and Data Sources for Natural Amenities and Outdoor Recreational Facilities

\begin{tabular}{|l|l|l|}
\hline Variable & Definition & Data Source \\
\hline CLIMATE & Climate Index & NORSIS 1997/Computed \\
\hline NAMIX & Natural Resource Amenity Index & NORSIS 1997/ Computed \\
\hline LANDREC & Land-based outdoor recreational facilities Index & NORSIS 1997/ Computed \\
\hline WATREC & Water-based outdoor recreational facilities Index & NORSIS 1997/ Computed \\
\hline WINREC & Winter-based outdoor recreational facilities Index & NORSIS 1997/ Computed \\
\hline HAMTY & Historical and cultural Amenity Index & NORSIS 1997/ Computed \\
\hline NAMTYADJ & Adjacent to metro times natural amenity Index & Computed \\
\hline NAMTYHWD & Highway density times natural amenity Index & Computed \\
\hline
\end{tabular}

standard convention in principal component analysis is to retain components with eigenvalues greater than one, the study retains only the first component. This is done to increase the degree of freedom in the estimation process. In most cases, the first component is the best summary of the entire data set and accounts for most of the variance. Tables 4.4.3-4.4.8 show the eigenvector loadings of the first component of each of the amenity indices. Furthermore, GIS maps that show the spatial distribution of each of the amenity indices in the Northeast region are included in Appendix 1.

The climate index is constructed from 5 climatic variables (Table 4.4.3). The first component explains $48.7 \%$ of the variability of the data. With the exception of average 
January sunshine, all of the rest make a significant contribution in the final index. As shown in Figure 4.1 (Appendix 1), the spatial distribution of the climate index is not uniform. Counties in the South and Southeastern part of the region scored high while counties found in the heavy snow and cold area in the Northern New England scored low. In the study area, the five counties with the highest score are found in Maryland (Somerset, St. Mary's, Wicomico, Talbot, and Dorchester).

Table 4.4.3. Climate Index

\begin{tabular}{|l|l|}
\hline Variable Name & Eigenvector \\
\hline Average January Temperature & 0.545 \\
\hline Average Precipitation & 0.529 \\
\hline Average July Temperature & 0.476 \\
\hline Average Humidity & 0.432 \\
\hline Average January Sunshine & 0.099 \\
\hline Total Variability explained & $\mathbf{4 8 . 7 0 \%}$ \\
\hline
\end{tabular}

The natural resource (landscape) amenity index (NAMIX) is constructed from 10 local physical attributes (Table 4.4.4). The first component explains $35.76 \%$ of the variability of the data. The major contributors for the final index are AWA total white water river miles, NRI total river miles (outstanding value), Bailey acres of mountains, NRI forest of acres, and USDA-FS forest and grassland acres. Attributes such as availability of coastal area, and FWS refuge acres open for recreation do not contribute to the final natural amenity index. As shown in Figure 4.2 (in the appendix), the spatial distribution of the natural resource amenity index is not uniform. Counties in the Northern part of the New England states and counties in Eastern and Southeastern part of West Virginia scored high in the index. Overall, counties in Maine, Aroostook, Piscataquis, Somerset, Washington, and Penobscot scored the highest in the index. 
Table 4.4.4. Natural Resource Amenity Index

\begin{tabular}{|l|l|}
\hline Variable Name & Eigenvector \\
\hline AWA total whitewater river miles & 0.417 \\
\hline BLY acres of mountains & 0.414 \\
\hline USDA-FS forest and grass land acres & 0.403 \\
\hline NRI total river miles outstanding value & 0.383 \\
\hline NRI forest acres & 0.339 \\
\hline Wild and scenic river miles & 0.308 \\
\hline Birch: acres of private forest land & 0.307 \\
\hline Coast & 0.020 \\
\hline FWS refuge acres open for recreation & 0.005 \\
\hline Total Variability explained & $\mathbf{3 5 . 7 6 \%}$ \\
\hline
\end{tabular}

The natural resource amenity index and the climate index reflect the natural amenities found in a county. Both of these measures are summed and the average is taken to form the natural amenity index (NAMTY). This measure contains majority of the attributes used by McGranahan (1999) to develop the natural amenity scale ${ }^{11}$. The difference is the natural amenity scale is sum of the six standardized attributes that form the scale while NAMTY is formed as an average of two indices that are formed by principal component analysis from 15 different attributes. NAMTY represents the average natural amenity of the county.

The outdoor recreational indices are constructed from 23 different attributes grouped into four categories: water-based outdoor recreation, winter-based outdoor recreation, land-based outdoor recreation, and historical and cultural amenities. As shown in Table 4.4.5, the land-based recreational amenity index is developed from 7 man-made recreational attributes. The major contributors to the final index are tennis

\footnotetext{
${ }^{11}$ The natural amenity scale is developed from four measures of climate (average January temperature, average January sunshine, average July temperature, and average humidity), topographic variation, and water attributes. All these attributes are first standardized to a mean of zero and standard deviation of 1 . Then they are added together to form the amenity scale. All the variables are given equal weight.
} 
courts, parks and recreational departments, golf courses, and playgrounds and recreational centers. The final index explains $56.4 \%$ of the variability in the data. As shown in Figure 4.3 in the Appendix, Westchester, Suffolk, and Nassau counties in the state of New York, Middlesex in Massachusetts, and Montgomery in Pennsylvania scored high in the index.

Table 4.4.5. Land-based Recreational Amenity Index

\begin{tabular}{|l|l|}
\hline Variable Name & Eigenvector \\
\hline$A B I$ number of private and public tennis courts & 0.444 \\
\hline$A B I$ number of parks and recreation departments & 0.438 \\
\hline$A B I$ number of private and public golf courses & 0.421 \\
\hline$A B I$ number of playgrounds and recreational centers & 0.409 \\
\hline$A B I$ number of organized camps & 0.394 \\
\hline$A B I$ number of private and public swimming pools & 0.317 \\
\hline ABI number of hunting, fishing preserves, lodges, and clubs & 0.103 \\
\hline Total Variability explained & $\mathbf{5 6 . 4 0 \%}$ \\
\hline
\end{tabular}

Table 4.4.6 shows the four attributes that form the water-based recreational amenity index. The first component of the water-based outdoor recreational amenity index explains $31.04 \%$ of the variability of the data. The major contributors for the final index are attributes related to fishing and marinas. Counties like Ocean in New Jersey, Suffolk in New York, and Anne Arundel in Maryland scored the highest in this index. The spatial distribution of water-based recreational amenities is shown in Figure 4.4 in the Appendix .

Table 4.4.6. Water-based Recreational Amenity Index

\begin{tabular}{|l|l|}
\hline Variable Name & Eigenvector \\
\hline$A B I$ number of fish camps, private and public fish lakes, piers and ponds & 0.663 \\
\hline$A B I$ number of marinas & 0.640 \\
\hline$A B I$ number of canoe outfitters, rental firms, raft trip firms & 0.316 \\
\hline$A B I$ number of diving instructors, tours, and snorkel outfitters & 0.224 \\
\hline Total Variability explained & $31.04 \%$ \\
\hline
\end{tabular}


The historical and cultural is constructed from 6 different specific historical, cultural, and other specific attractions (Table 4.4.7). They include museums, battlefields, zoos, aquarium, amusement places, arts and festivals. This attributes enhance the quality of life a particular area by making it a unique and interesting place to live. The first component of historical and cultural amenity explains $56.2 \%$ of the variability in the data. With the exception of historical places and government and civic attractions the rest of the attributes have more or less equal weight in the construction of the final index. Figure 4.5 in the Appendix shows the spatial distribution of historical and cultural amenity index.

Table 4.4.7. Historical and Cultural Amenity Index

\begin{tabular}{|l|l|}
\hline Variable Name & Eigenvector \\
\hline Historical/ Cultural/Arts/ Festivals & 0.443 \\
\hline Other unclassified attractions & 0.431 \\
\hline Natural resource based attractions (zoos, aquarium) & 0.415 \\
\hline Museums & 0.413 \\
\hline Amusement/Entertainment/Sports & 0.392 \\
\hline Government/Civic/Monuments/Memorials & 0.287 \\
\hline Historical places (ABI) & 0.197 \\
\hline Total Variability explained & $56.20 \%$ \\
\hline
\end{tabular}

The retained first component of the winter-based outdoor recreational amenity index captures $40.83 \%$ of the variability in the data. As shown in Table 4.4.7, it is constructed from six winter related recreational facilities. The two major contributors to the final index are the $A B I$ number of skiing centers and resorts and Cross country ski firms and public ski centers. Almost all counties in West Virginia and many counties in Maryland scored low in this index (Appendix Figure 4.6). Berkshire in Maryland, Worcester county in Massachusetts, Grafton and Carroll counties in New Hampshire, 
and Rutland and Windham counties in Vermont are the leaders in the region in this index.

Table 4.4.8. Winter-based Recreational Amenity Index

\begin{tabular}{|l|l|}
\hline Variable Name & Eigenvector \\
\hline ABI number of skiing centers and resorts & 0.512 \\
\hline Cross country ski firms and public ski centers & 0.501 \\
\hline ISS skiable acreage & 0.403 \\
\hline RTC rail-trail miles for $x$-c skiing & 0.336 \\
\hline RTC rail-trail miles for snowmobiling & 0.325 \\
\hline State park number with snowmobiling available & 0.293 \\
\hline Total Variability explained & $\mathbf{4 0 . 8 6 \%}$ \\
\hline
\end{tabular}

All the amenity attributes described above are expected to have positive impacts on growth in employment density (LEMPD) and population density (LPOPD) by either attracting business or people to the region. The effect on change in per capita income (LEMPD) is expected to be negative reflecting the willingness to substitute high amenity for lower wages.

One of the major objectives of the study is to assess the role of proximity and accessibility in the process of amenity-led development. To accomplish this objective, measures that will assess the combined effect of amenities and these two factors must be developed. The natural amenity index (NAMTY) developed above is selected to represent the total natural amenity. This natural amenity index reflects the physical and climatic attributes amenities that are available in the locality. The availability of highway density in a county is used as a proxy for accessibility. An interaction of natural amenity (NAMTY) with highway density is formed to measure the relative accessibility of natural amenities (NAMTYHWD). Counties with high accessibility and high amenities are more 
likely to attract more visitors and new migrants to the area than remote areas with low accessibility.

Table 4.4.9. Definition and Data Sources for Fiscal, Human Capital, Market Structure, and Economic Geography

\begin{tabular}{|l|l|l|}
\hline Variable & Definition & Data Source \\
\hline DGLEXP & Per capita direct local government expenditure, 1982 & CENSUS \\
\hline PCTAX & Per capita tax, 1982 & $\begin{array}{l}\text { CENSUS \& REIS/ } \\
\text { computed }\end{array}$ \\
\hline PCPTAX & Property tax per capita, 1982 & CENSUS \\
\hline NRSD & percentage of earnings in natural resource sector, 1980 & REIS/ computed \\
\hline MFG & percentage of earnings in manufacturing, 1980 & REIS/ computed \\
\hline SRV & percentage of employment in finance services, 1980 & REIS/ computed \\
\hline UNEMPR & percentage of employment whole and retail trade, 1980 & REIS/ computed \\
\hline CREATIVE & Percentage of the creative work force, 1990 & \\
\hline EDU & $\begin{array}{l}\text { Persons over 25 years and over, } \% \text { of college degree or } \\
\text { above 1980 }\end{array}$ & C \& CDB \\
\hline MHV & Median value of owner occupied housing, 1980 & C \& CDB \\
\hline UIFC & Urban influence code 1993 scale 1 to 9 & USDA (ERS) \\
\hline
\end{tabular}

County adjacency to large and small metro areas is used to measure proximity to high population centers. The demand for amenities is as important as the supply of amenities. An interaction term of natural amenities with adjacency to metro areas is formed to measure the relative of proximity of natural amenities to demand markets (NAMTYADJ). The outcome of amenity led-development in two regions with more or less the same level of amenities could be different because of their proximity to the demand market. The closer to large population centers the higher will be the demand for the amenities.

The rest of exogenous variables are county characteristics that describe fiscal (taxes and local government expenditures), human capital, market structure, and economic geography (level of urbanization) for 1980 as shown in Table 4.4.9. All these 
variables are collected from Bureau of Economic Analysis (BEA-REIS), City and County Data Book (C \& CDB), the Census Bureau, and the Economic Research Services (ERS) of USDA. The data reflect the year 1980 and are at the county level. The summary descriptive statistics of the variables in the two models are presented in Table 4.4.10.

Table 4.4.10 Summary Descriptive Statistics

\begin{tabular}{|l|r|r|r|r|r|}
\hline \multicolumn{1}{|c|}{ Variable } & Mean & Median & Maximum & \multicolumn{1}{c|}{ Minimum } & \multicolumn{1}{c|}{ Std. Dev. } \\
\hline LEMPD & 0.782 & 0.698 & 3.353 & -2.248 & 0.639 \\
\hline LPOPD & 0.409 & 0.315 & 4.197 & -2.784 & 0.844 \\
\hline LPCI & 1.007 & 1.010 & 1.240 & 0.682 & 0.098 \\
\hline EMPD80 & 8.354 & 1.583 & 325.164 & 0.033 & 29.469 \\
\hline PCI80 & 0.887 & 0.861 & 1.542 & 0.508 & 0.185 \\
\hline POPD80 & 8.992 & 1.776 & 495.356 & 0.045 & 35.550 \\
\hline NAMTY & 0.259 & 0.056 & 8.884 & -0.715 & 0.875 \\
\hline HAMTY & -0.065 & -0.360 & 10.132 & -0.489 & 0.912 \\
\hline LANDREC & 1.181 & 0.217 & 15.664 & -0.899 & 2.635 \\
\hline WATREC & 0.271 & -0.219 & 11.961 & -0.421 & 1.456 \\
\hline WINREC & 1.236 & 0.409 & 13.589 & -0.506 & 2.429 \\
\hline NAMTYADJ & 0.104 & 0.000 & 4.862 & -0.715 & 0.460 \\
\hline NAMTYHWD & 69.833 & 43.082 & 2095.672 & -1652.800 & 408.444 \\
\hline DLGEXP & 0.864 & 0.768 & 2.044 & 0.436 & 0.304 \\
\hline PCTAX & 0.922 & 0.891 & 3.671 & 0.156 & 0.479 \\
\hline PCPTAX & 1.028 & 1.015 & 4.405 & 0.196 & 0.594 \\
\hline NRSD & 1.740 & 0.651 & 20.511 & -1.157 & 3.079 \\
\hline MFG & 1.130 & 1.113 & 3.222 & 0.015 & 0.586 \\
\hline SRV & 0.861 & 0.837 & 2.268 & 0.000 & 0.343 \\
\hline UNEMPR & 1.201 & 1.169 & 2.938 & 0.292 & 0.394 \\
\hline CREATIVE & 0.176 & 0.168 & 0.397 & 0.071 & 0.059 \\
\hline EDU & 0.835 & 0.735 & 2.642 & 0.272 & 0.367 \\
\hline MHV & 0.870 & 0.803 & 2.059 & 0.336 & 0.276 \\
\hline UIFC93 & 4.058 & 3.000 & 9.000 & 1.000 & 2.738 \\
\hline
\end{tabular}




\section{CHAPTER 5: EMPIRICAL RESULTS AND ANALYSIS}

\subsection{Introduction}

The main focus of this chapter is to empirically estimate the relationship between natural and built amenities and regional economic growth. Growth in population density, employment density, and per capita income will be used as indicators of regional economic growth. Amenity indices representing natural amenities (climate and natural physical attributes), historical and cultural amenities, land, water, and winter based recreational amenities will be used as measures of local amenities.

This chapter consists of two major sections and four subsections within each section. Section one presents the results of the nonspatial model and section two discusses the estimated results of the spatial Durbin model. At the end of each section, a summary of major findings is presented.

\subsection{Findings and Analysis of Non-Spatial Regional Growth Model}

The nonspatial model (equations 4.26 through 4.30 ) estimates the relationship between the endogenous variables of growth in population density, employment density, and per capita income, with five amenity indices and a set of exogenous variables specific to each equation. In estimating the effects of amenities in the process of economic growth in the northeast region, the study follows a variety of Deller and Lledo (2007) slope shifters approach. A set of amenity slope shifters are introduced which allow each of the amenity variable coefficients to differ for the northeast region. This allows us to see whether amenities in the rural northeast behave in different ways than for the rest of rural America. When examining the slope coefficients we are looking 
for the overall statistical significances, signs, and magnitude of the coefficients. If the slope shifter coefficient is statistically significant, then it can be concluded that rural northeast behaved differently than the rest of the country in terms of amenities. If the coefficient has the same sign as the base variable, it indicates that the effects are stronger in rural northeast than the rest of rural America. If it is of opposite sign it means the effects are weaker.

First, each equation is estimated using all amenity and exogenous variables by the ordinary least square method. Amenity slope shifters for the northeast region are included in the estimation to see if there is a difference between the national and regional impacts. The US nonmetro data set is used to exploit the degrees of freedom of a large sample size. The first column of Tables 5.2.1-5.2.3 present the results of the ordinary least squares model with slope shifters (OLS_US_NE). This specification is similar to the reduced form estimation of Deller et al. (2001), Deller and Lledo (2007), and Nazku and Bukenya( 2005). Column 2 (3SLS_US_NE 1) of each of the three tables presents the base results from the estimation of system of equations with amenity slope shifters for the region using US nonmetro data set. Three stage least squares is preferred over two stage least squares because of the high correlation of the residuals of the population and employment equations. Column 3 (3SLS_US_NE 2) presents the tests for the role of proximity of natural amenities (NAMTYADJ) to the demand market and accessibility of the supply of natural amenities (NAMTYHWD). Finally, column four (3SLS_NE) presents estimation results using data for the nonmetro northeast region.

\subsubsection{Growth of Population Density (LPOPD)}

Table 5.2.1 shows the results of the population growth equation estimated using ordinary least square (OLS_US_NE) with amenity slope shifters for the northeast region 
(column 1) and three estimation results using three stage least squares. The overall fit of the estimation was good with adjusted $R^{2}$ ranging from $0.398-0.771$ which is consistent with similar studies (for example, Deller and Lledo (2007) reported $R^{2}$ ranging from $0.575-0.769$ in their reduced form estimation of amenities and population growth).

The first three rows of the table show the results of the endogenous dependent variables. As shown in the table, employment growth has a positive and significant effect on population growth in 3SLS_US_NE_1 and 3SLS_US_NE 2 and no effect in 3SLS_NE (probably due to small sample size). These results are consistent with labor demand theories of regional development. Employment growth indicates the availability of high labor demand in the area. People migrate to take advantage of the job opportunities. This result implies that people follow jobs. In all the equations, per capita income growth has no effect on population growth in the region. Thus, in this study, there is no evidence that indicates people migrate to capture higher income in the northeast region.

One of the key assumptions used in developing our model was that growth is dependent on initial conditions. In all the results, the initial level of population density was highly significant and negative. This result is consistent with past studies (Deller et al. 2001 and Hailu and Brown 2007). It implies that areas with initial high population densities are growing slower compared to areas with low initial population densities. This gives supports to the convergence of population density.

The results from the OLS_US_NE and 3SLS_US_NE 1 provide evidence of significant differences between the northeast region and the rest of the country in terms 
Table 5.2.1. Three Stage Least Square Estimation Results of Population Growth (LPOPD) and Amenities

\begin{tabular}{|c|c|c|c|c|c|c|c|c|}
\hline \multirow[b]{2}{*}{ Variable } & \multicolumn{2}{|l|}{ OLS_US } & \multicolumn{2}{|c|}{ 3SLS_US_NE 1} & \multicolumn{2}{|c|}{ 3SLS_US_NE 2} & \multicolumn{2}{|l|}{ 3SLS_NE } \\
\hline & Coef & t-stat & Coef & t-Stat & Coef & t-Stat & Coef & t-Stat \\
\hline \multicolumn{9}{|l|}{ LPOPD } \\
\hline LEMPD & & & $1.097^{* * *}$ & 19.96 & $1.092 * * *$ & 19.01 & $-0.021 * *$ & -0.04 \\
\hline $\mathrm{LPCl}$ & & & $-1.666 * * *$ & -3.39 & -0.749 & -1.44 & 2.156 & 1.15 \\
\hline POPD_80 & $-0.254 * * *$ & -7.19 & $-0.043 *$ & -1.94 & $-0.055^{* *}$ & -2.40 & $-0.226 * * *$ & -2.85 \\
\hline \multicolumn{9}{|l|}{ EMPD_80 } \\
\hline PCl_80 & $-0.708 * * *$ & -3.49 & $-1.056 * * *$ & -2.88 & -0.217 & -0.56 & & \\
\hline DLGEXP & $-0.345 * * *$ & -4.83 & $-0.11 * *$ & -2.46 & $-0.079 *$ & -1.79 & -0.144 & -0.50 \\
\hline PCTAX & $-0.147 * *$ & -2.45 & 0.002 & 0.07 & -0.057 & -1.63 & 0.107 & 0.57 \\
\hline \multicolumn{9}{|l|}{ PCPTAX } \\
\hline NRSD & $0.009 * * *$ & 3.02 & -0.0001 & -0.06 & 0.002 & 1.07 & $-0.047^{*}$ & -1.76 \\
\hline MFG & -0.003 & -0.08 & $0.117^{* * *}$ & 5.78 & $0.119 * * *$ & 5.70 & -0.120 & -0.93 \\
\hline \multicolumn{9}{|l|}{ SERV } \\
\hline UNEMPR & $0.091 * *$ & 2.28 & $-0.097 * * *$ & -3.24 & -0.026 & -0.76 & $-0.386 * *$ & -2.51 \\
\hline \multicolumn{9}{|l|}{ CREATIVE } \\
\hline \multicolumn{9}{|l|}{ EDU } \\
\hline MHV & $1.887 * * *$ & 8.65 & $0.767 * * *$ & 6.61 & $0.632 * * *$ & 5.46 & $1.243 * *$ & 2.02 \\
\hline UIFC & $-0.137 * * *$ & -10.36 & $-0.056 * * *$ & -6.73 & $-0.056 * * *$ & -6.50 & -0.034 & -0.99 \\
\hline WINREC & 0.038 & 1.54 & -0.001 & -0.05 & $-0.018 *$ & -1.80 & -0.022 & -1.13 \\
\hline LANDREC & $0.229 * * *$ & 3.12 & 0.026 & 0.71 & 0.023 & 0.71 & 0.114 & 1.52 \\
\hline WATREC & $0.238 * * *$ & 6.54 & $0.059 * * *$ & 2.96 & $0.057^{* * *}$ & 2.78 & $0.223^{* *}$ & 2.04 \\
\hline HAMTY & $-0.068 * * *$ & -4.22 & $-0.019 * *$ & -2.05 & $-0.020 * *$ & -2.11 & $0.33^{* * *}$ & 2.87 \\
\hline NAMTY & $0.190 * * *$ & 5.20 & $0.120 * * *$ & 7.69 & -0.033 & -1.34 & $-0.097^{*}$ & -1.65 \\
\hline NEWINREC & -0.031 & -1.03 & -0.007 & -0.39 & & & & \\
\hline NELANDREC & -0.013 & -0.14 & 0.098 & 1.49 & & & & \\
\hline NEWHAMTY & $0.467^{* * *}$ & 5.60 & $0.191 * *$ & 2.54 & & & & \\
\hline NENAMTY & $-0.339 * * *$ & -6.33 & $-0.174 * * *$ & -4.10 & & & & \\
\hline NEWATREC & $0.223 * *$ & 2.15 & 0.109 & 1.32 & & & & \\
\hline NAMTYADJ & & & & & -0.003 & -0.10 & & \\
\hline NAMTYHWD & & & & & $0.0005^{* * *}$ & 6.82 & & \\
\hline Constant & $1.11 * * *$ & 4.98 & $2.06 * * *$ & 2.91 & 0.528 & 0.70 & -1.333 & -0.76 \\
\hline$N$ & \multicolumn{2}{|l|}{2256} & \multicolumn{2}{|l|}{2256} & \multicolumn{2}{|l|}{2256} & \multicolumn{2}{|l|}{148} \\
\hline F-statistic & \multicolumn{2}{|l|}{47.44} & \multicolumn{2}{|l|}{ 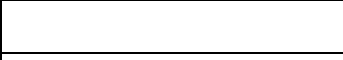 } & \multicolumn{2}{|l|}{ 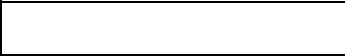 } & \multicolumn{2}{|l|}{\begin{tabular}{|l|l} 
\\
\end{tabular}} \\
\hline Adjusted R2 & \multicolumn{2}{|l|}{0.398} & \multicolumn{2}{|l|}{0.771} & \multicolumn{2}{|l|}{0.766} & \multicolumn{2}{|l|}{0.579} \\
\hline
\end{tabular}


of the role of amenities. The results of the reduced form show that with the exception of winter based recreational amenities (WINREC), all the base amenity variables are statistically significant. The coefficients of natural amenities (NAMTY), land based

recreational amenities (LANDREC), and water based recreational amenities (WATREC) are positive and significant while historical and cultural amenities (HAMTY) is negative.

Looking at the amenity slope shifters, only three were significant. NAMTY was negative and significant while HAMTY and WATREC were positive and significant. LANDREC which has a strong and positive effect in the rest of the country does not play any role in the region. The positive coefficient of WATREC indicates that the effect of this amenity is stronger in the northeast than in the rural America. The coefficient of HAMTY which is negative and weak in the base is positive and strong for the region. The direct opposite of this coefficient is the coefficient of NAMTY. It is positive and strong for the country but negative for the region. This is not a surprising finding. Even though, the Northeast region has its own natural qualities, the climate condition (snow and cold) is not as good as the southern part of the country. Furthermore, most of the non-metro parts of the region are found in the Appalachian mountains of West Virginia and Pennsylvania. This lack of natural appeal could be one of the reasons for the negative relationship.

The relatively strong and positive coefficient of HAMTY indicates that those counties in the region with historical and cultural sites, zoos, museums, amusement, sports, and other entertainment places, can greatly enhance the quality of life of the area which can draw new migrants and visitors. The same is true for counties with 
greater number of WATREC that can supply local residents and tourists with a variety of water based entertainments. These results indicate that conclusions based on generalization of national level analysis could be misleading. Different regions have different natural and built amenities which could have region specific effects. Generally, amenity indicators were hypothesized to play a positive role in population growth. But as discussed above some of the measures are negative.

The results from 3SLS_US_NE 2 in Table 5.2.1 presents the test result of the role of proximity to the amenity demand market and accessibility to supply of amenity in the population and amenity relationship. The two coefficients of interest are the interaction terms AMTYADJ and AMTYHWD. AMTYADJ is the interaction of NAMTY with adjacency ${ }^{12}$ to metro area which is used as proxy to measure the effect of proximity to the amenity demand market. AMTYHWD is the interaction of NAMTY with highway density which is used as proxy to show the relative accessibility of the supply of amenities. NAMTYHWD is positive and significant indicating accessibility to the supply of amenities matters. Counties which complement their natural appeal by investing in infrastructure could have a comparative advantage over others with similar natural appeals. This supports the hypothesis that places with higher accessibility and higher natural amenities attract in-migrants which boost the population. But the small magnitude of the coefficient of NAMTYHWD implies that a huge investment in infrastructure is needed to get the feasible effect. The coefficient of NAMTYADY is not significant indicating proximity to large population centers does not play a significant role.

\footnotetext{
${ }^{12}$ Adjacency to metro area is defined based on urban influence code of 1993 developed by the USDA. Urban influence codes 3, 4, 5, 6 are defined as counties adjacent to big and small metro areas.
} 
3SLS_NE presents the region specific 3SLS estimation results for the effects of amenities. Caution is needed in analyzing these results. The sample size is relatively small as the northeast has only 148 nonmetro counties. The estimation can suffer from small sample size. But, nevertheless the results are consistent with the estimation using slope shifters. WINREC and LANDREC do not play any role. NAMTY, as in the slope shifters, is negative and significant. HAMTY and WATREC are positive and significant.

From all these findings, it is clear that natural amenities, historical and cultural amenities, and water based recreational facilities play a role in shaping the population growth of the northeast region. But in interpreting these results an understanding of how these variables are constructed is required. For example, WATREC is positive and significant. This implies, holding everything equal, rural regions that have access to a variety of water based recreation resources also have higher level of population growth. This does not mean that all water based recreational facilities have equal impacts. In the construction of WATREC, places that have marinas and fishing related activities are weighted higher than the others and have a greater impact.

Several control variables which potentially affect population growth are included in all the estimation processes. Three out of 7 variables are significant and have the expected signs for the northeast region. Unemployment rate and earnings in natural resource dependent industries are negative while the median value of owner occupied housing is positive. But at the national level, with the exception of natural resource dependency variable, all are significant. The most important is the role of economic geography (UIFC). This measure of agglomeration and remoteness is significant and negative consistent with regional development theories. Both, lack of agglomeration and 
remoteness greatly reduce the attractiveness of place as destination for in-migrants but encourage out-migration of population. This suggests that even if amenities in two places are the same, people prefer places that are less remote. One unexpected result is the negative coefficient of the direct local government expenditure (DLGEXP). The effects of public expenditure depends on the type and magnitude of that expenditure. Public investments in education, health care, highways, and crime prevention are more likely to enhance quality of life as opposed to expenditures directed to welfare payments. Given that many of the rural counties of the northeast are found in Appalachia and depend on federal assistance programs, the negative relationship is not surprising. The coefficient of UNEMPR shows negative sign and is also statistically significant in the region specific estimation. This implies counties with higher unemployment rates also have lower population growth rates. However, at the national level, UNEMPR is positively associated with population growth.

\subsubsection{Employment Growth Equation (LEMPD)}

Similar to the population equation, the estimated employment growth equation explained in the range of $32 \%-75.7 \%$ of the variations (Table 5.2 .2 column $1-4$ ) in the dependent variable. As shown in the table, in national and region specific estimation, population growth has a positive and significant effect on employment growth. This result implies that jobs follow people. High population growth is one measure of the supply of labor. For any given demand for labor, if the supply of labor increases the wage rate falls. Firms will demand more of this cheap labor. Per capita income has a negative effect in the national level estimation and no effect in the regional estimation. The initial level of employment density is negative and significant at the national level. This shows counties with high employment density in the 1980s have had slower 
Table 5.2.2. Three Stage Least Square Estimation Results of Employment Growth and Amenities (LEMPD)

\begin{tabular}{|c|c|c|c|c|c|c|c|c|}
\hline \multirow[b]{2}{*}{ Variable } & \multicolumn{2}{|c|}{ OLS_US_NE } & \multicolumn{2}{|c|}{ 3SLS_US_NE 1} & \multicolumn{2}{|c|}{ 3SLS_US_NE 2} & \multicolumn{2}{|l|}{ 3SLS_NE } \\
\hline & Coef & Coef & Coef & $\begin{array}{l}\mathrm{t}- \\
\text { Stat }\end{array}$ & Coef & t-Stat & Coef & $\begin{array}{l}\mathrm{t}- \\
\text { Stat }\end{array}$ \\
\hline LPOPD & & & $0.704^{* * *}$ & 14.49 & $0.679 * * *$ & 16.12 & $0.433 * * *$ & 4.09 \\
\hline \multicolumn{9}{|l|}{ LEMPD } \\
\hline LPCI & & & $-1.146 * * *$ & -2.72 & $-0.788^{*}$ & -1.89 & 0.095 & 0.11 \\
\hline \multicolumn{9}{|l|}{ POPD_80 } \\
\hline EMPD_80 & $-0.24 * * *$ & -6.51 & 0.012 & 0.43 & -0.001 & -0.04 & -0.038 & -1.14 \\
\hline PCl_80 & $-0.765^{* * *}$ & -5.80 & $-1.266^{* * *}$ & -4.45 & $-1.093 * * *$ & -3.85 & & \\
\hline DLGEXP & $-0.194 * * *$ & -3.47 & 0.005 & 0.15 & -0.005 & -0.16 & $-0.365^{* * *}$ & -3.04 \\
\hline \multicolumn{9}{|l|}{ PCTAX } \\
\hline PCPTAX & $-0.05^{*}$ & -1.86 & $0.072^{* * *}$ & 2.70 & $0.066 * *$ & 2.48 & 0.107 & 1.51 \\
\hline NRSD & $0.004^{*}$ & 1.76 & $-0.003^{*}$ & -1.84 & $-0.003^{*}$ & -1.89 & $-0.025 * *$ & -2.21 \\
\hline MFG & -0.024 & -0.95 & $-0.075^{* * *}$ & -3.68 & $-0.087^{* * *}$ & -4.50 & $-0.109 *$ & -1.75 \\
\hline SERV & -0.007 & -0.13 & $0.107 * * *$ & 2.61 & 0.054 & 1.33 & $0.344 * * *$ & 3.38 \\
\hline \multicolumn{9}{|l|}{ UNEMPR } \\
\hline CREATIVE & $9.521 * * *$ & 10.97 & $2.248^{* *}$ & 3.27 & $2.271^{* * *}$ & 3.65 & 0.366 & 0.25 \\
\hline EDU & -0.082 & -0.77 & -0.074 & -1.49 & $-0.076^{*}$ & -1.72 & 0.141 & 0.68 \\
\hline \multicolumn{9}{|l|}{ MHV } \\
\hline UIFC & $-0.063 * * *$ & -6.22 & $0.022 * *$ & 2.13 & $0.016^{*}$ & 1.68 & -0.010 & -0.62 \\
\hline WINREC & $0.077^{* * *}$ & 5.52 & $0.029 * * *$ & 2.71 & $0.030 * * *$ & 3.47 & -0.012 & -1.09 \\
\hline LANDREC & $0.188^{* * *}$ & 4.07 & -0.0002 & -0.01 & -0.003 & -0.11 & $-0.101 * * *$ & -2.14 \\
\hline WATREC & $0.151 * * *$ & 5.97 & 0.005 & 0.26 & 0.012 & 0.67 & 0.083 & 1.50 \\
\hline HAMTY & $-0.032 * * *$ & -2.93 & 0.015 & 1.54 & 0.010 & 1.07 & -0.006 & -0.10 \\
\hline NAMTY & 0.027 & 1.51 & $-0.107 * * *$ & -5.88 & -0.016 & -0.70 & 0.022 & 0.67 \\
\hline NEWINREC & $-0.081 * * *$ & -4.67 & -0.004 & -0.22 & & & & \\
\hline NELANDREC & $-0.196 * * *$ & -3.47 & -0.093 & -1.43 & & & & \\
\hline NEWHAMTY & $0.258 * * *$ & 4.80 & -0.116 & -1.48 & & & & \\
\hline NENAMTY & $-0.093 * * *$ & -3.23 & $0.130 * * *$ & 2.91 & & & & \\
\hline NEWATREC & $0.121 *$ & 1.71 & 0.060 & 0.75 & & & & \\
\hline NAMTYADJ & & & & & -0.003 & -0.14 & & \\
\hline NAMTYHWD & & & & & $-0.0002 * * *$ & -3.50 & & \\
\hline Constant & $0.959 * * *$ & 6.51 & $2.042 * * *$ & 3.81 & 1.686 & 3.16 & 0.555 & 0.62 \\
\hline & & & & & & & & \\
\hline$N$ & \multicolumn{2}{|l|}{2256} & \multicolumn{2}{|l|}{2256} & \multicolumn{2}{|l|}{2256} & \multicolumn{2}{|l|}{148} \\
\hline F-statistic & \multicolumn{2}{|l|}{45.13} & & & \\
\hline Adjusted R2 & \multicolumn{2}{|l|}{0.321} & \multicolumn{2}{|l|}{0.612} & \multicolumn{2}{|l|}{0.651} & \multicolumn{2}{|l|}{0.757} \\
\hline
\end{tabular}


employment growth compared to counties with low employment density. The results support the employment convergence hypothesis. A high level of initial per capita income is also associated with negative employment growth.

The results from the OLS_US_NE in table 5.2.2 provide further evidence of significant difference between the northeast region and the rest of the country in terms of the role of amenities. The results of the reduced form show that with the exception of NAMTY, all the base amenity variables are significant. The coefficients of LANDREC, WATREC, AND WINREC are positive and significant while (HAMTY) is negative.

Looking at the amenity slope shifters, all are significant in the reduced form. NAMTY which is not significant in the base variable model is significant and negative. This is consistent with the impact of NAMTY on population growth. In both cases, the northeast not only differs from the rest of the country but also its NAMTY depresses growth. As in the population growth case, both HAMTY and WATREC are positive and significant for the region. The positive coefficient of WATREC indicates the effect of this amenity is stronger in the northeast than the rest of rural America. The coefficient of HAMTY which is negative and weak in the base is again positive and strong for the region. The direct opposite of this is the coefficients of LANDREC and WINREC. They are positive for the country but negative for the region.

In the 3SLS_US_NE1 case, only WINREC and NAMTY from the base variables and the slope shifter of NAMTY are significant. Moving from a simple OLS estimation to the full information estimation of three stage least square almost doubled the $R^{2}(32.1 \%$ to $61.2 \%)$ but reduced the magnitude of the amenity coefficients. The NAMTY coefficient 
which is consistently negative for the region turned positive. WINREC was positive in both OLS and 3SLS_US_NE1 results.

3SLS_US_NE 2 presents the test result of the role of proximity to the amenity demand market and accessibility to supply of amenity in the employment and amenity relationship. NAMTYHWD which is positive for the population equation turned negative and significant indicating accessibility to the supply of amenities depresses employment growth. In both cases the magnitude of the coefficients is very small $(0.0005$ for population growth and -0.0002 for employment growth) which greatly reduces its importance as a determining factor in the regional economic growth process. Similar to the population growth result, the coefficient of NAMTYADY is not significant indicating proximity to large population centers does not play a role in employment growth.

In the region specific estimation (3SLS_NE) only LANDREC is significant and in line with the OLS slope shifter case which is negative. (It is hard to explain the consistent negative relationship between land based recreational facilities and employment growth within the region). All the rest of the amenity variables are insignificant indicating no role of amenities in employment growth. But considering the simultaneity between population growth and employment growth, the indirect effect of amenities (WATREC and HAMTY positive and NAMTY negative effect on population growth, table 5.2.1 column 2) at the regional level cannot be ignored. One possible reason for this finding could be related to the argument and finding of Henderson and McDaniel (2005). They argued that the relationship between natural amenities and employment growth varies by industry and natural amenity type. The impact of amenities is clearer for the service and retail sectors than others. If this is the case then, 
our aggregate employment growth measure is not capturing this effect or the contribution of the service and retail sectors to the overall employment growth. Either way, there is a need for sector specific studies to reach a sound conclusion on the relationship.

The performance of the control variables is not as expected. With the exception of the percentage of creative class and economic structure indicators, the rest of the control variables switched signs from one to the other. As expected, the coefficient of the percentage of creative class is positive and significant in all the national level analyses. This implies counties with a higher percentage of this group will have higher growth in employment. The economic structure indicator variables are significant at the regional level. Percentage earnings in natural resource dependent industries (NRSD) and manufacturing (MFG) are negative and significant. This is a logical relationship as the importance of these two sectors has greatly decreased in the last quarter of the last century. The positive and significant coefficient of the percentage earnings in the service sector (SRV) shows the growing dominance of the sector in creating employment during the period. Again as in the population equation, DLGEXP is negative and significant. Henderson and McDaniel (2005) also found a similar negative relation between manufacturing sector employment growth and local government expenditures. Contrary to theoretical expectations, the coefficient of property tax per capita (PCPTAX) is positive and significant which implies the higher the property tax the higher will be the employment growth. There is no logical explanation for this relationship. Property taxes are part of business costs and there is no practical explanation that can support this finding. The percentage of adults with college degree 
(EDU) does not seem to play a role in regional or national employment growth. In most cases, the coefficient either has the unexpected sign or is not significant.

\subsubsection{Change in Per Capita Income Equation (LPCI)}

The overall fit of the per capita income growth equation, as shown Table 5.2.3, ranges from $35.5 \%-50.9 \%$. This is almost double the OLS reduced form estimation of Deller and Lledo (2007) for rural Appalachia. But given the difference in time period (10 vs. 25 years), estimation technique (OLS vs. 3SLS), and region (Appalachia vs. northeast US) such differences could be justifiable.

At the national level, there is a strong positive interdependence between LPOPD and $\mathrm{LPCl}$. This indicates the growth in population, which also a proxy to growth of the supply of labor, didn't affect the wage rate. Holding labor demand and other factors constant, the growth in labor supply is expected to lower the wage rate which is the major component of personal income. But during end of the last century, the US economy experienced a very low unemployment rate, which suggests that the demand for labor has been high. If the change in the demand for labor is higher than the supply of labor and if other sources of income (investment income) have been growing fast, it is not surprising to see strong positive relationship between growth in population and income. This relationship is reversed at the regional level. LPOPD is inversely related to $\mathrm{LPCl}$ in the Northeast region. One reason could be counties with higher population growth in the region have been experiencing lower per capita income growth. Average county income with a growing population may decline if income growth does not keep pace with population growth. As hypothesized, high employment growth is associated with high income growth in the region.

The initial level of per capita income ( $\mathrm{PCl} 80)$ is consistently negatively related to 
Table 5.2.3. Estimation Results of Income Growth and Amenities, 1980-2005

\begin{tabular}{|c|c|c|c|c|c|c|c|c|}
\hline \multirow[b]{2}{*}{ Variable } & \multicolumn{2}{|c|}{ OLS_US_NE } & \multicolumn{2}{|c|}{ 3SLS_US_NE 1} & \multicolumn{2}{|c|}{ 3SLS_US_NE 2} & \multicolumn{2}{|l|}{ 3SLS_NE } \\
\hline & Coef & t-stat & Coef & t-stat & Coef & t-stat & Coef & t-stat \\
\hline LPOPD & & & $0.038^{* *}$ & 2.56 & $0.056 * * *$ & 3.64 & $-0.153 * *$ & -2.08 \\
\hline LEMPD & & & -0.035 & -1.60 & $-0.054 * *$ & -2.37 & $0.201^{* *}$ & 2.16 \\
\hline \multicolumn{9}{|l|}{$\mathrm{LPCl}$} \\
\hline POPD_80 & $0.018 * * *$ & 5.16 & $0.018 * * *$ & 3.91 & $0.019 * * *$ & 4.17 & & \\
\hline \multicolumn{9}{|l|}{ EMPD 80} \\
\hline $\mathrm{PCl} \_80$ & $-0.762 * * *$ & -19.79 & $-0.76 * * *$ & -33.32 & $-0.774 * * *$ & -32.28 & $-0.480 * * *$ & -4.30 \\
\hline \multicolumn{9}{|l|}{ DLGEXP } \\
\hline PCTAX & $0.040 * * *$ & 3.16 & $0.045^{* * *}$ & 9.19 & $0.049 * * *$ & 9.80 & $0.052 * *$ & 2.27 \\
\hline \multicolumn{9}{|l|}{ PCPTAX } \\
\hline NRSD & $-0.002^{*}$ & -1.93 & $-0.002 * * *$ & -5.36 & $-0.002 * * *$ & -5.75 & $-0.005^{*}$ & -1.74 \\
\hline MFG & $0.010 *$ & 1.92 & $0.057 * * *$ & 6.65 & $0.055^{* * *}$ & 6.45 & -0.013 & -0.80 \\
\hline SERV & $0.053 * * *$ & 4.45 & 0.007 & 1.56 & 0.004 & 0.75 & -0.0002 & -0.01 \\
\hline UNEMPR & $-0.042 * * *$ & -7.28 & $-0.040 * * *$ & -8.36 & $-0.042 * * *$ & -8.36 & $-0.099 * * *$ & -2.59 \\
\hline \multicolumn{9}{|l|}{ CREATIVE } \\
\hline EDU & 0.011 & 0.75 & 0.015 & 1.10 & 0.013 & 0.96 & 0.012 & 0.29 \\
\hline MHV & $0.150 * * *$ & 7.53 & $0.113^{* * *}$ & 5.42 & $0.102 * * *$ & 4.94 & $0.231 * * *$ & 2.73 \\
\hline \multicolumn{9}{|l|}{ UIFC } \\
\hline WINREC & $0.008 * * *$ & 2.64 & $0.008 * * *$ & 3.73 & $0.010 * * *$ & 5.08 & 0.001 & 0.36 \\
\hline LANDREC & -0.002 & -0.27 & -0.005 & -0.58 & -0.003 & -0.45 & -0.002 & -0.12 \\
\hline WATREC & $0.007^{* *}$ & 2.38 & 0.004 & 0.96 & 0.005 & 1.14 & $0.046 * * *$ & 3.13 \\
\hline HAMTY & $0.004^{* * *}$ & 3.17 & $0.006 * * *$ & 2.86 & $0.005^{* * *}$ & 2.63 & 0.008 & 0.48 \\
\hline NAMTY & $-0.013 * * *$ & -3.18 & $-0.019 * * *$ & -5.32 & $-0.012 * *$ & -2.37 & 0.006 & 0.83 \\
\hline NEWINREC & 0.001 & 0.15 & 0.0003 & 0.07 & & & & \\
\hline NELANDREC & -0.002 & -0.15 & -0.006 & -0.40 & & & & \\
\hline NEWHAMTY & -0.017 & -1.60 & -0.026 & -1.64 & & & & \\
\hline NENAMTY & $0.014^{* * *}$ & 2.63 & $0.023^{* *}$ & 2.43 & & & & \\
\hline NEWATREC & $0.046 * * *$ & 3.56 & $0.044^{* * *}$ & 2.61 & & & & \\
\hline NAMTYADJ & & & & & 0.004 & 0.82 & & \\
\hline NAMTYHWD & & & & & $-0.00003^{*}$ & -1.82 & & \\
\hline Constant & $1.413^{* * *}$ & 47.08 & $1.438 * * *$ & 66.66 & $1.469 * * *$ & 64.66 & $1.212^{* * *}$ & 13.16 \\
\hline & & & & & & & & \\
\hline $\mathrm{N}$ & \multicolumn{2}{|l|}{2256} & \multicolumn{2}{|l|}{2256} & \multicolumn{2}{|l|}{2256} & \multicolumn{2}{|l|}{148} \\
\hline F-statistic & \multicolumn{2}{|l|}{70.8} & \multicolumn{2}{|l|}{ 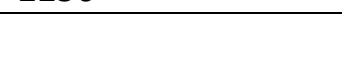 } & \multicolumn{2}{|l|}{ 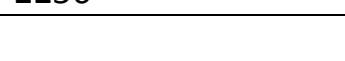 } & \multicolumn{2}{|l|}{-2} \\
\hline Adjusted R2 & \multicolumn{2}{|l|}{0.509} & \multicolumn{2}{|l|}{0.437} & \multicolumn{2}{|l|}{0.388} & \multicolumn{2}{|l|}{0.385} \\
\hline & & & & & & & & \\
\hline
\end{tabular}


the growth of income. This negative and significant relationship suggests that counties with lower income initially experienced greater income growth than counties with higher income in the earlier period. This may suggest a trend in regional growth towards development in rural areas (Deller et al. 2001) and supports the income convergence argument.

The negative but weak relationship between NAMTY and income growth at the national level lends evidence to the compensating differential argument. According to Roback (1982 and 1988), amenities are expected to have a negative effect on per capita income because households are willing to accept lower wages in high amenity areas. But the slope shifter of NAMTY for the northeast is positive and significant (almost of equal magnitude) which indicates that at the regional level NAMTY may play some role. The base variable for WATREC and the slope shifter are both positive and significant which suggest a strong role of WATREC in the region. This is also confirmed by the positive and significant coefficient of the region specific estimation. HAMTY and WINREC are positive at the national level but neither the slope shifter nor the region specific coefficient is significant for the northeast. This positive relationship of HAMTY, WATREC, and WINREC support the arguments of Wu and Mishra (2008) and the findings of Deller and Leldo (2008). Wu and Mishra (2008) argue that, "because amenities attract human capital, which in turn attracts firms, locations with superior amenities tend to have a higher demand for labor and thus higher wage rates" (p.98). Does this finding contradict the assumptions of Roback (1982 and 1988)? The relationship between amenities and income is not clear cut.

Many of the amenities such as HAMTY, WATREC, and WINREC are not pure 
natural amenities. They are built amenities which take advantage of the natural physical attributes of the area. There can also be a direct effect which is negative and indirect effect which is positive as suggested by Wu and Mishra (2008). If this is the case, then the net effect of amenities on income depends on the direct and indirect effects of income elasticity.

The 3SLS_NE 2 results of Table 5.2.3 presents the test result of the role of proximity to the amenity demand market and accessibility to supply of amenities in the income and amenity relationship. As in the case of employment growth NAMTYHWD is negative and significant indicating accessibility to the supply of amenities depress income growth. In both cases the magnitude of the coefficients is very small $(-0.0002$ for employment growth and -0.00003 for income growth) which greatly reduces its importance as a determining factor in the regional economic growth process. Similar to the population and employment growth results, the coefficient of NAMTYADY is not significant indicating proximity to large population centers does not play any role in income growth.

Counties with higher level of NRSD (percentage of earning from farming, agricultural services, and mining) are also associated with low levels of income growth. This is true because the share of the extractive resources sector is declining in the US. In Chapter 1 a comparison is made between Jefferson and McDowell, two counties in West Virginia. The growth of per capita income for McDowell county which depends on coal (extractive resource) was almost half of Jefferson county $(156 \%$ and $336 \%$ respectively). Jefferson transformed and diversified its economy and was able to record high income growth. 
In line with the economic theory and past studies, counties with higher unemployment rates (UNEMPR) experienced slower income growth. The coefficient of UNEMPR is significant and negative in all the estimated results. The unemployment rate may be measuring the local business climate, with higher unemployment rates indicating a less attractive place to do business. Contrary to theoretical expectations, the percentage of adults with college degree (EDU) does not seem to play a role in regional or national income growth. In all cases, the coefficient has the expected sign, but it is not statistically significant.

\subsubsection{Summary Findings of Non-Spatial Regional Growth Model}

The main goal of the regional economic growth model is to understand and assess the relationships between regional growth trends and natural and built amenities. For this reason, growth in population density, employment density, and per capita income were modeled as endogenous variables, and the role of natural and built amenities in the regional economic growth process was examined. This section provides the major findings of the non-spatial empirical estimation.

- Natural (NAMTY) and built amenities (specifically HAMTY and WATREC) play opposing roles in shaping the growth rate of population density for the northeast region of the US. In addition to the amenity factors, initial population density, dependence on the natural resource extraction sector, median value of owner occupied housing value, and the unemployment rate are found to be determinants of population growth during the period of 1980-2005. From all these findings, it is clear that natural amenities, historical and cultural amenities, and water based recreational facilities play a role in shaping the northeast region's population growth. 
- The role of amenities in influencing the growth in employment density at the regional level is different from the growth of employment density at the national level. Amenities, except for land based recreational facilities, are found to have no role in determining employment density growth. Growth in population density, local government expenditures per capita, percentage of earnings in the natural resources, manufacturing, and service sectors, and percentage of the creative class are found to be the major determinants of growth in employment density.

- Water based recreational amenities are found to be the only amenity variable that influenced the growth in per capita income in the last quarter of the 20th century. Other factors such as growth in population and employment densities, initial level of per capita income, earnings in the natural resource extraction sector, median value of owner occupied housing value, per capita tax rate and the unemployment rate are found to be determinants of population growth during 1980-2005 period.

- The national data set for all metro areas is used to test for the relationship between proximity to amenity demand markets (AMTYADJ) and accessibility to the supply of amenities (AMTYHWD) and regional growth indicators. No relationship is detected between the proximity to the amenity demand market and all three measures of regional growth. The test is conducted using adjacency to metro areas as a proxy to proximity to the amenity demand market. One of the reasons for this finding could be the choice of proxy. Instead of adjacency, distance from metro areas could be an alternative proxy.

- There is no clear cut relationship between regional growth indicators and the 
proxy for the supply of natural amenities (NAMTYHWD). In line with the expectations, it is positive and significant in the population growth equation indicating accessibility to the supply of amenities matters. But it is negative and significant for the employment and income growth equations which indicates that accessibility to the supply of amenities depresses regional growth. There are no logical explanations for these two contradicting results. In all cases, the magnitudes were very small which diminishes but does not eliminate its significance as a major determining factor.

\subsection{Findings and Analysis of Spatial Durbin Model}

The results of the empirical estimation in section 5.1 were based on the assumption that there is no spatial dependence. Regular regression models are applied that assumed that regions are independent of one another. As discussed in section 4.3, it is not realistic to ignore space when observations are collected from regions located in space. Ignoring the existence of spatial dependence produces estimates that are biased and inconsistent. This section accounts for the spatial dependence by estimating the spatial models developed in Chapters 3 and 4 . The spatial Durbin model that accounts for spillover effects by adding spatial lags for the dependent and independent variables is used as a method of spatial analysis. By using this method, the model is expected to capture the direct and indirect effects of amenities in the process of regional growth.

The issue of simultaneity of the regional economic growth indicators creates a challenge in the estimation of the spatial Durbin model. The current mat lab code that is used to estimate this model does not have the internal capability of estimating simultaneous equations. For this reason, the study follows the traditional approach of 
instrumenting the dependent variables. First, a reduced form is estimated to generate the fitted values of the dependent variables. These estimated dependent variables are then included as any other independent variable in estimating the spatial Durbin method. Therefore, each of the three equations in the model are estimated as a function of endogenous dependent variables (LPOPD, LEMPD, and LPCI), spatially weighted dependent variables (WLPOPD, WLEMPD, and WLPCI), independent variables (vector X), spatially weighted independent variables (WX).

As discussed in Chapter 4, the estimation and interpretation of the coefficients of the spatial model are not straightforward. According to Kirby and LeSage (2009), in the spatial Durbin method, changes in the independent variable $x_{i}$ lead to a direct impact (effect) on a county's marginal regional economic growth as well as a spatial spillover (indirect) impact on neighboring county's marginal regional economic growth. This study will follow this approach and present the direct, indirect, and total effects alongside the estimated coefficients of the model. Since the objective of the study is to assess the spatial effects of amenities on regional economic growth, the focus of the discussion will be on the estimated direct, indirect, and total effects not on the estimated coefficients of the model.

The strength of the estimated spatial dependence is measured by rho. As shown in table 5.3.1, none of the rho values for the nonmetro northeast region is statistically significant at any level. This could be due to the estimation of rho using a small sample size or the construction of the weight matrix. The use of nonmetro counties only in the construction of the weight matrix eliminates all the metro counties in the region that could have strong spatial relationships. In this case, the spillover effects of the metro 
counties to the surrounding nonmetro counties are not captured.

One way to overcome this problem is to separately construct the weight matrix using all counties in the region and estimate the model using the nonmetro counties.

Table 5.3.1. Estimated Value of the Spatial Dependence Statistic, Rho

\begin{tabular}{|c|c|c|c|c|}
\hline \multirow{2}{*}{ Equations } & \multicolumn{2}{|c|}{ Non-metro NE } & \multicolumn{2}{c|}{ All counties NE } \\
\cline { 2 - 5 } & Coeff. & P-level & Coeff. & P-level \\
\hline LPOPD & 0.101 & 0.27 & $\mathbf{0 . 3 2 8}^{* * *}$ & $\mathbf{0}$ \\
\hline LEMP & 0.072 & 0.33 & $\mathbf{0 . 1 4 7}^{*}$ & $\mathbf{0 . 0 9}$ \\
\hline LPCl & -0.265 & 0.10 & $\mathbf{0 . 3 3 3 ^ { * * * }}$ & $\mathbf{0 . 0 0}$ \\
\hline N & \multicolumn{2}{|c|}{148} & \multicolumn{2}{c|}{$\mathbf{2 9 9}$} \\
\hline
\end{tabular}

However, the existing available methodology which is used to estimate the spatial Durbin model does not have this flexibility. Another option is to construct all the spatial lags and export them to other statistical software and use nonmetro counties in the final estimation of the model. But this also has the problem of estimating only the initial direct and indirect effects. The additional feedback effects which are set in motion by the initial effects are ignored. Thus, the estimated coefficient could under or overestimate the spatial spillover effect.

In light of the above empirical estimation challenge, this study estimates both cases. First the model is estimated using data for the whole northeast metro and nonmetro counties and then a separate estimation is made using the subsample of only the nonmetro counties. But the analysis of the results will depend on the full sample size of all northeast counties. For comparison, the results of the estimation of the nonmetro counties are attached in the appendix. The weight matrix is constructed using the nearest eight neighboring counties.

\subsubsection{Spatial Result of Growth in Population Density}

Table 5.3.2. presents the results of the spatial Durban model for the growth in 
population density equation. The statistically significant value of the spatial dependence measure (rho) shows a strong spatial interdependence among regions. The model explains an estimated $68.2 \%$ of the variation in the growth of population density. In terms of magnitude, median value of owner occupied houses has the highest direct positive effect while percentage of earnings in manufacturing exerted the greatest impact in reducing population growth. Natural amenity (NAMTY) and historical and cultural amenity (HAMTY) are the only two with positive spatial spillover effects.

The estimated results show that growth in employment density has a positive direct effect on population growth. This result is similar to the result of the nonspatial model of 5.2.1. Growth in employment density indicates an increase in labor demand. This job opportunity attracts new in-migrants to the region which leads to growth in population and implies people follow jobs. The direct effect of per capita income is also positive. Contrary to the results of the nonspatial model which found no relationship, these results suggest that people migrate to capture higher incomes. Growth in per capita income is associated with high growth in population density. However, the indirect effects of employment and per capita income are not significant. This indicates the growth of employment and per capita income in surrounding counties does not have an impact on population growth. The value of rho which is also the coefficient for growth in population density in surrounding counties is positive and significant. This means growth in population in surrounding counties has positive spillover effect.

Turning to the amenity variables, the direct effect of NAMTY is negative and significant while the indirect effect is positive. This strong and positive indirect effect is not captured by the nonspatial model. This implies that a county that lacks natural 
Table 5.3.2. Spatial Durbin Estimation Results of Population Growth and Amenities

\begin{tabular}{|c|c|c|c|c|c|c|c|c|}
\hline \multirow[b]{2}{*}{ Variable } & \multicolumn{2}{|c|}{ Model results } & \multicolumn{2}{|c|}{ Direct effect } & \multicolumn{2}{|c|}{ Indirect effect } & \multicolumn{2}{|l|}{ Total effect } \\
\hline & Coeffi & p-level & Coeff & t-prob & Coeffi & p-level & Coeff & t-prob \\
\hline LEMPD & $0.220 * * *$ & 0.03 & $0.209 * *$ & 0.08 & -0.355 & 0.41 & -0.146 & 0.75 \\
\hline $\mathrm{LPCl}$ & $0.936^{* * *}$ & 0 & $0.960 * * *$ & 0 & 0.748 & 0.48 & 1.707 & 0.14 \\
\hline POPD80 & -0.001 & 0.14 & -0.001 & 0.22 & -0.003 & 0.14 & $-0.004 *$ & 0.07 \\
\hline DLGEXP & $-0.261^{*}$ & 0.09 & -0.262 & 0.18 & -0.038 & 0.95 & -0.3 & 0.63 \\
\hline PCTAX & 0.001 & 0.51 & 0.003 & 0.99 & 0.061 & 0.9 & 0.064 & 0.9 \\
\hline NRSD & $-0.018^{*}$ & 0.09 & $-0.026 * *$ & 0.06 & $-0.242 * * *$ & 0 & $-0.268 * * *$ & 0 \\
\hline MFG & $-0.250 * * *$ & 0 & $-0.278 * * *$ & 0 & $-0.906 * *$ & 0.01 & $-1.184 * * *$ & 0 \\
\hline UNEMPR & 0.047 & 0.35 & 0.035 & 0.77 & -0.376 & 0.38 & -0.341 & 0.43 \\
\hline $\mathrm{MHV}$ & $1.085^{* * *}$ & 0 & $1.087^{* * *}$ & 0 & 0.058 & 0.94 & 1.145 & 0.16 \\
\hline UIFC & $0.034 * *$ & 0.04 & 0.031 & 0.1 & -0.096 & 0.17 & -0.065 & 0.36 \\
\hline LANDREC & $-0.075^{* * *}$ & 0 & $-0.077 * * *$ & 0 & -0.084 & 0.29 & $-0.161 * *$ & 0.05 \\
\hline WATREC & 0.023 & 0.2 & 0.024 & 0.37 & 0.024 & 0.84 & 0.048 & 0.69 \\
\hline HAMTY & $0.076 * *$ & 0.01 & $0.087^{* *}$ & 0.01 & $0.380 * *$ & 0.04 & $0.467 * *$ & 0.02 \\
\hline NAMTY & $-0.145^{* *}$ & 0.01 & $-0.134^{* *}$ & 0.02 & $0.357^{*}$ & 0.06 & 0.223 & 0.16 \\
\hline WINREC & 0.016 & 0.18 & 0.016 & 0.37 & -0.01 & 0.85 & 0.005 & 0.93 \\
\hline WLEMPD & -0.316 & 0.14 & & & & & & \\
\hline WLPCI & 0.186 & 0.39 & & & & & & \\
\hline WPOPD80 & $-0.002^{*}$ & 0.09 & & & & & & \\
\hline WDLGEXP & 0.063 & 0.44 & & & & & & \\
\hline WPCTAX & 0.041 & 0.45 & & & & & & \\
\hline WNRSD & $-0.158 * * *$ & 0 & & & & & & \\
\hline WMFG & $-0.531 * *$ & 0.01 & & & & & & \\
\hline WUNEMPR & -0.272 & 0.18 & & & & & & \\
\hline WMHV & -0.33 & 0.28 & & & & & & \\
\hline WUIFC & $-0.077^{*}$ & 0.06 & & & & & & \\
\hline WLANDREC & $-0.032 * *$ & 0.27 & & & & & & \\
\hline WWATREC & 0.009 & 0.47 & & & & & & \\
\hline WHAMTY & $0.232^{* *}$ & 0.02 & & & & & & \\
\hline WNAMTY & $0.292^{* *}$ & 0.02 & & & & & & \\
\hline WWINREC & -0.012 & 0.37 & & & & & & \\
\hline rho & $0.328 * * *$ & 0 & & & & & & \\
\hline constant & 0.548 & 0.33 & & & & & & \\
\hline $\mathrm{R} 2$ & 0.682 & & & & & & & \\
\hline $\mathrm{N}$ & 299 & & & & & & & \\
\hline$* *$ & & & & & & & & \\
\hline
\end{tabular}


attractions of its own can still benefit from high amenities in its surrounding areas. From the built amenities, the direct, indirect, and total effect of historical and cultural amenity is positive and significant while the direct and total effect of land based recreational facilities is negative. There is no theoretical justification for this negative relationship of LANDREC with population density growth. This index is driven mainly by the availability of parks and recreation departments, private and public tennis courts, recreational centers, and golf courses. One possible reason for the negative relationship could be the construction and developments of land based recreational facilities are reducing land available for growth.

The total effect of the initial population density is negative indicating convergence in population growth within the region. Counties with high population density in 1980 were growing slower compared to those with low population density. The direct, indirect, and total effect of NRSD and MFG is negative and significant. Natural resource and manufacturing dependent counties are associated with population loss. McDowell County of West Virginia, which depends on coal (extractive resource), is a good example. It lost $52.1 \%$ of its population during the study period. The strong positive direct effect of median value of owner occupied suggests that Increase in population density is high in areas where the median housing values is high like VT and $\mathrm{NH}$.

\subsubsection{Spatial Result of Employment Density Growth}

The relatively weak statistical significance of rho in Table 5.3.3. shows a weak spatial interdependence among regions in the estimated employment density growth equation. The model explains an estimated $65.9 \%$ of the variation in the growth of employment 
Table 5.3.3. Spatial Durbin Estimation Results of Employment Growth and Amenities

\begin{tabular}{|c|c|c|c|c|c|c|c|c|}
\hline \multirow[b]{2}{*}{ Variable } & \multicolumn{2}{|c|}{ Model results } & \multicolumn{2}{|c|}{ Direct effect } & \multicolumn{2}{|c|}{ Indirect effect } & \multicolumn{2}{|l|}{ Total effect } \\
\hline & Coeffi & p-level & Coeff & t-prob & Coeffi & p-level & Coeff & t-prob \\
\hline POPD & $0.460 * * *$ & 0 & $0.461^{* * *}$ & 0 & 0.068 & 0.72 & $0.529 * * *$ & 0 \\
\hline $\mathrm{LPCl}$ & $0.661^{* * *}$ & 0 & $0.661^{* * *}$ & 0 & -0.027 & 0.97 & 0.635 & 0.37 \\
\hline EMPD80 & 0.00001 & 0.5 & 0.00003 & 0.97 & 0.001 & 0.64 & 0.001 & 0.66 \\
\hline DLGEXP & $-0.443 * * *$ & 0 & $-0.444 * * *$ & 0 & -0.033 & 0.93 & -0.477 & 0.23 \\
\hline PCPTAX & $0.328 * * *$ & 0 & $0.330 * * *$ & 0 & 0.118 & 0.74 & 0.448 & 0.23 \\
\hline NRSD & $-0.044 * * *$ & 0 & $-0.046 * * *$ & 0 & $-0.140 * * *$ & 0 & $-0.185 * * *$ & 0 \\
\hline MFG & $-0.322 * * *$ & 0 & $-0.329 * * *$ & 0 & -0.388 & 0.07 & $-0.716 * * *$ & 0 \\
\hline SRV & 0.109 & 0.17 & 0.105 & 0.34 & -0.271 & 0.46 & -0.166 & 0.68 \\
\hline EDU & -0.018 & 0.44 & -0.018 & 0.88 & -0.007 & 0.98 & -0.025 & 0.94 \\
\hline UIFC & $0.058 * * *$ & 0 & $0.058^{* * *}$ & 0 & -0.029 & 0.5 & 0.029 & 0.5 \\
\hline LANDREC & $-0.025^{* *}$ & 0.04 & $-0.026^{*}$ & 0.08 & -0.049 & 0.25 & $-0.075^{*}$ & 0.09 \\
\hline WATREC & -0.018 & 0.2 & -0.019 & 0.38 & -0.062 & 0.44 & -0.081 & 0.31 \\
\hline HAMTY & 0.025 & 0.19 & 0.029 & 0.32 & $0.216^{* *}$ & 0.04 & $0.244 * *$ & 0.03 \\
\hline NAMTY & $-0.154 * * *$ & 0.00 & $-0.151 * * *$ & 0.00 & 0.155 & 0.19 & 0.004 & 0.97 \\
\hline WINREC & 0.014 & 0.17 & 0.014 & 0.34 & -0.008 & 0.79 & 0.005 & 0.86 \\
\hline WPOPD1 & -0.016 & 0.45 & & & & & & \\
\hline WLPCI1 & -0.128 & 0.41 & & & & & & \\
\hline WEMPD80 & 0.001 & 0.32 & & & & & & \\
\hline WDLGEXP & 0.042 & 0.46 & & & & & & \\
\hline WPCPTAX & 0.049 & 0.44 & & & & & & \\
\hline WNRSD & $-0.112 * * *$ & 0.000 & & & & & & \\
\hline WMFG & $-0.279 * *$ & 0.05 & & & & & & \\
\hline WSRV & -0.249 & 0.21 & & & & & & \\
\hline WEDU & -0.005 & 0.49 & & & & & & \\
\hline WUIFC & -0.034 & 0.18 & & & & & & \\
\hline WLANDREC & -0.038 & 0.15 & & & & & & \\
\hline WWATREC & -0.05 & 0.23 & & & & & & \\
\hline WHAMTY & $0.180 * *$ & 0.01 & & & & & & \\
\hline WNAMTY & $0.157^{*}$ & 0.07 & & & & & & \\
\hline WWINREC & -0.009 & 0.36 & & & & & & \\
\hline Rho & $0.147^{*}$ & 0.09 & & & & & & \\
\hline constant & 0.884 & 0.13 & & & & & & \\
\hline $\mathrm{R} 2$ & 0.659 & & & & & & & \\
\hline $\mathrm{N}$ & 299 & & & & & & & \\
\hline
\end{tabular}

density. In terms of magnitude, per capita income growth followed by population density 
growth has the highest direct positive effects. The historical and cultural amenity variable is the only with a positive spatial spillover. DLGEXP, NRSD, MFG, and NA MTY all have negative

direct effects on employment density growth. The growth in per capita income and population density together indicate a potential increase in demand for goods and services. This increase in demand for goods and services increases the demand for factor inputs including labor which leads to employment growth. In line with the results of the nonspatial model, percentage earnings in manufacturing exerted the greatest direct impact in reducing employment growth.

From the amenity variables, the direct impacts of LANDREC and NAMTY are negative. This result reinforces previous similar findings using amenity slope shifters. But as discussed above, there is no theoretical justification for this consistent negative relationship between growth indicators and land based recreational facilities. The indirect and total effect of HAMTY was positive and significant. This strong and positive indirect effect was not captured by the nonspatial model. This implies that a county that lacks human attractions of its own can still benefit from high amenity in its surrounding counties.

\subsubsection{Spatial Result of Per Capita Income Growth}

Table 5.3.4. presents the estimated results of the spatial Durbin model for per capita income growth. The estimated model explains $56.4 \%$ of the total variation in per capita income growth during 1980-2005. Surprisingly, unlike in the nonspatial model, the coefficients of the population and employment density variables are not significant. Growth in per capita income in the region is not directly or indirectly related to income 
Table 5.3.4. Spatial Durbin Estimation Results of Income Growth and Amenities

\begin{tabular}{|c|c|c|c|c|c|c|c|c|}
\hline \multirow[b]{2}{*}{ Variable } & \multicolumn{2}{|c|}{ Model results } & \multicolumn{2}{|c|}{ Direct effect } & \multicolumn{2}{|c|}{ Indirect effect } & \multicolumn{2}{|c|}{ Total effect } \\
\hline & Coeffi & p-level & Coeff & t-prob & Coeffi & t-prob & Coeff & t-prob \\
\hline LPOPD1 & $-0.031 * *$ & 0.04 & -0.029 & 0.11 & 0.070 & 0.30 & 0.042 & 0.56 \\
\hline LEMP1 & $0.027^{*}$ & 0.07 & 0.025 & 0.19 & -0.070 & 0.37 & -0.045 & 0.59 \\
\hline $\mathrm{PCl} 80$ & $-0.184 * * *$ & 0.00 & $-0.194 * * *$ & 0.00 & -0.322 & 0.10 & $-0.516 * *$ & 0.01 \\
\hline PCTAX & -0.004 & 0.39 & -0.005 & 0.72 & -0.033 & 0.51 & -0.038 & 0.46 \\
\hline NRSD & $-0.005^{* *}$ & 0.01 & $-0.006 * * *$ & 0.01 & -0.007 & 0.33 & -0.013 & 0.11 \\
\hline MFG & $-0.028 * *$ & 0.01 & $-0.030 * *$ & 0.01 & -0.052 & 0.28 & -0.082 & 0.12 \\
\hline SRV & -0.018 & 0.16 & -0.014 & 0.47 & 0.132 & 0.10 & 0.118 & 0.17 \\
\hline UNEMPR & 0.008 & 0.33 & 0.004 & 0.80 & $-0.129 * *$ & 0.04 & $-0.125^{* *}$ & 0.05 \\
\hline EDU & $0.096 * * *$ & 0.00 & $0.099 * * *$ & 0.00 & 0.104 & 0.30 & $0.203^{*}$ & 0.06 \\
\hline $\mathrm{MHV}$ & $0.184^{* * *}$ & 0.00 & $0.176 * * *$ & 0.00 & $-0.282^{*}$ & 0.08 & -0.107 & 0.52 \\
\hline LANDREC & 0.002 & 0.19 & 0.003 & 0.24 & $0.027^{* *}$ & 0.02 & $0.030 * *$ & 0.01 \\
\hline WATREC & $0.009 * *$ & 0.02 & $0.008 * *$ & 0.05 & -0.023 & 0.18 & -0.015 & 0.40 \\
\hline HAMTY & -0.004 & 0.22 & -0.004 & 0.39 & -0.014 & 0.54 & -0.019 & 0.46 \\
\hline NAMTY & -0.002 & 0.43 & -0.001 & 0.90 & 0.017 & 0.50 & 0.016 & 0.48 \\
\hline WINREC & 0.000 & 0.44 & -0.001 & 0.82 & -0.008 & 0.27 & -0.009 & 0.26 \\
\hline WLPOPD & 0.058 & 0.10 & & & & & & \\
\hline WLEMP & -0.056 & 0.14 & & & & & & \\
\hline WPCl80 & -0.153 & 0.12 & & & & & & \\
\hline WPCTAX & -0.020 & 0.27 & & & & & & \\
\hline WNRSD & -0.003 & 0.27 & & & & & & \\
\hline WMFG & -0.025 & 0.20 & & & & & & \\
\hline WSRV & $0.095^{* *}$ & 0.03 & & & & & & \\
\hline WUNEMPR & $-0.090 * *$ & 0.01 & & & & & & \\
\hline WEDU & 0.037 & 0.29 & & & & & & \\
\hline WMHV & $-0.254^{* *}$ & 0.01 & & & & & & \\
\hline WLANDREC & $0.017^{* * *}$ & 0.00 & & & & & & \\
\hline WWATREC & $-0.019 *$ & 0.06 & & & & & & \\
\hline WHAMTY & -0.008 & 0.29 & & & & & & \\
\hline WNAMTY & 0.012 & 0.25 & & & & & & \\
\hline WWINREC & -0.005 & 0.14 & & & & & & \\
\hline Rho & $0.333 * * *$ & 0.00 & & & & & & \\
\hline Constant & $1.041^{* * *}$ & 0.00 & & & & & & \\
\hline $\mathrm{R} 2$ & 0.564 & & & & & & & \\
\hline $\mathrm{N}$ & 299 & & & & & & & \\
\hline
\end{tabular}

growth. But the negative coefficient of initial value of per capita income strongly 
reinforces the result of the nonspatial model $(-0.480$ for nonspatial and -0.516 for the spatial). This negative and significant relationship suggests that counties with lower income initially experienced greater income growth than counties with higher incomes in the earlier period.

Only two of the amenity variables are significant. Areas with higher levels of water based recreational facilities are associated with high levels of per capita income. The spillover effect of land based recreational facilities is positive which highlights the importance of surrounding counties in income growth. Again as in the case of the nonspatial model, these findings support the arguments of Wu and Mishra (2008) and the findings of Deller and Leldo (2008) which are discussed above.

Median housing value is a major direct factor in driving per capita income in the region. The strong positive direct effect of median value of owner occupied housing suggests that growth in per capita income is high in areas where the median housing values is high as in $\mathrm{VT}$ and $\mathrm{NH}$. But the indirect effect is negative and high in magnitude which indicates median values of surrounding counties discourages income growth.

The positive and significant coefficient of high level of college education indicates a high educational attainment leads to high level of per capita income. In contrast to the nonspatial model, the relationship between the proportion of a county's population with a bachelor's degree or higher, a measure of human capital, and per capita income growth, indicating that counties with high human capital endowments experience high income growth. Even though, the direct effect of the unemployment rate is insignificant, the indirect effect is negative and significant. This suggests that a county surrounded by counties with high unemployment rate is likely to have low income growth. 


\subsubsection{Summary Findings of Spatial Durbin Model}

The main goal of the spatial growth model is to help understand the relationships between regional growth trends and natural and built amenities. The spatial interdependence among regional growth indicators, natural and built amenities, and other factors that affect regional growth are modeled in the spatial Durbin method. For this reason, growth in population density, employment density, and per capita income are modeled as a functions of the endogenous variables $(\mathrm{Yi})$ and their spatial lags $(I+W) Y i$, amenity variables $(\mathrm{Ai})$ and their spatial lags $(I+W) A i$, and other local factors $(\mathrm{X})$ and their spatial lags $(\mathrm{I}+\mathrm{W}) \mathrm{Xi}$ that are expected to affect regional growth. This section provides a summary of the major findings of the estimated results.

- County population growth is directly affected by employment and per capita income growth within the county. Amenities within the county and/or surrounding counties play a significant role in the process of population growth. Historical and cultural amenities like museums, historical sites, zoos, and other attractions play a positive direct and indirect role in attracting new immigrants. While the direct effect of the natural amenity (NAMTY) is negative, the indirect effect coming from surrounding counties is positive. This is an important finding with major policy implications. This implies that a county that lacks natural attractions of its own can still benefit from the natural richness of its surrounding counties. From the local factors, median housing value, earnings from natural resource sector and manufacturing sector are important factors in affecting population growth.

- County employment density growth is significantly driven by growth in population density and per capita income. The relationship of amenities with employment growth generally is either negative or insignificant. There is no positive and direct 
effect found in the relationship. The direct effects of natural amenities and land based recreational facilities are negative but the indirect effect of historical and cultural amenities is positive. Local factors such as earnings in the natural resource and manufacturing sectors, direct local government expenditures, and per capita taxes also play a role in influencing employment growth.

- County per capita income growth is directly affected by water related recreational facilities within the county and land based recreational facilities of surrounding counties. The rest of the amenity variables do not directly or indirectly affect per capita income growth. Both, the endogenous variables, population and employment densities do not play a significant role in influencing income growth. But the initial level of per capita income is negative and significant indicating that counties with lower incomes initially experienced greater income growth than counties with higher income in the earlier period. Earnings in manufacturing and natural resource sectors, median housing values, and college education are the major local and nonlocal factors affecting income growth. 


\section{CHAPTER 6: SUMMARY AND CONCLUSIONS}

\subsection{Introduction}

The main objective of this research is to examine the association between natural and built amenities and regional economic growth among counties in the northeast region of the United States. Spatial and nonspatial models were developed and estimated. The simultaneity nature of the dependent variables is accounted for by using three stage least squares in the nonspatial model and two stage least squares in the spatial Durbin model. The Northeast region of the United States is used as a study area. It is composed of 12 states and consists 299 counties of which 148 are nonmetro. It is highly urbanized with $50.5 \%$ of the counties considered as metro. Most of the nonmetro areas are found in the Appalachian portion of the region. Although the region as a whole has very few poverty persistent counties compared to the US, it has the highest population loss counties $(21.7 \%)$ due to out-migration. In this final chapter, Summary and Conclusions, policy implications, limitations and future work related to the study are discussed.

\subsection{Summary and Conclusion}

As indicated above, the primary objective of this research is to evaluate the relationship between natural and built amenities and regional economic growth among counties in the northeast region of the United States. The general conclusion of the study is that, indeed, some amenities were positively associated with regional economic growth during the 1980-2005 period. But there is no evidence of a consistent and strong relationship. At best, the results are mixed and inconclusive. Based on the estimated 
results, this study contributes by providing policy makers with information on the role of natural and recreational amenities in rural economic development in the Northeast region.

To estimate the models, a database of natural and built amenities, socioeconomic, and fiscal variables of the northeast region from 1980 to 2005 was compiled. Nonspatial and spatial econometric models were empirically developed and estimated. A system of equations was used to examine relationships between regional economic growth indicators (growth in population density, employment density, and per capita income) and natural and built amenities.

In the nonspatial estimation, ordinary least squares and three stage-leastsquares with amenity slope shifters for the northeast were applied. These slope shifters were included to see whether amenities in rural northeast behave in different ways from the rest of rural America. As presented in Table 5.2.1-5.2.3, clearly many of the slope shifters were significant indicating amenities in rural northeast behaved differently from the rest of the country. These results indicate that conclusions based on generalization from national level analyses could be misleading. Different regions have different natural and built amenities which could have region specific effects.

Generally, amenity indicators were hypothesized to play a positive role in population growth. In the growth of population density equation, natural (NAMTY) and built amenities (specifically HAMTY and WATREC) play opposing roles in shaping the growth rate of population density of the northeast region of the US. Amenities, except for land based recreational facilities, generally are found to have no role in determining employment density growth. Water based recreational amenities are found to be the 
only amenity variable that positively influences the growth in per capita income in the last quarter of the 20th century. From all these findings, it is clear that natural amenities, historical and cultural amenities, water and land based recreational facilities play a role in shaping the economic growth of the northeast region. Surprisingly enough, even though the region is endowed with winter based recreational facilities, it did not show an influence in the process of regional economic growth.

A modified version of the spatial Durbin model (Lesage and Pace, 2009) is used to estimate the spatial distribution of amenities and regional economic growth. To account for the simultaneity in the dependent variables, first a reduced form is estimated to generate the fitted values of the dependent variables. These estimated dependent variables are then included as any other independent variable in estimating the spatial Durbin model. Therefore, each of the three equations in the model are estimated as a function of the fitted endogenous dependent variables (LPOPD, LEMPD, and LPCI), spatially weighted fitted dependent variables (WLPOPD, WLEMPD, and WLPCI), independent variables (vector $X)$, spatially weighted independent variables (WX). This method helped to examine not only the strength of the spatial dependence but also to estimate the direct impacts/effects of local factors on county's marginal economic growth as well as a spatial spillover or indirect impact from neighboring counties. This is the first time the spatial Durbin model has been used in assessing the relationship between amenities and regional growth. This is one of the major contributions of this study to the amenity and regional growth literature.

The results of the spatial impact of amenities on regional economic growth are mixed. Amenities within a county and/ or surrounding counties play a significant role in 
the process of population growth. Historical and cultural amenities like museums, historical sites, zoos, and other attractions play a positive direct and indirect role in attracting new immigrants. While the direct effect of natural amenity (NAMTY) was negative, the indirect effect coming from surrounding counties was positive. This is an important finding with major policy implications. This implies that a county that lacks natural attractions of its own can still benefit from the natural richness of its surrounding counties.

The relationship of amenities with employment growth was either negative or insignificant. There was no positive direct effect found. The direct effect of natural amenities and land based recreational facilities were negative but the indirect effect of historical and cultural amenities was positive. County per capita income growth is directly affected by water related recreational facilities within the county and land based recreational facilities of surrounding counties (both positive). Given these mixed results and the fact that the total effect of historical and cultural amenities (in two of the three equations) was positive and the total effect of land based recreational facilities was mixed (negative in two and positive in one), we cannot ignore the role of amenities. One possible reason for these mixed and weak relationships is the choice of the sample data.

As discussed in chapter five, the spatial model was estimated using data for all metro and nonmetro counties. Therefore, the estimated coefficients are the average direct and indirect effects of the metro and nonmetro areas. Given that the region is highly urbanized and economically diversified, the effects of amenities is dwarfed by other socio-economic factors that are in play in the region. Consequently, many of the 
amenity factors that were expected to play an important role on the regional economic growth of nonmetro counties became insignificant or minor players. However, the results of the spatial estimation of the nonmetro counties (Table 5.3.5-5.3.6 in the appendix), even with all its limitations discussed in chapter five, show that with the exception of winter based recreational facilities, the rest of the amenity indices play a significant but inconsistent role in the economic growth of the region.

Using a national data set of all nonmetro counties, the role of proximity to the demand market and accessibility to supply of amenities was tested. The results were contrary to the expectations. No relationship was detected between the proximity to the amenity demand market and all three measures of regional growth. The test was conducted using an interaction term of natural amenity measure and adjacency to metro area as proxy to proximity to the amenity demand market. One of the reasons for this finding could be the choice of proxy. There is no clear cut relationship between regional growth indicators and the proxy for the supply of natural amenities (NAMTYHWD). In line with expectations, it was positive and significant in the population growth equation indicating accessibility to the supply of amenities matters. But it was negative and significant for the employment and income growth equations which show accessibility to the supply of amenities depresses regional growth. There are no logical explanations for these two contradicting results. In all cases, its magnitude was very small which diminishes its significance as a major determining factor.

One of the hypotheses tested in this study was the role of economic activities of surrounding counties. It was hypothesized that growth is conditional and affected by economic activities in surrounding counties. The results of the spatial Durbin model give 
evidence for this test. In addition to the indirect effects (positive and negative) of amenities discussed above, high dependence on natural resource and manufacturing sectors, and unemployment rate in the surrounding counties are found to depress regional economic growth by exerting negative influences on population and employment growth.

\subsection{Policy Recommendations}

Based on empirical findings of this study a couple of recommendations can be suggested for effective application of amenity-led development in the northeastern United States.

- The findings of the study show that historical and cultural amenity and water based recreational facilities were positively associated with regional economic growth during the 1980-2005 period. Given this fact, preservation of historical and cultural sites and development of water based recreational sites should be encouraged. The presence of these local attributes could encourage not only people to live and stay in these areas but also to attract new migrants. But the preservation of amenities has an opportunity cost and the decision should be on a case by case based. Therefore, local policy makers should identify, preserve, develop, and promote only attributes that has the potential to serve as a development strategy.

- Regional cooperation in preservation, development and management of natural resources and recreational facilities should be one of the main strategies in developing amenity- led development. The results show a positive spatial spillover effect of natural and historical and cultural amenities as well as land 
based recreational facilities. Then the question policy makers have to address is how are these resources managed and funded? Generally amenities are public goods. If the cost of maintenance and development is left to the county within which they reside, they will tend to be underfunded and underdeveloped. Regional internalization of this positive externality is required to take full advantage of the natural asset in the regional economic growth process.

- While there are some similarities across the United States, the country is sufficiently heterogeneous that the impact of amenities or other policy variables may be significantly different depending on where one is within the country. Specifically, the coefficients of the amenity slope shifters in the results suggest that the non-metropolitan northeast region follows different pattern. These findings should be recognized by regional policy makers in developing regional policies. Policies developed based on generalization of national level analyses could be misleading. Thus, understanding the spatial distribution of local amenities within the specific region is an important factor for promoting amenityled development.

\subsection{Limitations and Future Research}

\subsubsection{Limitations}

The main contribution of the study is its ability to estimate the direct and indirect effects of amenities on regional economic growth. But this is also one of its limitations. As discussed in Chapter 5, the spatial model was estimated using data for all metro and nonmetro counties. This was done to capture the spillover effects from the metro counties surrounding the nonmetro counties. Therefore, the estimated coefficients are the average direct and indirect effect of the metro and nonmetro counties. Given that 
the region is highly urbanized and economically diversified, the effects of amenities is dwarfed by other socio-economic factors that are in play in the region. Consequently, many of the amenity factors that were expected to play an important role on the regional economic growth of nonmetro counties became insignificant or minor players.

The amenity data used in the study was compiled from the USDA Forest Service, National Outdoor Recreation Supply Information System (NORSIS). Even though, it is the most comprehensive database available for amenity related studies, it is by no means exhaustive. Furthermore, the way the amenity indices were constructed also has its limitations. The study followed the literature in selecting the different attributes that formed the indices. There is no standard or theoretical base for including or excluding different amenity attributes. Different combinations of attributes could be used and could produce different results.

The weight matrix used in the spatial estimation was based on the nearest eight neighbors. There is no rule that guides the construction of a weight matrix. A weight matrix constructed based on contiguity, distance, and other choices of neighbors could give different results.

\subsubsection{Future Research}

There are several ways this study could be extended. Additional research in this area could focus on and significantly contribute to the knowledge of amenity-led development by expanding into the following areas:

1. Finding a mechanism to apply the spatial Durbin model to nonmetro counties but using all relevant counties to construct the weight matrix could help to solve the current estimation challenge. This could help to estimate the impact of amenities on nonmetro counties. 
2. The spatial results are based on one form of weight matrix. Developing a different weight matrix could lead to different results. Generating different results for each of the weight matrix using the spatial Durbin model and comparing these results could show the overall impact of the spatial distribution of amenities.

3. Extending this study to include all nonmetro counties in the US can be a next logical step. This can enrich the study by providing a bigger sample size and variability in the dataset.

4. Estimating the impact of specific amenities (not indices) in a specific county or group of counties by conducting a case study could lead to more practical policy implications. 


\section{REFERENCES}

Anselin, Luc, (1988). Spatial Econometrics: Methods and Models. Kluwer Academic Press, Dordrecht.

Anselin, Luc, and Anil K. Bera. (1998). Spatial Dependence in Linear Regression Models with an Introduction to Spatial Econometrics. In Aman Ullah and David Giles (Eds.). Handbook of Applied Economic Statistics (pp. 237-289). New York: Marcel Dekke

Beale, C.L, and K.M. Johnson (1998). "The Identification of Recreational Counties in Nonmetropolitan Area of the USA." Pop. Res. Policy Rev. 17:37-53

Blanchflower, D.G. and Oswald, A.J. (1996). The Wage Curve. Cambridge, MA:MIT Press.

Boarnet, M.G. 1995. "Transportation Infrastructure, Economic Productivity, and Geographic Scale: Aggregate Growth versus Spatial Distribution." Available online at http://www.uctc.net/papers/255.pdf

Carlino, G.A. and Mills, E.S. (1987). "The Determinants of County Growth." Journal of Regional Science, 27, 39-54

Carruthers JI, Hollar MK, Mulligan, GF (2006). "Growth and Convergence in the Space Economy: Evidence from the United States." Presented at the $46^{\text {th }}$ Congress of the European Regional Science Association, August 30-Spetember 3, 2006 in Volos, Greece

Cromartie, J.B. (2001). "Migrants in the Rural South Choose Urban and Natural Amenities." Rural America 15, 7-18.

Duncombe, W., M. Robbins and D. Wolf. (2000). "Chasing the elderly: Can State and Local Governments Attract Recent Retirees?" Paper No. 22. Syracuse, NY: Center for Policy Research, Maxwell School of Citizenship and Public Affairs, Syracuse University.

Deller and Victor Lledo (2007). "Amenities and Rural Appalachia Economic Growth." Agricultural and Resource Economics Review, 36:107-132.

Deller and Victor Lledo, and Marcouiller W.D. (2008). "Modelling Regional Economic Growth with a Focus on Amenities." Review of Urban and Regional Development Studies, 20,1-21

Deller, C.D., Tsai, T.-H.S.M. and English, B.K.D. and V. Liedo (2005). "Regional Economic Growth with a Focus on Amenities." In "Amenities and Rural 
Development: Theory, Methods and Public Policy." G.P. Green, S.C. Deller, and D.W. Marcouiller, eds., Northampton, MA: Edward Elgar.

Deller, C.D., Tsai, T.-H.S.M. and English, B.K.D. (2001). "The Role of Amenities and Quality of Life in Rural Economic Growth." American Journal of Agricultural Economics 83, 352-365.

Deller, S.C. and Tsai, T.S. (1999). "An Examination of the Wage Curve. A Research Note." Journal of Regional Analysis and Policy 28, 3-12.

Dissart, Jean-Christophe. (2007). "Landscapes and regional development: What are the links?" Cahiers d'économie et sociologie rurales, $\mathrm{n}^{\circ}$ 84-85.

Doreian, Patrick. (1980). "Linear Models with Spatially Distribute Data: Spatial Disturbances or Spatial Effects." Sociological Methods \& Research 9(1): 29-60.

........ (1981). "Estimating Linear Models with Spatially Distributed Data". In Samuel Leinhardt (Ed.). "Sociological Methodology" (pp. 359-388). San Francisco, CA: The Jossey-Bsess Inc.

Duffy-Deno, K.T. (1997a). "The Effect of State Parks on the County Economies of the West." Journal of Leisure Research, 29, 201-2224.

(1998). "The Effect of Federal Wilderness on County Growth in the Intermountain Western US." Journal of Regional Science 38, 109-136.

Economic Research Service (ERS)(1999). Natural Amenities Scale Available from: http://www.ers.usda.gov/emphases/rural/data/amenities

English, D.B.K., Marcouiller, D.W. and Cordell, H.K. (2000). "Linking Local Amenities with Rural Tourism Incidence: Estimates and Effects." Society and Natural Resource 13, 185-202.

Fabian Waltert and Felix Schläpfer. (2007). "The Role of Landscape Amenities in Regional Development: A Survey of Migration, Regional Economic and Hedonic Pricing Studies." Socioeconomic Institute, University of Zurich, Working Paper No. 0710

Galston, William A., and Karen J. Baehler. (1995). Rural Development in the United States: Connecting Theory, Practice, and Possibilities. Washington, DC: Island Press.

Gebremariam, G.H., T.G. Gebremedhin, and P.V. Schaeffer. (2006). "An Empirical Analysis of County-Level Determinants of Small Business Growth in Appalachia: 
A Spatial Simultaneous-Equations Approach." Paper presented at the Southern Agricultural Economics Association Annual Meeting, Orlando, FL (February 5-8).

Gibson, Lay James. (1993). "The Potential for Tourism Development in Nonmetropolitan Areas," in David L. Barkley, ed., "Economic Adaptation: Alternatives for Nonmetropolitan Areas", pp. 145-64. Boulder, CO: West-view Press.

Goe, W.R., and G.P. Green. 2005. "Analyzing the Relation-ship Between Amenities and Change in the Well-Being of Nonmetropolitan Localities." "In Amenities and Rural Development: Theory, Methods and Public Policy." G.P. Green, S.C. Deller, and D.W. Marcouiller, eds., Northampton, MA: Edward Elgar.

Golding, Shaun A. and Auken, Paul M. Van. (2006). "Amenities and Inequality in Rural America: A preliminary Spatial Analysis." Paper presented at the Population Association of America Annual Meeting

Gottlieb, P.D. (1994). "Amenities as an Economic Development Tool: Is There Enough Evidence?” Economic Development Quarterly 8, 270-285.

Gottlieb, P.D. (1995). "Residential Amenities, Firm Location and Economic Development", Urban Studies, Vol. 32, No. 9, 1413-1436

Graves,P.E. and Muser, P.R. (1993). "The Role of Equilibruim and Disequilibruim in Modeling Regional Growth and Decline.A critical Reassessment." Journal of Regional Science, 33

Green, G.P. (2001). "Amenities and Community Economic Development: Strategies for Sustainability." Journal of Regional Analysis and Policy 31, 61-76.

Gunderson, Ronald J. and Ng Pint T. (2006). "Summarizing The Effect of Wide Array of Amenity into Simple Components." Social Indicators Research 79: 313-335

Hailu, Y.G., and C. Brown. (2006). "A Spatial Simultaneous Growth Equilibrium Modeling of Agricultural Land Development in the Northeast United States." Paper presented at the American Agricultural Economics Association Annual Meeting, Long Beach, CA (July 23-26). . 2007. "Regional Growth Impacts on Agricultural Land Development: A Spatial for Three States." Agricultural and Resource Economics Review 36(1)

Henderson, J. and K. McDaniel. (1998). "Do scenic amenities foster economic growth in rural areas?" Federal Reserve Bank of Kansas City, Regional Economic Digest, 1st quarter:11-17. 
Henderson, J. and K. McDaniel. (2005). "Natural Amenities and Rural Employment Growth: A Sector Analysis." The Review of Regional Science 35(1)

Hoehn, J.P., Berger, M.C., Blomquist, G.C., (1987). "A Hedonic Model of Interregional Wages, Rents, and Amenity Values." Journal of Regional Science 27 (4), 605620.

Judson, D.H., S. Reynolds-Scanlon, and C.L. Popoff. (1999). "Migrants to Oregon in the 1990's: Working age, near-retirees, and retirees make different destination choices." Rural Development Perspectives 14:24-31.

Keith, John, and Christopher Fawson. (1995). "Economic Development in Rural Utah: Is Wilderness Recreation the Answer?" Annals of Regional Science. 29,3: 303-313

Kim, K., Marcouiller, D.W., Deller, S.C., (2005). "Natural Amenities and Rural Development: Understanding Spatial and Distributional Attributes." Growth and Change 36 (2), 273-297.

Kirby, Dustin K. and LeSage, James P. (2009). "Changes in commuting to work times over the 1990 to 2000 period." Regional Science and Urban Economics

LeSage, James P (1997). "Regression Analysis of Spatial Data." Journal of Regional Analysis and Policy, 27(2), 83-94

LeSage, James P. and R. Kelly Pace. (2009). Introduction to Spatial Econometrics. CRS Press

Lewis, D.J., Hunt, G.L., Plantinga, A.J., (2002). "Public Conservation Land and Employment Growth in the Northern Forest Region." Land Economics 78 (2), 245-259.

Lewis, D.J., Hunt, G.L., Plantinga, A.J., (2003). "Does Public Lands Policy Affect Local Wage Growth?" Growth and Change 34 (1), 64-86.

Marcouiller, David W., and Gary Paul Green. (2000). "Outdoor Recreation and Rural Development." In Gary E. Machlis and Donald R. Field, eds., "National Parks and Rural Development: Practice and Policy in the United States", Washington, DC: Island Press

Marcouiller, D.W., K.K. Kim, and S.C. Deller. (2004). "Natural Amenities, Tourism and Income Distribution." Annals of Tourism Research 31(4): 1031-1050.

MacDonald, John F., (1992). "Assessing the Development Status of Metropolitan Areas", in Edwin S.Mills and John F. MacDonald (ed.), "Sources of Metropolitan Growth", New Brunswick, NJ: Center for Urban Policy Research. 
McGranahan, D.A. (1999). Natural Amenities Drive Rural Population Change. Food and Rural Economics Division, Economic Research Service, US Department of Agriculture. [AER-781], 1-24.

MaGranhan, D.A. and Beale, C.L.(2003). The Roots of Rural Population Loss. Amber Waves.

Monchuk, Daniel. (2003). "The Role of Amenities on Employment Growth in the U.S. Heartland: A Spatial Analysis Examining the Role of Recreational Amenities in Surrounding Counties." Working Paper: lowa State University Ames, lowa 2003

Northeastern Regional Center for Rural Development (NRCRD). "Regional Listening Sessions on Rural Entrepreneurship: Lessons from Northeast." Rural Development Paper No. 37, July 2007.

Nzaku, Kilungu and James Bukenya (2005). "Examining the relationship between Quality of Life Amenities and Economic Development in the Southeast USA." Review of Urban and Regional Development Studies Vol. 17, No. 2, July 2005.

Nord, M. and Cromartie, J.B. (1997). "Migration: The Increasing Importance of Rural Natural Amenities." Choices 3, 22-23.

Ohman, Debra. (1999). "Restructuring and Well-being in the nonmetropolitan Pacfic Northwest." Growth and Change, 30, 161-183

Organization for Economic Cooperation and Development (OECD). (1994). The Contributions of Amenities to Rural Development. Paris: OECD

Power, Thomas M. (1988). The Economic Pursuit of Quality. Armonk, NY: M.E. Sharpe, Inc.

..(1996). Lost Landscapes and Failed Economies. Washington, D.C.: Island Press.

...(2005). "The supply and demand for natural amenities: An overview of theory and concepts." In "Amenities and Rural Development: Theory, Methods and Public Policy." G.P. Green, S.C. Deller, and D.W. Marcouiller, eds., Northampton, MA: Edward Elgar.

Rey, S.J. and M.G.Boarnet. (1998). "A Taxonomy of Spatial Econometrics Models for Simultaneous Equations Systems." Paper presented at the $45^{\text {th }}$ Annual North America Meetings of the Regional Science Association International, Sanata Fe, New Mexico 
Roback, J. (1982). "Wages, Rents, and the Quality of Life." Journal of Political Economy 90, 1257-1277.

(1988). "Wages, Rents, and Amenities: Differences among Workers and Regions." Economic Inquiry 26(1): 23-41.

Rudzitis, G. (1999). "Amenities Increasingly Draw People to the Rural West." Rural Development Perspective. 14: 9-13.

Shaffer R., Deller S. and Marcouiller D.( 2006). "Rethinking Community Economic Development." Economic Development Quarterly; 20: 59-74

Shields M., Goetz S.J., and Wang Quiyan (2005). "Out-migration from the Northeast US: The Relative roles of Economic and Amenity Differentials." In "Amenities and Rural Development: Theory, Methods and Public Policy." G.P. Green, S.C. Deller, and D.W. Marcouiller, eds., Northampton, MA: Edward Elgar.

Steinnes, D., and W. Fisher. (1974). "An Econometric Model of Intraurban Location." Journal of Regional Science 14(1): 65-80.

Treyz, G.I., D.S. Rickman, G.L. Hunt, and M.J. Greenwood. (1993). "The Dynamics of U.S. Internal Migration." Review of Economics and Statistics 75(2): 209-214.

USDA, Economic Research Service (ERS). "Urban Influence Code (1993)." [Online] available from http://www.ers.usda.gov/Data/UrbanInfluenceCodes/2003; accessed 17 June 2008.

US Census Bureau. 1980. Selected Historical Decennial Census, Urban and Rural Definitions and Data. Available from: http://www.census.gov/population. accessed 15 June 2008

US Department of Commerce, Bureau of Economic Analysis. 1980-2005. Interactive Regional Data [Internet document]. Available from: http://www.bea.doc.gov/bea/regional/reis/default.cfm accessed 14 June 2008

USDA Forest Service, National Outdoor Recreation Supply Information System (NORSIS 1997). available upon request from USDA Forest Service Southern Station

Vias, A.C., and G.F. Mulligan. (1999). "Integrating Economic Base Theory with Regional Adjustment Models: The Nonmetropolitan Rocky Mountain West Region." Growth and Change 30: 507-525. 
White, Kristopher D. and Hannik, Dean M. (2003), "Moderate Environmental Amenities and Economic Change: The Nonmetropolitan Northern Forest of the Northeast U.S.", 1970-2000, Growth and Change 35(1): 42-60

Wooldridge J.M. (2002). "Econometric Analysis of Cross Section and Panel Data." The

\section{MIT Press}

Wu, JunJie., and Mishra,Sanjiv (2007). "Natural Amenities, Human Capital, and Economic Growth: An Empirical Analysis." In "Frontiers in Resource and Rural Economics." JunJie Wu, Paul W. Barkley, and Bruce A. Weber (eds). RFF Press

Yang, Tse-Chuan, and Anastasia R. Snyder, 2007. "Population Change in the Northeast 2000-2005",The Northeast Regional Center for Rural Development RDP No. 39, available at http://nercrd.psu.edu/Publications/rdppapers/rdp39.pdf 


\section{APPENDICES}

Figure 4.1. Climate Index

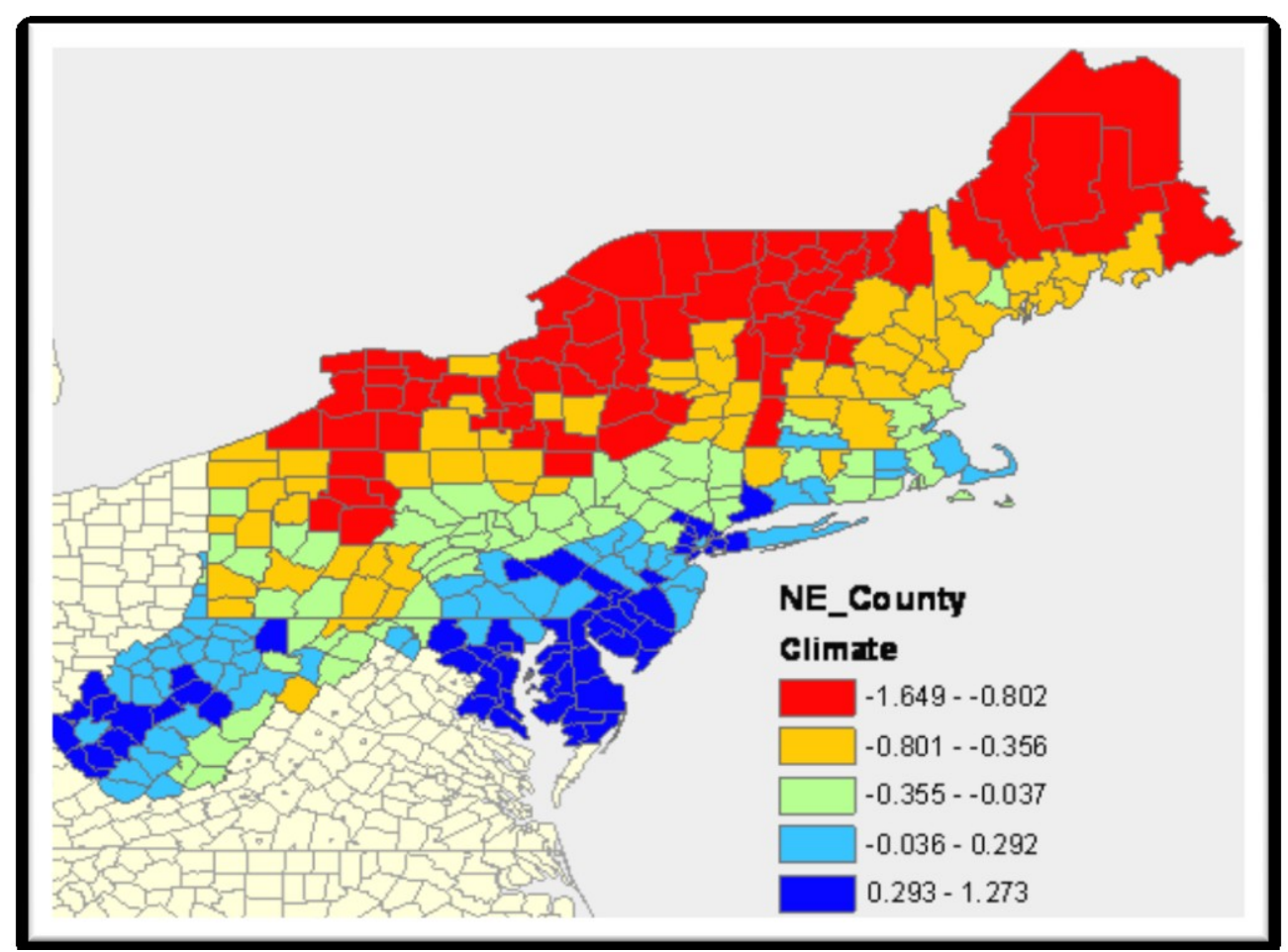

Fiqure 4.2. Natural Resource Amenities

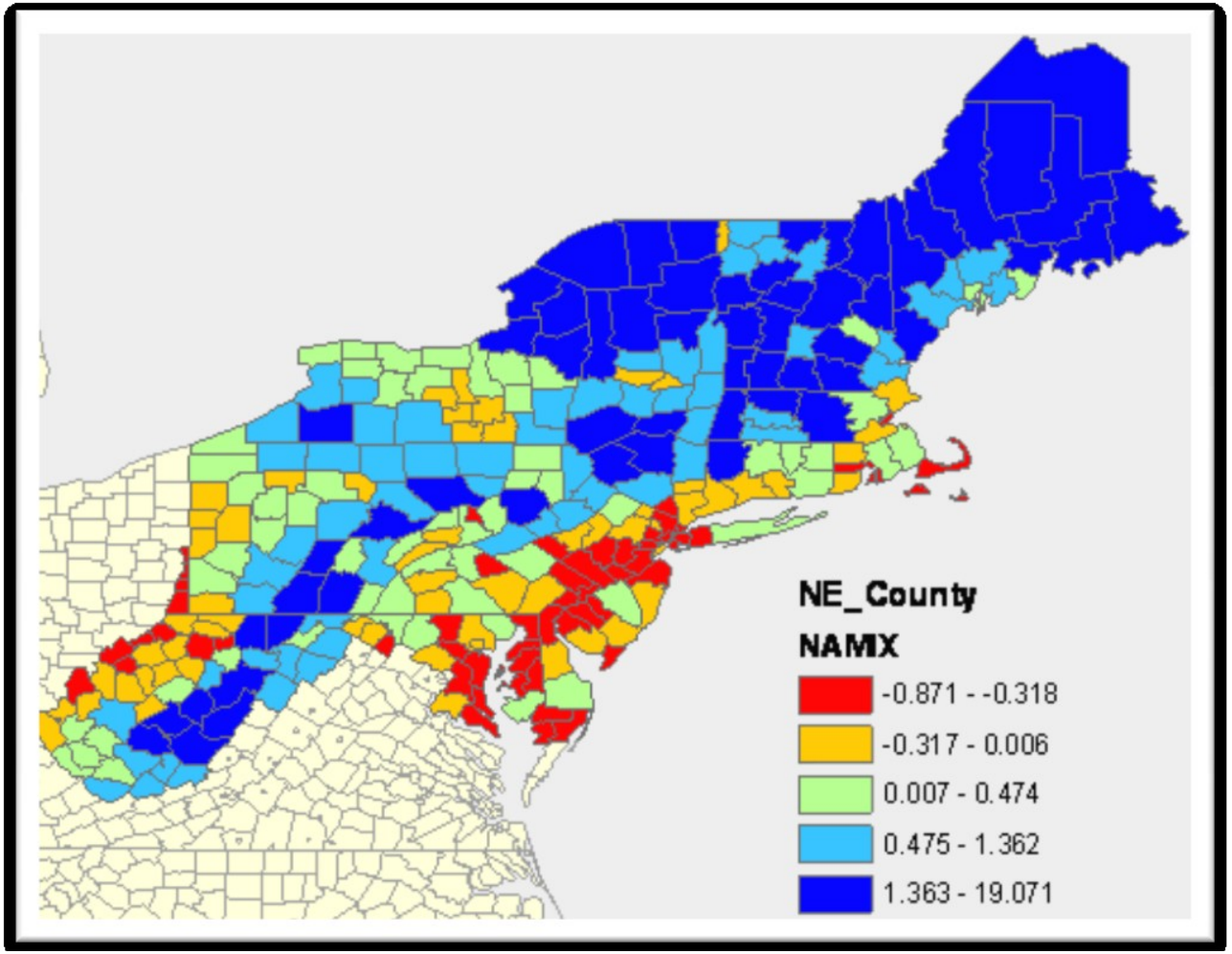


Fiqure 4.3. Land Based Recreational Amenities

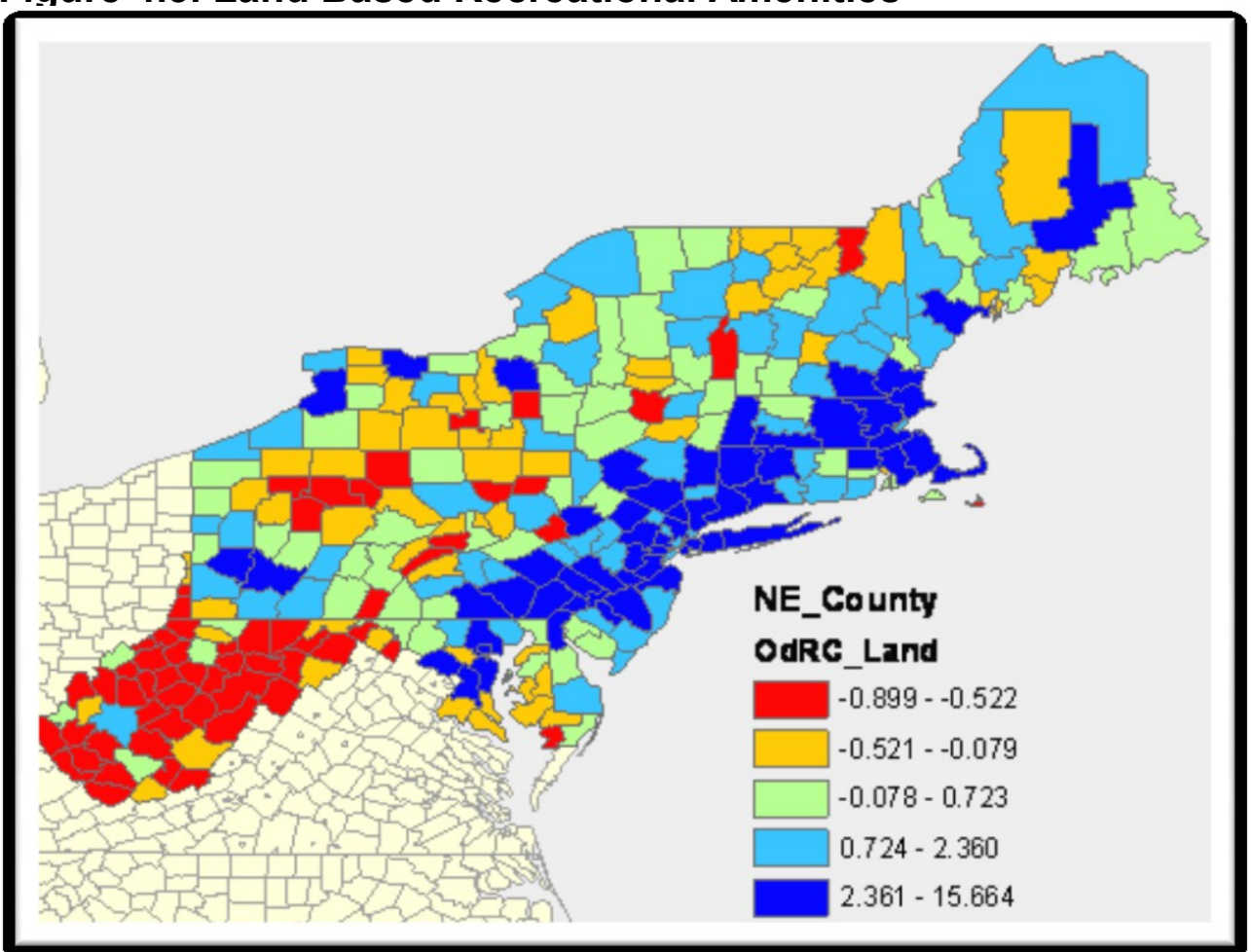

Figure 4.4. Water Based Recreational Amenities

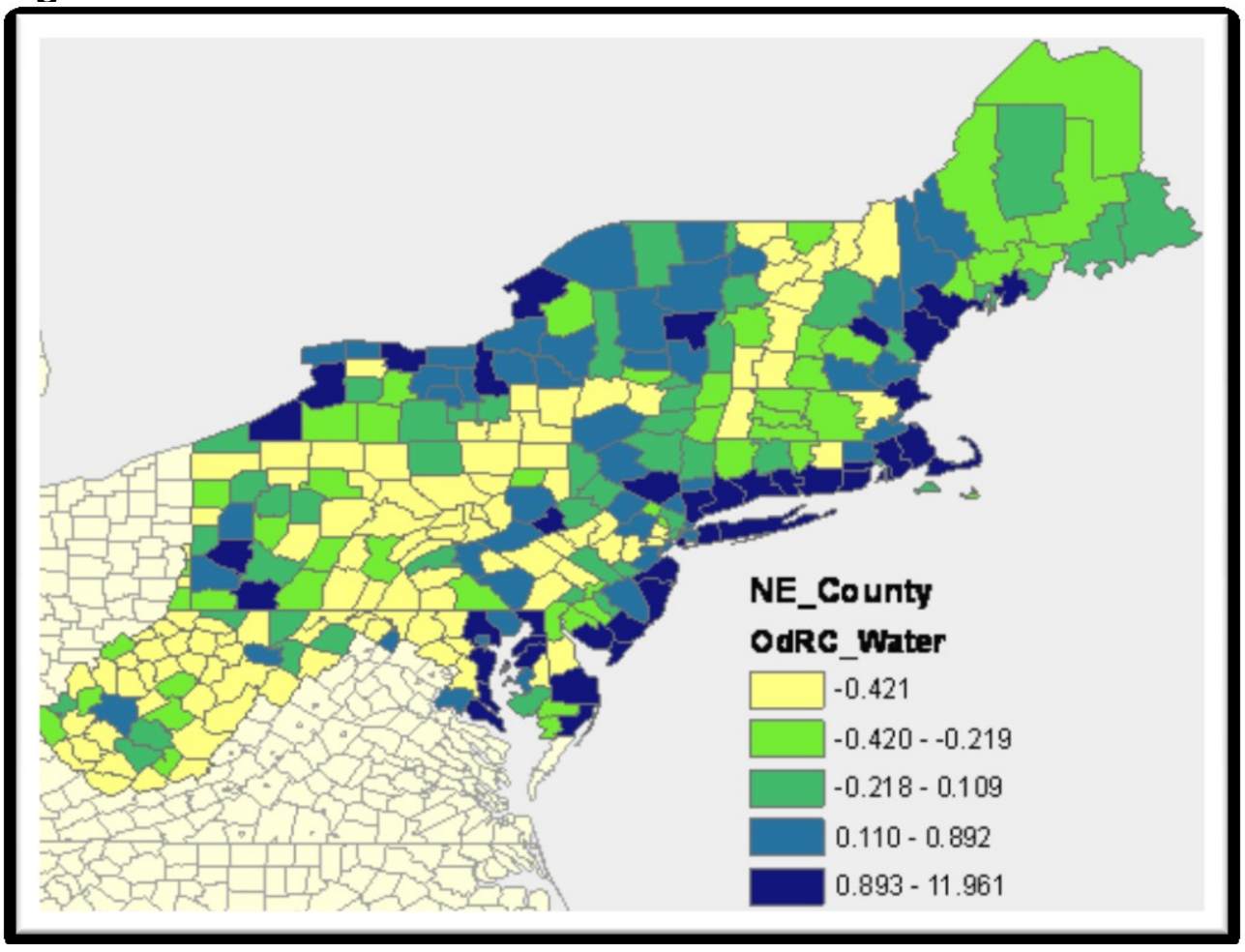


Fiqure 4.5. Historical and Cultural Amenities

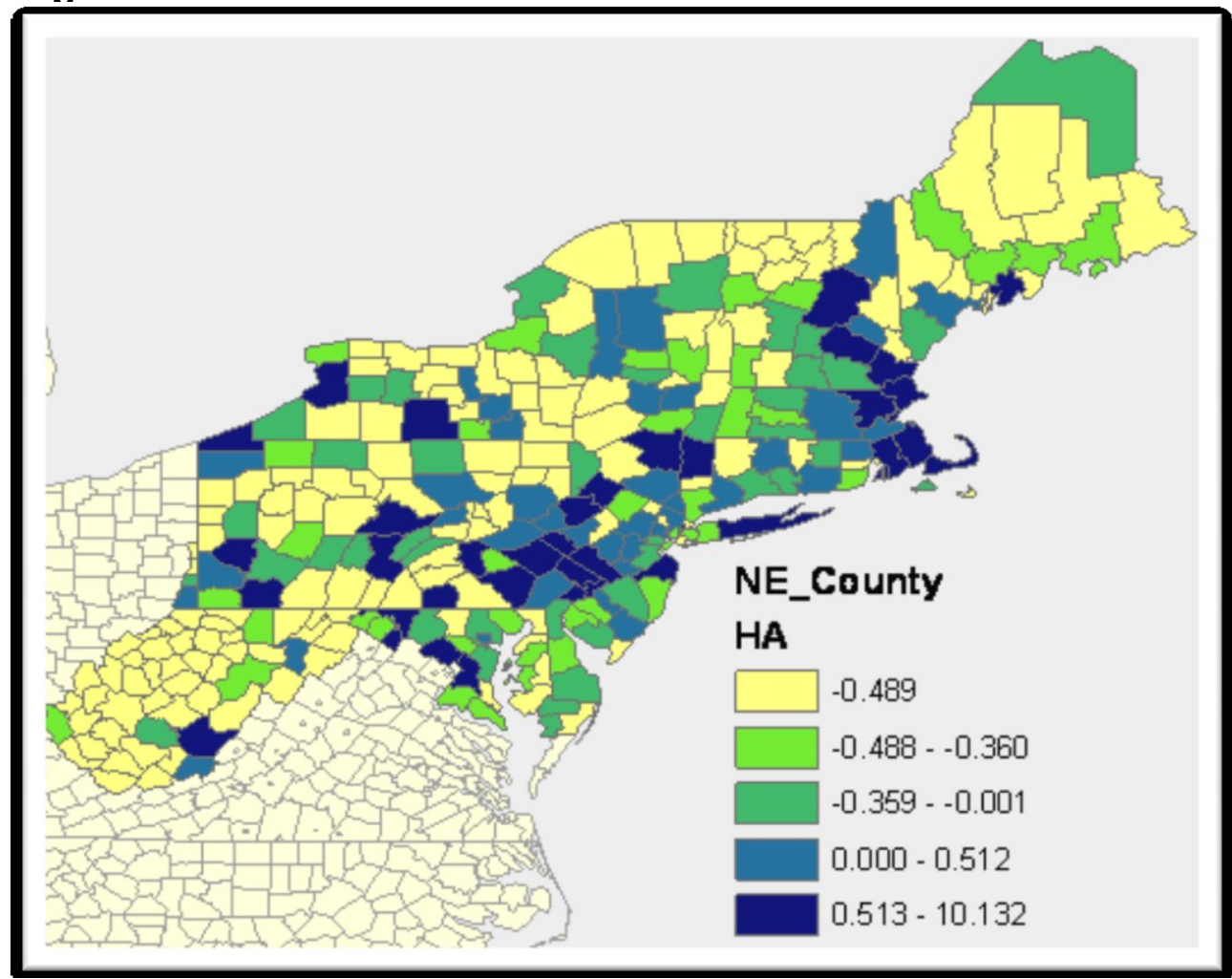

Figure 4.6. Winter Based Recreational Amenities

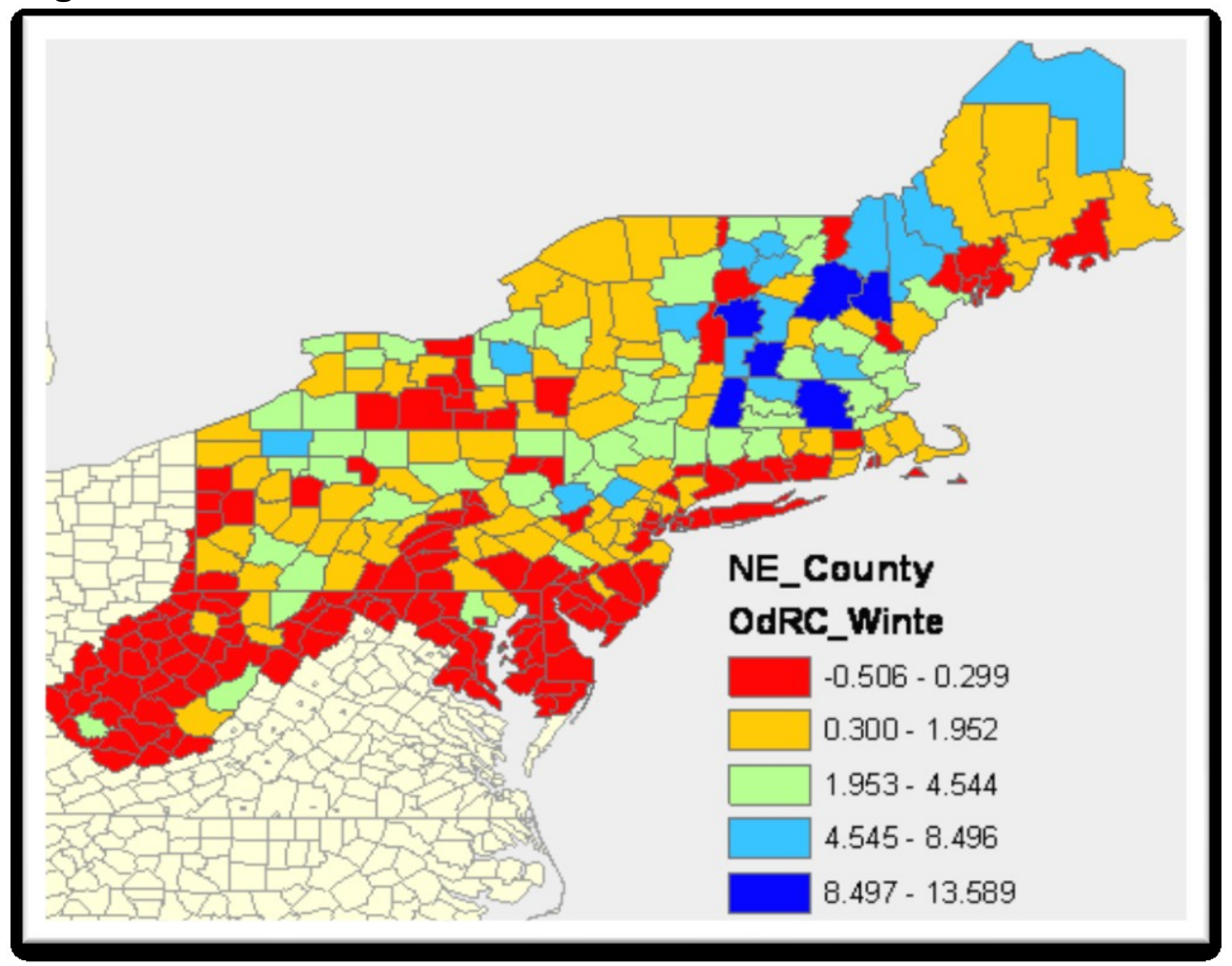


Table 5.3.5. Spatial Durbin Estimation Results of Population Growth and Amenities

\begin{tabular}{|c|c|c|c|c|c|c|c|c|}
\hline \multirow[b]{2}{*}{ Variable } & \multicolumn{2}{|c|}{ Model results } & \multicolumn{2}{|c|}{ Direct effect } & \multicolumn{2}{|c|}{ Indirect effect } & \multicolumn{2}{|c|}{ Total effect } \\
\hline & Coeffi & p-level & Coeff & t-prob & Coeffi & p-level & Coeff & t-prob \\
\hline LEMPD & -0.031 & 0.45 & -0.051 & 0.81 & $-1.699 * *$ & 0.029 & $-1.750 * *$ & 0.03 \\
\hline $\mathrm{LPCl}$ & $1.721 * *$ & 0.03 & $1.805^{*}$ & 0.07 & $6.818^{* *}$ & 0.034 & $8.623 * * *$ & 0.01 \\
\hline POPD80 & $-0.172 * * *$ & 0.00 & $-0.170 * * *$ & 0.00 & 0.171 & 0.421 & 0.001 & 1.00 \\
\hline DLGEXP & 0.060 & 0.40 & 0.055 & 0.83 & -0.406 & 0.643 & -0.352 & 0.72 \\
\hline PCTAX & -0.199 & 0.12 & -0.200 & 0.26 & -0.071 & 0.933 & -0.271 & 0.77 \\
\hline NRSD & -0.008 & 0.32 & -0.008 & 0.65 & 0.012 & 0.845 & 0.004 & 0.95 \\
\hline MFG & $-0.171 *$ & 0.05 & -0.171 & 0.10 & 0.043 & 0.910 & -0.128 & 0.76 \\
\hline UNEMPR & -0.083 & 0.29 & -0.085 & 0.57 & -0.114 & 0.819 & -0.199 & 0.69 \\
\hline $\mathrm{MHV}$ & $1.515^{* * *}$ & 0.00 & $1.535 * * *$ & 0.00 & 1.329 & 0.436 & 2.865 & 0.10 \\
\hline UIFC & -0.008 & 0.40 & -0.011 & 0.73 & $-0.265^{*}$ & 0.084 & $-0.276^{*}$ & 0.09 \\
\hline LANDREC & 0.078 & 0.11 & 0.078 & 0.22 & 0.009 & 0.970 & 0.087 & 0.72 \\
\hline WATREC & $0.154^{* *}$ & 0.03 & $0.165^{* *}$ & 0.05 & $0.910 * *$ & 0.014 & $1.075^{* *}$ & 0.01 \\
\hline HAMTY & $0.274 * * *$ & 0.00 & $0.279 * * *$ & 0.00 & 0.275 & 0.397 & 0.553 & 0.12 \\
\hline NAMTY & $-0.192 * * *$ & 0.00 & $-0.189 * * *$ & 0.00 & 0.349* & 0.068 & 0.160 & 0.35 \\
\hline WINREC & 0.015 & 0.24 & 0.016 & 0.47 & 0.069 & 0.415 & 0.084 & 0.35 \\
\hline WLEMPD & $-1.485^{* * *}$ & 0.00 & & & & & & \\
\hline WLPCI & $5.763 * * *$ & 0.01 & & & & & & \\
\hline WPOPD80 & 0.174 & 0.17 & & & & & & \\
\hline WDLGEXP & -0.360 & 0.32 & & & & & & \\
\hline WPCTAX & -0.042 & 0.46 & & & & & & \\
\hline WNRSD & 0.011 & 0.42 & & & & & & \\
\hline WMFG & 0.062 & 0.43 & & & & & & \\
\hline WUNEMPR & -0.087 & 0.42 & & & & & & \\
\hline WMHV & 0.964 & 0.24 & & & & & & \\
\hline WUIFC & $-0.231 * *$ & 0.03 & & & & & & \\
\hline WLANDREC & -0.004 & 0.50 & & & & & & \\
\hline WWATREC & $0.778 * * *$ & 0.00 & & & & & & \\
\hline WHAMTY & 0.205 & 0.22 & & & & & & \\
\hline WNAMTY & $0.332 * *$ & 0.02 & & & & & & \\
\hline WWINREC & 0.059 & 0.20 & & & & & & \\
\hline & & & & & & & & \\
\hline rho & 0.101 & 0.27 & & & & & & \\
\hline constant & $-5.282 * *$ & 0.04 & & & & & & \\
\hline & & & & & & & & \\
\hline $\mathrm{R} 2$ & 0.777 & & & & & & & \\
\hline $\mathrm{N}$ & 148 & & & & & & & \\
\hline
\end{tabular}


Table 5.3.6. Spatial Durbin Estimation Results of Employment Growth and Amenities

\begin{tabular}{|c|c|c|c|c|c|c|c|c|}
\hline \multirow[b]{2}{*}{ Variable } & \multicolumn{2}{|c|}{ Model results } & \multicolumn{2}{|c|}{ Direct effect } & \multicolumn{2}{|c|}{ Indirect effect } & \multicolumn{2}{|c|}{ Total effect } \\
\hline & Coeffi & p-level & Coeff & t-prob & Coeffi & p-level & Coeff & t-prob \\
\hline POPD & $0.616^{* * *}$ & 0.00 & $0.614 * * *$ & 0.00 & -0.469 & 0.45 & 0.146 & 0.82 \\
\hline $\mathrm{LPCl}$ & 0.910 & 0.15 & 0.918 & 0.29 & 0.625 & 0.79 & 1.543 & 0.52 \\
\hline EMPD80 & 0.0003 & 0.36 & 0.0003 & 0.68 & 0.004 & 0.21 & 0.004 & 0.21 \\
\hline DLGEXP & -0.196 & 0.18 & -0.194 & 0.40 & 0.384 & 0.65 & 0.190 & 0.84 \\
\hline PCРTAX & $0.215^{*}$ & 0.08 & 0.209 & 0.18 & -0.784 & 0.30 & -0.575 & 0.49 \\
\hline NRSD & $-0.030 * *$ & 0.03 & $-0.030 * *$ & 0.05 & -0.074 & 0.23 & -0.104 & 0.12 \\
\hline MFG & $-0.142 *$ & 0.08 & -0.143 & 0.15 & 0.010 & 0.98 & -0.133 & 0.77 \\
\hline SRV & $0.348 * * *$ & 0.01 & $0.344^{* *}$ & 0.03 & -0.490 & 0.34 & -0.146 & 0.79 \\
\hline EDU & -0.277 & 0.12 & -0.271 & 0.25 & 0.766 & 0.33 & 0.495 & 0.54 \\
\hline UIFC & $0.095^{* * *}$ & 0.00 & $0.094 * * *$ & 0.01 & -0.126 & 0.36 & -0.031 & 0.83 \\
\hline LANDREC & -0.043 & 0.23 & -0.044 & 0.45 & -0.084 & 0.66 & -0.128 & 0.51 \\
\hline WATREC & 0.020 & 0.39 & 0.025 & 0.74 & $0.477 *$ & 0.09 & 0.501* & 0.09 \\
\hline HAMTY & $0.122 * *$ & 0.03 & $0.125^{*}$ & 0.07 & 0.315 & 0.26 & 0.440 & 0.15 \\
\hline NAMTY & $-0.205 * * *$ & 0.00 & $-0.203 * * *$ & 0.00 & 0.296 & 0.10 & 0.092 & 0.57 \\
\hline WINREC & 0.012 & 0.27 & 0.013 & 0.50 & 0.039 & 0.54 & 0.052 & 0.44 \\
\hline WPOPD1 & -0.486 & 0.19 & & & & & & \\
\hline WLPCI1 & 0.479 & 0.40 & & & & & & \\
\hline WEMPD80 & 0.004* & 0.09 & & & & & & \\
\hline WDLGEXP & 0.367 & 0.31 & & & & & & \\
\hline WPCPTAX & -0.729 & 0.14 & & & & & & \\
\hline WNRSD & -0.063 & 0.12 & & & & & & \\
\hline WMFG & 0.026 & 0.48 & & & & & & \\
\hline WSRV & -0.475 & 0.15 & & & & & & \\
\hline WEDU & 0.717 & 0.15 & & & & & & \\
\hline WUIFC & -0.123 & 0.16 & & & & & & \\
\hline WLANDREC & -0.072 & 0.34 & & & & & & \\
\hline WWATREC & $0.427 * *$ & 0.03 & & & & & & \\
\hline WHAMTY & 0.271 & 0.12 & & & & & & \\
\hline WNAMTY & $0.288^{* *}$ & 0.04 & & & & & & \\
\hline WWINREC & 0.034 & 0.26 & & & & & & \\
\hline Rho & 0.072 & 0.33 & & & & & & \\
\hline constant & -0.134 & 0.49 & & & & & & \\
\hline $\mathrm{R}^{2}$ & \multicolumn{2}{|l|}{0.664} & & & & & & \\
\hline $\mathrm{N}$ & \multicolumn{2}{|l|}{148} & & & & & & \\
\hline
\end{tabular}


Table 5.3.7. Spatial Durbin Estimation Results of Income Growth and Amenities

\begin{tabular}{|c|c|c|c|c|c|c|c|c|}
\hline \multirow[b]{2}{*}{ Variable } & \multicolumn{2}{|c|}{ Model results } & \multicolumn{2}{|c|}{ Direct effect } & \multicolumn{2}{|c|}{ Indirect effect } & \multicolumn{2}{|c|}{ Total effect } \\
\hline & Coeffi & p-level & Coeff & t-prob & Coeffi & p-level & Coeff & t-prob \\
\hline LPOPD1 & 0.020 & 0.29 & 0.024 & 0.50 & -0.157 & 0.16 & -0.132 & 0.25 \\
\hline LEMP1 & -0.008 & 0.40 & -0.008 & 0.82 & -0.029 & 0.73 & -0.036 & 0.68 \\
\hline $\mathrm{PCl} 80$ & $-0.333 * * *$ & 0.00 & $-0.329 * * *$ & 0.00 & -0.189 & 0.41 & $-0.518 * *$ & 0.02 \\
\hline PCTAX & 0.023 & 0.14 & 0.024 & 0.27 & -0.027 & 0.65 & -0.003 & 0.96 \\
\hline NRSD & $-0.004 * *$ & 0.03 & $-0.004^{*}$ & 0.08 & -0.004 & 0.60 & -0.008 & 0.30 \\
\hline MFG & -0.019 & 0.13 & -0.018 & 0.29 & -0.044 & 0.36 & -0.062 & 0.24 \\
\hline SRV & $0.044^{* *}$ & 0.04 & $0.042^{*}$ & 0.09 & 0.054 & 0.46 & 0.096 & 0.21 \\
\hline UNEMPR & -0.016 & 0.24 & -0.012 & 0.62 & $-0.155^{* *}$ & 0.02 & $-0.167 * * *$ & 0.01 \\
\hline EDU & $0.066^{*}$ & 0.07 & 0.067 & 0.13 & -0.016 & 0.86 & 0.051 & 0.58 \\
\hline $\mathrm{MHV}$ & 0.110 & 0.11 & 0.099 & 0.29 & 0.432 & 0.12 & $0.53^{* *}$ & 0.05 \\
\hline LANDREC & $-0.017 * *$ & 0.02 & $-0.016^{*}$ & 0.08 & $-0.051^{*}$ & 0.07 & $-0.067 * *$ & 0.02 \\
\hline WATREC & $0.029 * * *$ & 0.01 & $0.028 * *$ & 0.03 & 0.036 & 0.34 & 0.064 & 0.10 \\
\hline HAMTY & -0.008 & 0.22 & -0.009 & 0.39 & 0.025 & 0.43 & 0.016 & 0.64 \\
\hline NAMTY & 0.003 & 0.39 & 0.001 & 0.92 & $0.069 * *$ & 0.02 & $0.07^{* *}$ & 0.02 \\
\hline WINREC & -0.001 & 0.38 & -0.001 & 0.77 & 0.000 & 0.96 & -0.001 & 0.91 \\
\hline WLPOPD & $-0.183 *$ & 0.08 & & & & & & \\
\hline WLEMP & -0.036 & 0.36 & & & & & & \\
\hline WPCI80 & -0.304 & 0.11 & & & & & & \\
\hline WPCTAX & -0.027 & 0.35 & & & & & & \\
\hline WNRSD & -0.005 & 0.26 & & & & & & \\
\hline WMFG & -0.057 & 0.15 & & & & & & \\
\hline WSRV & 0.075 & 0.19 & & & & & & \\
\hline WUNEMPR & $-0.189 * * *$ & 0.00 & & & & & & \\
\hline WEDU & -0.004 & 0.49 & & & & & & \\
\hline WMHV & $0.543^{* *}$ & 0.04 & & & & & & \\
\hline WLANDREC & $-0.065^{* *}$ & 0.02 & & & & & & \\
\hline WWATREC & 0.050 & 0.12 & & & & & & \\
\hline WHAMTY & 0.027 & 0.23 & & & & & & \\
\hline WNAMTY & $0.083 * * *$ & 0.01 & & & & & & \\
\hline WWINREC & 0.000 & 0.50 & & & & & & \\
\hline & & & & & & & & \\
\hline Rho & -0.265 & 0.10 & & & & & & \\
\hline Constant & $1.614^{* * *}$ & 0.00 & & & & & & \\
\hline $\mathrm{R} 2$ & 0.67 & & & & & & & \\
\hline $\mathrm{N}$ & 148 & & & & & & & \\
\hline
\end{tabular}

